Anne-Sofie Reng Rasmussen

How well do financial and macroeconomic variables predict stock returns: Time-series and cross-sectional evidence

Finance

Research Group 


\title{
How well do financial and macroeconomic variables predict stock returns: Time-series and cross-sectional evidence.
}

\author{
Anne-Sofie Reng Rasmussen ${ }^{1}$
}

October 15, 2006

\footnotetext{
${ }^{1}$ Aarhus School of Business, Fuglesangs Allé 4, 8210 Aarhus V, Denmark. E-mail: arr@asb.dk. I thank Tom Engsted for helpful comments.
} 


\begin{abstract}
Recent evidence of mean reversion in stock returns has led to an explosion in the development of forecasting variables. This paper evaluates the relative performance of these many variables in both time-series and cross-sectional setups. We collect the different measures and compare their forecasting ability for stock returns, and we examine the forecasting variables' ability to reduce pricing errors in the conditional C-CAPM. A key result of the analysis is that the traditional pricedividend ratio performs surprisingly well compared to the many new forecasting variables. We also find that at short and mid-range horizons Lettau and Ludvigson's (2001a) consumption-aggregate wealth variable offers the strongest forecasting ability, although this variable's predictive ability is sensitive to the sample period chosen. At longer horizons, price-normalized variables such as the traditional price-dividend ratio, the price-consumption ratio of Menzly et al. (2004), and the price-output variable of Rangvid (2006) outperform the other variables. These variables also turn out to be superior in reducing pricing errors in the conditional C-CAPM. Thus, the same set of variables dominate in both time-series and cross-sectional settings.
\end{abstract}

JEL classification: C52, G12.

Keywords: Return predictability, C-CAPM, conditional asset pricing. 


\section{Introduction}

For the past decades, attempts to model predictive behaviour of stock returns have played a prominent role in the finance literature. Recent empirical investigations of stock market returns have shown evidence of mean reversion, which has led to a surge in the development of variables with forecasting ability for stock returns. Initial research focused on variables describing the fundamental value of the stock relative to the current stock price. The latest research, however, has moved beyond the traditional financial ratios by introducing a large range of macroeconomic variables into the setting of stock return predictability. In this paper we attempt to collect the different measures and compare their forecasting ability for stock returns, and we examine the forecasting variables ability to reduce pricing errors in the conditional C-CAPM.

The first evidence of predictability in stock returns was based on analysis using the dividendprice ratio and earnings-price ratio. These can be interpreted as indicators of the intrinsic value of the stock, as quantified by the dividends paid on the stock or the earnings obtained, relative to the current price of the stock. Fama and French (1988b) and Campbell and Shiller (1988a) find the two variables to be strong predictors of especially long-horizon returns, i.e. returns measured over a period of several years. The measures have shown good forecasting performance for stock returns, although having some problems explaining the stock return patterns at the end of the previous century and the beginning of this century.

This break in the link between stock fundamentals and prices has been a driving force behind the development of new forecasting variables. Is there some pattern in returns which the traditional variables are unable to catch? Many of the new variables have kept the idea of using a measure that is price relative. Instead of stock dividends and earnings, research now turns towards macroeconomic variables. Rangvid (2006) scales the stock price by GDP and finds that this variable explains a large fraction of the variation over time in aggregate stock returns. Menzly, Santos, and Veronesi (2004) find that predictive regressions for returns should include both the dividend yield and the consumption/price ratio.

Other papers have completely eliminated the idea of using stock prices as a component of the forecasting variable. Santos and Veronesi (2005) regress stock returns on lagged values of a labour income to consumption ratio and find statistically significant regression coefficients and large $R^{2}$ 's. Piazzesi, Schneider, and Tuzel (2006) introduce housing in the asset pricing relation through a new risk factor termed composition risk. The composition risk factor is determined by changes in the expenditure share of housing in the consumption basket. The expenditure share is found to outperform the traditional dividend yield in predicting excess stock returns.

These ratios are all relatively simple to compute. Some papers have introduced slightly more complex series based on residuals from various cointegration relationships shown to exist. The cay variable of Lettau and Ludvigson (2001a) started the ball rolling. cay is a proxy for the consumptionaggregate wealth ratio. It is determined as a cointegration residual between log consumption, $c$, $\log$ nonhuman wealth, $a$, and $\log$ labour income, $y$. Empirically, this variable has been found to outperform traditional financial ratios in forecasting excess stock returns (Lettau and Ludvigson (2001b, 2005)).

Since then other cointegrating relations have been developed. Lettau and Ludvigson (2005) develop $c d y$. This is a cointegration residual between $\log$ consumption, $c$, log dividends from financial wealth, $d$, and log labour income, $y$. This is also found to forecast excess stock returns. In an extension of Lettau and Ludvigson's cay, Julliard (2005) introduces a variable determined by expected labour income growth rates, $l r$. It is found that both real and excess stock returns are well forecast by this variable. The conditional C-CAPM with a linear combination of cay and $l r$ as conditioning variable is shown to outperform the 3-factor model of Fama and French (1993) in a cross sectional pricing of the 25 Fama-French portfolios. 
Benzoni et al. (2006) suggest a cointegrating relationship between log labour income and log dividends, $y_{-} l d$. This variable is also shown to be a better predictor variable for stock returns than the traditional dividend yield often used empirically. Finally, Lustig and Nieuwerburgh (2005) develop the housing collateral ratio $m y$, which is determined by a cointegrating relation between housing wealth and human wealth. In a conditional C-CAPM setup, this variable is found to summarize the time variation in the investors information, and the model fits the returns on the 25 Fama-French portfolios well.

As noted above, all these variables claim good empirical fit for the US stock market. Many of the new variables claim to outperform the traditional dividend-price ratio which is most often used as the benchmark variable. However, as the group of predictor variables expands, it becomes relevant to see whether the dividend yield should still remain the benchmark case and how these new variables are performing compared to each other. This wide variety of forecasting variables will be investigated in both a time-series and a cross-sectional setting.

First, we will look at the predictability of stock returns over varying time horizons. We will regress stock market returns measured at frequencies ranging from 1 quarter to returns accumulated over several years on the predictor variables and compare the forecasting power resulting from the various measures.

Second, the predictor variables will be used in connection with the conditional C-CAPM to see how well they perform in a cross-sectional asset pricing framework. Can the forecasting ability be seen in economically significant improvements in pricing errors?

This will give an overview of the current state of the literature on predictability of stock returns. We will show the relative performance of the wide variety of forecasting variables and give an indication of which variables are best under differing circumstances. Some measures may work better at short-horizon forecasting while others catch the long-horizon behaviour of stocks. Some variables require very little modelling and are based on easily obtainable empirical measures, while others are harder to model empirically. Is the extra work worth it?

Our empirical investigation shows relatively weak robust statistical support for the idea of predictability of stock returns. In time-series regressions few of the predictor variables obtain significant coefficient estimates, although eliminating the past 10 years of data does improve support for the phenomenon. Generally, we observe rising predictability with the length of time over which returns are aggregated. At short and mid-range horizons, cay provides the strongest predictive ability. This variable is closely followed by especially the price-normalized variables such as the price-dividend ratio and price-output ratio. Moving to long horizons these price normalized variables capture the highest proportion of return variance. Multivariate regressions show that very few of the new variables introduced add any predictability over that of the price-dividend ratio. The price-dividend ratio clearly dominates.

When it comes to cross-sectional asset pricing in the conditional C-CAPM setup, a large group of variables perform almost equally well. These are generally the same variables as those found to predict aggregate stock returns at varying time horizons. The lowest average pricing errors are achieved when using the price-output or price-consumption ratios, closely followed by cay and the traditional price-dividend ratio.

The paper is structured in the following manner. Section II introduces the many predictor variables to be used in the analysis of this paper. Section III presents the econometric methodology underlying time-series regressions and IV the cross-sectional methodology. In section V data used for the empirical analysis is described. Next, we move to the empirical results of the paper. In section VI.1 the time-series analysis is presented followed by the cross-sectional analysis in section VI.2. Finally, section VII concludes. 


\section{Predictability in stock returns}

Attempts to predict stock returns via forecasting variables have flourished in recent years, with many variables showing remarkable forecasting ability. The evidence is often in the form of timeseries analysis performed by running univariate regressions of stock returns, measured over various horizons, onto the forecasting variables. At short horizons most variables result in very weak evidence of forecastability. However, when the time interval over which stock returns are compounded is increased, the level of predictability also increases.

In the following sections we present a variety of financial and macroeconomic variables which have been shown to contain forecasting ability for stock returns. The variables are divided into three groups: traditional variables, new ratios, and cointegrating relationships. The first group contains variables which have been present in the literature for many years and which are generally accepted as reasonable forecasting variables, theoretically or empirically. The second group contains a number of new ratios shown to outperform the traditional variables in forecasting long-horizon stock returns. Finally, much recent research has focused on using deviations from some long-run financial or macroeconomic steady state relation to predict stock returns. These cointegrating relations have shown strong empirical results and have gained a large following in the finance literature.

\section{II.1 Traditional variables}

The foundations for research in predictability of stock returns were laid with papers using ratios of stock prices to dividends or earnings. These variables can be seen as indicators of the fundamental value of the stock, relative to the current price. The idea of using these as predictor variables is that variation in the ratios should reflect variation in the market's rational expectation of the future value of stock returns and dividend growth or earnings growth respectively. More mathematically, Campbell and Shiller (1988) show (ignoring constants)

$$
p_{t}-d_{t}=E_{t} \sum_{j=0}^{\infty} \rho^{j}\left(\Delta d_{t+1+j}-r_{t+1+j}\right)
$$

where $p_{t}$ is the $\log$ of the share price at time $t, d_{t}$ is $\log$ dividends paid out on the share, $r_{t}$ is the $\log$ stock return, and $\rho \equiv \frac{\exp (\overline{p-d})}{1+\exp (\overline{p-d})}$. If growth in dividends is expected to be relatively stable, variation in the price-dividend ratio should capture variation in expected stock returns.

Fama and French (1988b) run regressions of real returns on the value weighted NYSE stock portfolio onto dividend yields. They find that the forecasting ability of dividend yields, measured by the $R^{2}$ of the regression, is increasing over the return horizon. Monthly returns give an $R^{2}$ of 0.01 , while 4-year returns regressed on the dividend yield result in an $R^{2}$ as high as 0.45 . Campbell and Shiller (1988a) perform a similar analysis and also find significant predictive power of the dividend yield on real returns. In addition to the dividend yield, the log earnings-price ratio is also used as a forecasting variable. This is found to result in even higher $R^{2}$ than the dividend yield when using 10- or 30-year moving averages of log real earnings in constructing the earnings-price ratio.

Lamont (1998) suggests combining dividend and earnings data into one forecasting variable, instead of normalizing the two series by the stock price - the reasoning being that dividends contain information about future stock returns and earnings about the general business conditions of the economy. Combining the series should therefore result in superior forecasting ability. The payout ratio is computed as log dividends minus log earnings, $d_{t}-e_{t}$. It is found to forecast excess stock returns at short horizons, but at long horizons Lamont (1998) finds that the price normalization is 
needed to obtain forecasting ability.

Moving away from predictor variables based directly on stock data, Fama and French (1989) show that the yield spread between low- and high-grade corporate bonds, the default premium, can also be used as a predictor variable for long horizon stock returns. The intuition is that the default premium, def, is an indicator of general business conditions and hence should be able to capture long-term business cycle variation in stock returns. Campbell (1991) and Hodrick (1992) suggest using the the relative bill rate, $r t b$, to forecast future stock returns. This is measured as the 3 -month treasury bill rate minus its 1 -year backward moving average.

These traditional variables have been a staple of the literature for the past 15 years. However, research in the late 1990's and early part of this century indicates that the empirical link between the fundamentals, in the form of dividends and earnings, and stock prices has become weak. The pricedividend and price-earnings ratios may no longer be strong predictors of stock market movements (Campbell and Shiller (2001)).

\section{II.2 New ratios}

The break in the link between stock dividends, earnings, and prices of recent years has led to a surge in the literature on forecasting variables. It raises the question of whether stock returns are predictable at all. A wide range of ratios based on financial and macroeconomic variables have been introduced in the predictability literature in recent years. These appear to capture movements in stock prices, which traditional ratios are not able to.

Rangvid (2006) suggests using the price-output ratio $p y$ as a predictor variable. The idea is to rewrite the nonstationary dividend component of the dividend yield as the sum of output in the economy, assumed to be nonstationary, and a mean zero stationary disturbance term. Applying this assumption to the relation of Campbell and Shiller (1988b) shown in eq. (8) results in the following expression

$$
p_{t}-y_{G D P, t}=E_{t} \sum_{j=0}^{\infty} \rho^{j}\left(\Delta y_{G D P, t+1+j}-r_{t+1+j}\right)+\nu_{t}
$$

where $y_{G D P, t}$ is the log of time $t$ output in the economy, proxied by GDP, and $\nu_{t}$ is the stationary disturbance term. Variation over time in the price-output ratio thus captures variation over time in expected returns if expected output growth is relatively stable. If stock prices are high relative to the level of output in the economy, investors expect future returns to be low and vice versa. Rangvid (2006) shows the price-output ratio outperforms the traditional dividend yield and price-earnings ratio when predicting long-horizon returns.

Menzly et al. (2004) suggest expected excess stock returns to be a linear function of both the dividend yield and price-consumption ratio $p c$. When regressing long-horizon aggregate stock market returns on these two ratios, the price-consumption ratio is not found to have predictive power over the dividend yield. However, when looking at industry portfolios, this second ratio becomes an important predictor variable.

Santos and Veronesi (2005) introduce the labour income to consumption ratio $y c$ as a predictor variable. The wealth of agents in the economy is assumed to stem from two sources: financial and human. The mix of these two income sources varies over time. If the proportion of consumption funded by labour income is high, the proportion funded by financial income will be small. Hence, the relation between movements in consumption and financial assets will be weak and investors will only require a small premium to hold these financial assets. Hence, a rise in the labour income to consumption ratio should imply low returns on the aggregate stock market. The labour income to consumption ratio is found to result in statistically significant coefficient estimates in univariate 
long-horizon regressions of the stock market return and higher adjusted $R^{2}$ than regressions with the dividend yield.

Piazzesi et al. (2006) also look at the composition of consumption. However, instead of looking at the income types funding consumption, focus is on the types of assets of which consumption consists, specifically on the proportions of consumption devoted to housing and other consumption. This leads to development of the non-housing expenditure share nhe as a predictor variable. The theoretical prediction is that the non-housing expenditure share is high during recessions when expected excess returns are high. Once again, the non-housing expenditure share is found to outperform the traditional dividend yield as predictor variable for long-horizon excess returns.

\section{II.3 Cointegrating relations}

As is evident from the previous section, the new predictor variables focus on macroeconomic variables such as labour income, consumption, and housing. So far all the variables presented have been based on relatively simple ratios. The following variables all follow the idea of using long-run relationships, in the form of cointegrating relations, between financial and macroeconomic variables to predict stock returns.

The first variable we will present is the cay variable introduced in Lettau and Ludvigson (2001a). More specifically cay is a proxy for the log consumption-wealth ratio measured empirically as the deviation from the common trend in consumption, asset wealth, and labour income

$$
c a y_{t} \equiv c_{t}-\omega a_{t}-(1-\omega) y_{t}
$$

$c_{t}$ is $\log$ consumption, $a_{t}$ is $\log$ of nonhuman wealth, $y_{t}$ is $\log$ labour income, $\omega$ is the steady state share of nonhuman wealth $A$ in aggregate wealth $W$. $\omega$ is estimated empirically as the coefficient of cointegration between the three variables. Lettau and Ludvigson (2001a) show that this variable should be a good proxy for expected future market returns, providing that labour income and consumption growth are relatively stable over time. Empirical findings support this hypothesis, with cay proving to be a good forecaster of market returns at short and intermediate horizons. Univariate regressions of cay on long-horizon excess stock returns performed in Lettau and Ludvigson (2005) result in significantly positive coefficient estimates and an adjusted $R^{2}$ of up to 0.52 at a 6 -year horizon.

A similar relation for the consumption-aggregate dividend ratio is developed in Lettau and Ludvigson (2005)

$$
c d y_{t} \equiv c_{t}-v d_{t}-(1-v) y_{t}
$$

$d_{t}$ is $\log$ of dividends from asset wealth and $v$ is the steady state share of income from asset wealth in total income. Here it is assumed that a cointegrating relation exists between consumption, dividends on asset wealth, and labour income. This relation should in principle predict dividend growth, not stock returns. However, Lettau and Ludvigson (2005) find that the variable also predicts excess stock returns due to common variation in expected returns and expected dividend growth.

Julliard (2004) develops further on the cay variable under the assumption that labour income is not approximately a random walk, unlike that assumed by Lettau and Ludvigson (2004). If this is the case, Julliard argues that we must take expectations of future labour income growth into account when using cay to forecast stock returns. By combining cayt and $l r_{t}$, where $l r_{t} \equiv$ $E_{t} \sum_{j=0}^{\infty} \rho^{j} \Delta y_{t+1+j}$, we should obtain a good forecaster of asset returns. Hence, whether the Lettau and Ludvigson model or the Julliard model is correct depends on the time series behavior of labour income. Julliard (2004) finds the labour income process to be well described by an $\operatorname{ARIMA}(0,1,2)$ model. Fluctuations in future labour income growth are found to be good forecasters of excess stock returns and cross-sectionally in a conditional C-CAPM setup, $l r_{t}$ is found to outperform cayt 
as state variable when pricing the 25 Fama-French portfolios.

Benzoni et al. (2006) also follow the idea of using cointegrating relations to forecast stock returns. They propose a two-variable relation between dividends and labour income, unlike the trivariate relation underlying $c d y$. Here we take priors on the coefficients of the relationship and the forecasting variable is given by $y_{-} l d=y_{t}-d_{t}-\overline{l d}$ where $\overline{l d}$ is the long-run log ratio of aggregate labour income to dividends. A second measure is also introduced $y_{-} l s=y_{t}-s_{t}+\delta t$, where $s_{t}$ is the log-level of the CRSP value-weighted market index, inclusive of all distributions, and $\delta$ is the sample average of the dividend yield.

The final variable investigated in this paper is from Lustig and Nieuwerburgh (2005). This paper suggests using a measure of housing collateral, the ratio of housing wealth to human wealth, as a predictor variable. The idea is that negative shocks to house prices lead to lower collateral value of housing, thereby increasing the households' exposure to idiosyncratic labour income risk and in return the conditional market price of risk. A cointegrating relationship between log, real, per household real estate wealth $h v$ and log, real, per household aggregate labour income ya is established. It is argued that both a constant and a trend term should be included in the cointegrating relationship, implying that the cointegrating vector eliminates deterministic trends

$$
m y_{t}=h v_{t}+\varpi y a_{t}+\vartheta t+\chi
$$

where $[1, \varpi, \vartheta, \chi]$ is the cointegrating vector. This empirical measure is a deviation from the cointegration relation. Hence, it can be negative and positive. However, the measure of housing collateral developed in the theoretical model of the paper is a ratio and always positive. To put it back in the same sense, the ratio is rescaled so that $\widetilde{m y_{t}}=m y_{\max }-m y_{t}$. Lustig and Nieuwerburgh impose the condition $\varpi=-1$ as this is close to the estimated coefficients in their empirical section. A version of the variable computed with this restriction imposed will also be presented.

All the cointegrating relationships described in this section are estimated by the dynamic least squares (DLS) approach of Stock and Watson (1993). The DLS method simply involves running an OLS regression of time $t$ values of one of the variables in the cointegrating relation onto time $t$ levels of the remaining variables, leads and lags of the first difference of the remaining variables, and a constant. The resulting parameter estimates are asymptotically equivalent to estimates based on a vector error correction model (VECM) of Johansen (1991), as noted in Stock and Watson (1993). As a robustness check we also estimate the relations by the Johansen procedure.

\section{Time-series analysis methodology}

All the forecasting variables presented above should theoretically contain information about expected stock market returns not so much the day to day changes in expected returns, but the long-term trends in the return pattern. In order to investigate whether such predictive powers exist empirically, we analyze the relation between predictors and stock portfolio returns measured over horizons ranging from 1 to 48 quarters and 1 to 8 years.

$\mathrm{K}$-period continuously compounded log excess returns are computed as

$$
r_{t+k, k}^{e}=r_{t+1}-r_{f, t+1}+\ldots \ldots .+r_{t+k}-r_{f, t+k}
$$

where $r_{t+1}$ is the log portfolio return from time $t$ to $t+1$ and $r_{f, t+1}$ is the risk-free rate. Checking for long-horizon predictability is done by projecting K-period returns on the respective predictor variables.

$$
r_{t+k, k}^{e}=\alpha_{k}+\beta_{k} f_{t}+e_{t+k, k}
$$


where $f_{t}$ is the predictor variable. Equation 7 is stated as a univariate regression, which will be the main focus of our empirical estimations. It can easily be extended to a multivariate form.

The long-horizon regressions based on K-period returns computed as in eq. 6 may result in problems of overlapping returns when interpreting the traditional statistical evidence of our regressions. Valkanov (2003) shows that these new long-horizon returns behave asymptotically like I(1) series, even though the original series $r_{t+1,1}^{e}$ is $\mathrm{I}(0)$. Also, as will become evident later, many of our regressor variables are highly persistent and we may not be able to reject the hypothesis of a unit root. These issues imply that it may be problematic to use the traditional $t$-statistic and adjusted $R^{2}$ to evaluate the statistical significance of our models. To control for these issues, we compute two alternate test statistics. The scaled $t$-statistic of Valkanov (2003) and the implied $R^{2}$ of Hodrick (1992).

Valkanov (2003) introduces a rescaled $t$-statistic, $t / \sqrt{T}$, to be used when evaluating the significance of coefficient estimates from long-horizon regressions. We use critical values, computed in Valkanov (2003) table 4 case 1 , to evaluate the significance of the rescaled $t$-statistics. To use these critical values, we need to compute the value of two parameters: $c$ and $\delta . c$ is a measure of the deviation from unity in the highest autoregressive root of the regressor variable. The parameter is computed using the methodology of Stock (1991). $\delta$ is the correlation between innovations in returns and innovations in the forecasting variable $f_{t}$.

The long-horizon implied $R^{2}$ of Hodrick (1992) is computed using a vector-autoregressive approach. We estimate a first order VAR in two variables: the one-period excess return on the stock market portfolio, $r_{t}^{e}$, and a predictor variable $f_{t}$. Based on the parameter estimates and variancecovariance matrix of the VAR, an implied $R^{2}$, which is not affected by overlapping returns, can be computed $^{1}$.

\section{Cross-sectional methodology}

Now that we have investigated the various predictor variables' ability to forecast the excess aggregate stock market return at differing time horizons, we wish to look at how well the variables perform when attempting to price a cross section of stock portfolio returns. To do this, we need a model which incorporates the predictive power of our forecasting variables into an asset pricing model. We use the conditional consumption-based capital asset pricing model, the conditional C-CAPM. This model is based on introducing a state variable $z_{t}$ to scale the consumption growth variable $\Delta c_{t+1}$ of the traditional C-CAPM. This state variable should be a description of the state of the economy, which is a function fitting our forecasting variables. Following Cochrane (1996), at a given point in time, $t$, the cross-sectional model can be written as

$$
r_{t}^{e i}=\beta_{i, z_{t}} \lambda_{z_{t}}+\beta_{i, \Delta c_{t+1}} \lambda_{\Delta c_{t+1}}+\beta_{i, \Delta c_{t+1} * z_{t}} \lambda_{\Delta c_{t+1} * z_{t}}
$$

$r_{t}^{e i}=r_{i, t+1}-r_{f, t+1}$ where $r_{i, t+1}$ is the $\log$ return on asset $i, r_{f, t+1}$ is the return on the zerobeta portfolio or risk-free rate of return, $\beta_{i, z_{t}}, \beta_{i, \Delta c_{t+1}}, \beta_{i, \Delta c_{t+1} * z_{t}}$ are the risk terms of the model estimated as regression coefficients stemming from regressing returns $r_{i, t+1}$ on $z_{t}, \Delta c_{t+1}$, and $\Delta c_{t+1} *$ $z_{t}$ respectively, and $\lambda_{z_{t}}, \lambda_{\Delta c_{t+1}}$, and $\lambda_{\Delta c_{t+1} * z_{t}}$ are free parameters quantifying the price of the risk terms. This model has been shown to perform well when pricing a cross section of asset portfolios, but it is theoretically dependent on the choice of state variable $z_{t}$. Hence, it is a good framework to show us the relative performance of our various forecasting variables when pricing assets crosssectionally.

\footnotetext{
${ }^{1}$ For a precise description of the computation of the implied $R^{2}$, see Hodrick (1992).
} 
To estimate the $\beta$ and $\lambda$ parameters, we use the methodology of Fama and MacBeth (1973). The Fama-MacBeth estimation technique is as follows. First, run time-series regressions of portfolio excess returns on the factors of the respective models to find estimates of $\boldsymbol{\beta}$.

$$
r_{t}^{e i}=a_{i}+\boldsymbol{\beta}_{i}^{\prime} \mathbf{f}_{t}+\varepsilon_{i, t}, \quad t=1,2, \ldots, T \text { for each } i .
$$

This gives us a vector of beta estimates. Now run one cross-sectional regression for each time period of excess returns on the time-series regression betas

$$
r_{t}^{e i}=\boldsymbol{\beta}_{i}^{\prime} \boldsymbol{\lambda}_{t}+\alpha_{i, t}, \quad i=1,2, \ldots ., N \text { for each } t .
$$

The Fama-MacBeth estimates $\widehat{\boldsymbol{\lambda}}$ and $\widehat{\alpha}_{i}$ are then found as the time-series average of the parameters estimated in the cross-sectional regressions and the residuals resulting. To correct for sampling error in $\widehat{\boldsymbol{\beta}}$, we use the methodology of Shanken (1992). Jagannathan and Wang (1998) find that Fama-MacBeth standard errors may not overstate the precision of the estimated coefficients when conditional heteroskedasticity is present. For this reason we also present uncorrected standard errors.

To compare the pricing ability of the various forecasting variables, we want to be able to compare the magnitude of the pricing errors. Firstly, we report the square root of the average squared pricing errors, $R M S E$. In this case, pricing errors from all portfolios investigated are thus given equal weighting. Following Campbell and Vuolteenaho (2004) we also compute a composite pricing error given by

$$
\widehat{C E}=\left[\widehat{\alpha}^{\prime} \Omega^{-1} \widehat{\alpha}\right]^{\frac{1}{2}}
$$

where $\widehat{\alpha}$ is the vector of estimated residuals from the cross-sectional regression and $\boldsymbol{\Omega}^{-1}$ is the variance-covariance matrix of asset returns. Here the weight given to the pricing error of each portfolio is dependent on the precision with which the average returns on that portfolio are measured. There may be concerns with the accuracy of the estimate of the full variance-covariance matrix of asset returns given a high number of asset portfolios relative to time-series observations. Hence we also report composite pricing errors based on a diagonal variance matrix. The diagonal elements of the matrix contain the variance of returns and the remaining elements are set to zero.

Finally, the Hansen-Jagannathan distance measure is also reported. This is computed as

$$
\widehat{H J}=\left[\widehat{\alpha}^{\prime} \mathbf{E}\left(\mathbf{R R}^{\prime}\right)^{-1} \widehat{\alpha}\right]^{\frac{1}{2}} .
$$

In this case we weight the vector of estimated residuals from the cross-sectional regression by the moment matrix of asset returns to achieve a measure of model pricing ability. Hansen and Jagannathan (1997) show that this measure can be interpreted as the maximum pricing error per unit payoff norm. Asymptotic standard errors are calculated for the four pricing error measures following the delta method ${ }^{2}$.

\section{Data}

The data for this paper consists of quarterly and annual frequency observations of returns on a number of stock portfolios and predictive variables. Annual stock return observations cover the period 1946-2005 and quarterly data covers the period 1952Q1-2005Q4. The predictor variables

${ }^{2}$ For futher information on the computation of asymptotic standard errors, we refer to Rasmussen (2006). 
are lagged one period in both time-series and cross-sectional regressions. Hence, these are observed over the annual period 1945-2004 and 1951Q4-2005Q3 at quarterly frequencies. This is the main sample.

Our stock return data and some of the predictor variables can be observed over longer time periods. Therefore, we also include estimations on this subset of predictors over their maximum sample period. For annual data the long sample runs from 1930-2005. For quarterly data two long samples exist: one running from 1926Q4-2005Q4 and one for the period 1947Q2-2005Q4.

Long-horizon time-series regressions of stock market portfolio returns on various predictor variables are estimated. The empirical proxy for the return on the stock market portfolio is the return on the CRSP value-weighted stock index (NYSE/AMEX/NASDAQ). The stock return data is measured in excess of the risk-free rate, which is defined as the one-month T-bill rate. All returns are in $\log$ form.

Next, data for the many forecasting variables used in the paper is described.

The SMB and HML variables of the Fama-French three-factor model are downloaded from the website of Kenneth French. They are based on 6 portfolios of U.S. stocks sorted on size and the ratio of book equity to market equity (BE/ME) of the assets. SMB is the difference in returns between the small and big stock portfolios sorted by size. HML is the difference in returns on the high- and low-BE/ME portfolios.

Consumption $c$ is measured as per capita personal consumption expenditure on nondurables and services, excluding shoes and clothing. Data is seasonally adjusted and deflated by the relevant personal consumption expenditure chain-type deflators $(2000=100)$. Data is downloaded from the NIPA tables on the U.S. Bureau of Economic Analysis website ${ }^{3}$.

The default spread is defined as the difference between Moody's BAA-rated corporate bond rate and the AAA corporate bond rate. The relative t-bill rate $r t b$ is computed as the difference between the 3-month t-bill rate and its 1-year backward moving average. Data are downloaded from the website of the Federal Reserve Board ${ }^{4}$.

The price-dividend ratio $p d$ is computed as the current price divided by dividends over the past year, and the price-earnings ratio pe is computed as the current price divided by a moving average of earnings over the past ten years. This goes for both annual and quarterly data, to avoid seasonalities. We use data for the CRSP value-weighted return to compute the price-dividend ratio. Since earnings data is not available for the CRSP series, we instead use the corresponding price-earnings ratio from S\&P 500 available on the website of Robert Shiller ${ }^{5}$. Both series are log transformed. The payout ratio de is also based on data on the S\&P 500 index from Robert Shiller's homepage. de is the log ratio of dividends to earnings. Following Lamont (1998), earnings are not smoothed with a moving average approach as was the case for $p e$.

The price-output ratio $p y$ is based on the relation between the price on the aggregate stock market portfolio and GDP. The stock market price is proxied by the log of the price on the CRSP value-weighted stock index. Nominal GDP data is obtained from the U.S. Bureau of Economic Analysis 6 .

The price-consumption ratio $p c$ of Menzly et al. (2004) is computed as the ratio of the price on the CRSP value-weighted stock index divided to the real per capita consumption, computed as stated above. The CRSP index price is stated in $\$ 2000$ terms by deflating with the full PCE. The ratio is $\log$ transformed.

\footnotetext{
${ }^{3}$ http://www.bea.gov/bea/dn1.htm

${ }^{4} \mathrm{http}: / /$ www.federalreserve.gov/releases/H15/data.htm

${ }^{5} \mathrm{http}: / /$ www.econ.yale.edu/ shiller/data.htm. Observations for 2004 and 2005 are obtained directly from Standard \& Poors http://www2.standardandpoors.com/spf/xls/index/SP500EPSEST.XLS

${ }^{6} \mathrm{http}: / /$ www.bea.gov/bea/dn1.htm
} 
cay and $c d y$ are available on the website of Sydney Ludvigson ${ }^{7}$. However, in order to lengthen the sample period, we gather data from the original sources as described in the appendix of Lettau and Ludvigson (2005). The variables used in estimating these cointegration relations are aggregate consumption, asset wealth, labour income, and dividends. Consumption is computed as noted above. In computing cay and $c d y$, the series is scaled up so that the sample mean matches the sample mean of total personal consumption expenditures. Wealth is proxied by household net worth from the Federal Reserve Board ${ }^{8}$. Labour income $y$ is defined as wages and salaries + transfer payments + employer contributions for employee pension and insurance funds - employee contributions for social insurance. Taxes are defined as [wages and salaries /(wages and salaries + proprietors' income with IVA and Ccadj + rental income + personal dividends + personal interest income)]*personal current taxes. IVA is inventory valuation and Ccadj is capital consumption adjustments. Dividends are annual dividends on the CRSP value-weighted stock index. The CRSP dividends are scaled by the average ratio of stock market wealth to the price of the value-weighted CRSP index. Stock market wealth is also obtained from the website of the Federal Reserve Board, as a component of household net worth. Household net worth, labour income, and dividends are all deflated by the PCE to obtain data in 2000-dollar values. Finally, consumption, household net worth, labour income, and dividends are all divided by a measure of the population obtained from the Bureau of Economic Analysis. The series are log transformed to obtain log real per capita variables.

To compute the $l r$ series Julliard (2004) uses labour income data from the BEA NIPA table $1.12^{9}$. The series is given by log per capita real compensation of employees comp. If we follow the theoretical derivation of the model, the labour income measure used to construct $l r$ should be the same labour income measure used in cay. Hence, we also estimate the model using log per capita real labour income $y$, computed as stated above.

The labour income series $y$ is also used in computing $y \_l d$ and $y \_l s$ of Benzoni et al. (2006). $y \_l d$ combines the labour income series with the dividend yield series $d$ defined previously, whereas $y \_l s$ uses $s$ given by the log-level of the CRSP value-weighted market index, inclusive of all distributions. $y_{-} l s$ is computed as $y_{-} l s=y_{t}-s_{t}+\delta t$ where $\delta$ is the sample average of the dividend yield. The dividend yield is based on annual dividends paid, to avoid seasonality. Hence, when we estimate $y_{-} l s$ at quarterly frequencies, we scale the $\delta t$ term by $\frac{1}{4}$ so that only one quarter of the average annual dividend payments are added each period.

Three versions of the labour income to consumption ratio yc of Santos and Veronesi (2005) are computed. Firstly, we use real per capita labour income $y$ divided by real per capita consumption $c$ giving $y c_{1}$. The exact definition of both these variables is stated above. Secondly, we use per capita compensation of employees scaled by consumption data to give $y c_{2}$. The final variable does not actually include consumption data. Instead it consists of labour income scaled by disposable income, $y c_{3}$. Both the compensation of employees and disposable income series are from the NIPA tables of the U.S. Bureau of Economic Analysis. The ratios are all log transformed ${ }^{10}$.

To construct the non-housing expenditure share nhe of Piazzesi et al. (2006), we need a measure of consumption that excludes housing expenditures. This is defined as per capita personal

\footnotetext{
${ }^{7}$ http://www.econ.nyu.edu/user/ludvigsons/

${ }^{8}$ Data is downloaded from the FED website where a full description of the series' construction is also available http://www.federalreserve.gov/releases/z1/current/data.htm.

${ }^{9}$ In the appendix of Julliard (2004) it is stated that labour income data is taken from NIPA table 1.14. However, a revision of the NIPA tables performed by the BEA in 2003 changed the "National Income by Type of Income" table from table 1.14 to table 1.12 .

${ }^{10}$ Santos and Veronesi (2005) do not log transform the ratios when running long-horizon regressions of stock returns on the labour income-consumption ratios. To keep in line with the other predictor variables in this paper, we choose to perform a log transformation.
} 
consumption expenditure on nondurables and services, excluding shoes, clothing, and housing services. Again, this measure is seasonally adjusted and deflated by the relevant elements of the PCE. Our source is the NIPA tables of the U.S. Bureau of Economic Analysis. nhe is then computed as the ratio of this consumption measure to total consumption, measured as in the previous variables. The ratio is $\log$ transformed.

To compute the my measure of Lustig and Nieuwerburgh (2005), three alternative housing collateral measures are used. Firstly, the value of outstanding home mortgages mo, which is given by Non-Farm Home Mortgages (FL153165105) from the Flow of Funds, Balance sheet of households and non-profit organizations, available on the website of the Federal Reserve Board ${ }^{11}$. The second variable is the market value of residential real estate wealth $r w$. This is taken from the same source and is given by the market value of household real estate (code FL155035015). The final variable is the current cost of net stock of owner-occupied and tenant-occupied residential fixed assets for non-farm persons $f a$ from the Bureau of Economic Analysis fixed asset tables. The labour income series $y a$ is given by labour income plus transfers. This is obtained from the BEA NIPA tables as wage and salary disbursements + employer contributions for employee pension and insurance funds + proprietors' income with inventory valuation and capital consumption adjustments + personal current transfer receipts - employee contributions for social insurance. All series are deflated by the total personal consumption expenditure chain-type deflator $(2000=100)$ and rescaled in per household terms. Number of households is obtained from the U.S. Bureau of the Census.

Once long-horizon time-series regressions of the various predictor variables on the market portfolio return have been completed, a cross-sectional analysis is also introduced. The cross-sectional stock return data is taken from the website of Kenneth French ${ }^{12}$. A number of portfolios constructed from the stocks on NYSE, AMEX, and NASDAQ are used. These are 25 portfolios sorted by size and the book equity to market equity ratio (BE/ME) quantiles. The portfolios are the intersections of 5 portfolios formed on size (market equity, ME) and 5 portfolios formed on the ratio of book equity to market equity (BE/ME). The stock return data is measured in excess of the risk free rate, which is defined as the one-month T-bill rate. All returns are in log form.

\section{Empirical results}

Before we start on the long-horizon return regressions, we need to look at the properties of the elements comprising these regressions, namely excess returns on the stock market over varying time horizons and the forecasting variables. If we start with excess returns, table 1 presents descriptive statistics for returns at horizons of 1 to 8 years. Over the 60-year sample average annual excess returns on the U.S. stock market have been $6.1 \%$. Increasing the time horizon of course results in higher excess returns. We also observe rising autocorrelation coefficients with longer time horizons. At an 8-year horizon this is as high as 0.858 . This is partly due to the use of overlapping returns. Another consequence hereof is that we cannot reject the hypothesis of a unit root in excess returns at horizons of 6 to 8 years $^{13}$. As is evident from table 1, quarterly excess returns suffer from the same stationarity issues at long horizons. When we aggregate returns over 24, 36 or 48 quarters, we cannot reject the hypothesis of a unit root in the series. The tendency of rising autocorrelation coefficients observed on annual data carries through to quarterly frequencies. The correlation coefficient rises from 0.048 at quarterly frequencies to 0.960 at a horizon of 48 quarters. To emphasize the importance of overlapping returns, we compare the autocorrelation coefficient at 4 quarters of

\footnotetext{
${ }^{11} \mathrm{http}: / /$ www.federalreserve.gov/releases/z1/current/data.htm

${ }^{12} \mathrm{http}: / /$ mba.tuck.dartmouth.edu/pages/faculty/ken.french/data_library.html

${ }^{13}$ For both excess returns and predictor variables we test for a unit root by the Augmented Dickey-Fuller test. The lag length used is determined by the Schwarz information criteria and a trend term is included when necessary.
} 
0.748 to that of annual returns at a 1-year horizon of -0.025 and see just how large the difference is. Average quarterly excess returns are $1.4 \%$ over the sample period.

We now turn to the predictor variables to be used in our time-series analysis. Table 2 presents descriptive statistics for the traditional predictor variables at quarterly frequencies. Most of the variables have relatively low autocorrelation coefficients and are clearly stationary. However, for both the price-earnings and price-dividend ratio we cannot reject the hypothesis of a unit root. These two ratios are both highly autocorrelated and are also highly correlated with each other with a correlation coefficient of 0.899 . Table 5 contains summary statistics for the traditional predictor variables at annual frequencies. The pattern is similar to that found for quarterly data. We are still unable to reject the unit root hypothesis for the price-earnings and price-dividend ratios, whereas the remaining ratios appear stationary.

For the new ratios at quarterly frequencies presented in table 3, we observe high autocorrelation coefficients: ranging from 0.960 for the disposable income-consumption ratio to 0.981 for the nonhousing expenditure share. We cannot reject the hypothesis of a unit root for the price-output, priceconsumption, labour income-consumption ratios and the non-housing expenditure share. There is thus a general pattern of high persistence in all the new ratios. Also we observe that the price-output ratio and price-consumption ratio are almost perfectly correlated with a correlation coefficient of 0.999. Moving to data at annual frequencies, the new ratios, price-output and price-consumption presented in table 6, again result in non-rejection of the unit root hypothesis. As was the case at quarterly frequencies, the two variables are highly correlated.

The final group of variables treated in this paper require a bit more in-depth analysis. Firstly, before we estimate a cointegrating relation, we would like statistical evidence that such a relation actually exists in the data. In order for this to be the case, the underlying variables assumed to be cointegrated must be integrated of the same order. Once this is shown, we can use tests developed by Johansen (1991) to see whether the variables are in fact cointegrated. Finally, we can estimate the cointegrating coefficients and compute the variables suggested to be good predictor variables.

If we start of with cay, all three variables used in constructing the cay series contain unit roots. To see whether the series are in fact cointegrated, as suggested by Lettau and Ludvigson (2001a), we perform tests using the VAR-based procedure suggested by Johansen (1991). This consists of two tests: the Trace test and the Maximum Eigenvalue test. These allow us to estimate the number of cointegrating relations present in the group of variables to be evaluated ${ }^{14}$. As noted, these tests are based on a VAR model setup, and the test statistics are sensitive to the number of lags included in the VAR. Therefore, we estimate the tests over lag lengths of 0 to 4 lags in first differences of the variables.

The Maximum Eigenvalue test for cay estimated on annual data shows evidence of a cointegrating relation existing only at 0 lags, whereas the Trace test indicates one cointegrating relation at lag lengths of 0 and 2 , using a $90 \%$ confidence level. The remaining tests show no evidence of a cointegrating relation existing. This weak evidence of cointegration is further emphasized when looking at the cointegrating coefficients of cay in table 9. Lettau and Ludvigson suggest estimating the relation by the DLS procedure with 2 lags. However, if the relation was stable, we would expect to observe similar coefficient estimates using other estimation methodologies. The first two models presented in table 9 show cay estimated by DLS and the procedure suggested by Johansen (1991), both with lag and lead length 2 . We observe large differences in the cointegration coefficients estimated by the two procedures. The cointegration vector of $(c, a, y)$ from

\footnotetext{
${ }^{14}$ The Trace test tests the null hypothesis that there exist $r$ cointegrating relations against the alternative hypothesis of $p$ cointegrating relations where $p$ is the number of variables in the group. The Maximum Eigenvalue test tests the null hypothesis of $r$ cointegrating relations against the alternative of $r+1$. As we have 3 non-stationary variables in cay, we can have a maximum of 2 cointegrating relationships.
} 
DLS is $(1,-0.258405,-0.663826)$, which is in line with estimates reported by Sydney Ludvigson on her homepage, and $(1,-0.583294,-0.288472)$ by the Johansen procedure. Lettau and Ludvigson (2001a) note that the coefficient on $a$ should be the empirical estimate of the steady state share of nonhuman wealth in total wealth. Similarly the coefficient on $y$ should be the share of human wealth in total wealth. This is expected to be approximately $2 / 3$, which is very much in line with the estimates resulting from the DLS estimation. Based on economic theory, DLS estimates are most likely. We will estimate long-horizon return predictability regressions with both the resulting cay variables to see whether these differences in coefficient estimates have an impact on the predictive power of the variable.

$c d y$ does not run into the problems observed for cay. All variables used to generate the relation are found to contain a unit root and there is stronger evidence of a cointegration relation existing. From table 9 we also observe relatively stable coefficient estimates from the two estimation procedures.

Using data for cay and $c d y$ at quarterly frequencies with 8 leads and lags in the cointegration estimation results in similar coefficient estimates across the two estimation procedures for both variables. This is the case despite the evidence for the existence of cointegration relations in the data being even weaker than was the case at annual frequencies. Computing the Trace and Maximum Eigenvalue tests with up to 8 lags in first differences of the VAR elements only results in evidence of cointegration for cay with the Maximum Eigenvalue test at 0 lags. The remaining cay cases do not show evidence of cointegration.

The final group of variables presented in table 9 are the housing collateral relations suggested by Lustig and Nieuwerburgh (2005). As has been the case in the cay and $c d y$ series, all variables underlying the cointegration relations are integrated of order 1 . Also, tests for the existence of cointegration relations provide support for this hypothesis. In their paper Lustig and Nieuwerburgh estimate cointegration relations between housing collateral and labour income via the Johansen (1991) procedure, including both a constant and trend term in the model and 8 lags. For consistency we also estimate the relation by DLS. The correlation between mymo estimated by the two procedures is 0.90 . Tests for cointegration between labour income and the housing collateral measure at a quarterly frequency show no evidence of such a relation existing. As a result we have chosen not to include the variables in the long-horizon regressions at quarterly frequencies. This is in line with Lustig and Nieuwerburgh (2005) who only estimate the relations using annual data ${ }^{15}$.

As noted in the data section of this paper, Julliard bases his $l r$ measure on a compensation of employees' labour income measure which differs from that used to generate cay. For theoretical consistency we estimate $l r$ using both Julliard's measure and the labour income variable used in cay. $l r$ is constructed by fitting an ARIMA process to the labour income data. In line with Julliard, we find an $\operatorname{ARIMA}(0,1,2)$ to be the best fit for the compensation of employees measure at annual and quarterly data frequencies as can be seen from table 10. However, turning to the labour income measure of cay, this more closely resembles a random walk process when looking at quarterly data. If this is the true process underlying the data, $l r$ disappears from the theoretical model of Julliard (2005) and we are back in the setup suggested by Lettau and Ludvigson (2001a) where only cay is used as a forecaster of financial returns. For the time-series analysis of the next section we estimate $l r$ on both the labour income and compensation of employees measures using the $\operatorname{ARIMA}(0,1,2)$, but with the reservation that this is in fact a bad fit for the labour income series ${ }^{16}$. Looking at

\footnotetext{
${ }^{15}$ Similar results regarding stationarity are obtained when estimating the $m y$ relation using the two alternative houring collateral definitions $r w$ and $f a$.

${ }^{16}$ The ARIMA $(0,1,2)$ results in empirical estimates of $\Delta y_{t}=\mu_{y}+\varepsilon_{t}+\theta_{1} \varepsilon_{t-1}+\theta_{2} \varepsilon_{t-2}$ where $\varepsilon_{t}$ is the time $t$ labour income innovation and $\theta_{1}$ and $\theta_{2}$ are MA coefficients. Following Julliard (2005), $l r$ is computed as $\widehat{l r}_{t}=$ $\left(\widehat{\theta}_{1}+\rho_{h} \widehat{\theta}_{2}\right) \widehat{\varepsilon}_{t}+\widehat{\theta}_{2} \widehat{\varepsilon}_{t-1} \cdot \rho_{h}=0.957$ as in Baxter and Jermann (1997).
} 
the descriptive statistics of the resulting $l r$ measure in tables 4 and 7 , we observe that the variable is stationary and mean zero both when computed using the labour income and compensation of employees measures.

The final measures used are the labour income-dividend yield relations $y_{-} l d$ and $y_{-} l s$ of Benzoni et al. (2006). We can reject the hypothesis of a unit root in $y \_l d$ at both annual and quarterly frequencies, whereas $y \_l s$ appears to contain a unit root at both frequencies. Our results thus provide stronger evidence of a cointegration relation existing between labour income and dividends than Benzoni et al. (2006) themselves find. Their paper does not provide any insight into the stationarity of $y_{-} l s$, which we find to be questionable. The two variables both have autocorrelation coefficients of 0.89 at annual frequencies, and these rise to 0.980 and 0.968 respectively with quarterly data. So once again we have very high persistence in the predictor variables. The correlation between the two variables, which both act as proxies for the cointegration of stock and labour markets, is 0.60 at annual frequencies. They are thus far from perfect substitutes.

\section{VI.1 Time-series results}

We next turn to the results of the univariate long-horizon time-series regressions. Each predictor variable is regressed on excess stock returns measured at horizons of 1 to 8 years and 1 to 48 quarters. This will allow us to analyze the forecasting ability of each variable at short, intermediate and long horizons, as well as compare performance across variables. For each estimated equation we present $\beta$ estimates, Newey-West corrected standard errors, the $t / \sqrt{T}$ statistic suggested by Valkanov (2003), and the adjusted $R^{2}$.

To evaluate the significance of the Valkanov $t$-statistics, we must first compute the nuisance parameters $c$ and $\delta$ for each predictor variable. Estimates of these are presented in table 11. Critical values of $t / \sqrt{T}$ are available in Valkanov (2003) table 4, case 1. However, the values are only available for $\delta=\{0,-0.9\}$ and $c=\{0,-0.5,-1,-5,-10\}$. In evaluating the significance of our coefficient estimates, we use critical values from Valkanov's table for the values of $c$ and $\delta$ most closely fitting our estimates.

Table 12 presents results of regressions of the traditional variables on excess stock market returns at quarterly frequencies. The first thing we observe is that lagged excess stock market returns are a very poor predictor of future returns at all horizons. Similar regressions using annual data, presented in table 15, show that this pattern carries over to these longer horizons ${ }^{17}$.

The default premium on bonds shows a similar pattern. The relative bill rate $r t b$ shows some forecasting ability at short horizons, with significant coefficient estimates at horizons of up to 8 quarters, when evaluated by the traditional $t$-statistic.

Consumption growth provides significantly negative regression coefficients from horizons of 4 quarters and up. Higher consumption growth thus predicts lower stock market returns. There is no clear pattern in the forecasting ability across horizons. The adjusted $R^{2}$ starts to become positive at a horizon of 4 quarters where it is 0.034 . Longer horizons, still with quarterly data, result in a slight increase in the adjusted $R^{2}$. Regressing consumption growth on annual returns as in table 15 gives an adjusted $R^{2}$ of 0.07 , whereas a two-year horizon produces an adjusted $R^{2}$ of 0.13. Regressions at longer horizons fall within this interval.

Two of the variables traditionally used to forecast excess stock market returns are the priceearnings and price-dividend ratios. Price-earnings and, even more so, price-dividend ratio show clear patterns of rising forecasting ability with growing return horizons. High price-earnings ratios or price-dividend ratios predict lower future stock market returns; that is, if the intrinsic value of

\footnotetext{
${ }^{17}$ We also estimate multivariate long horizon regressions with the three Fama-French factors as regressors. These provide just as poor forecasting ability for excess market returns as the lagged market return alone.
} 
the firm is low relative to the current price, we expect lower future returns on the market. Using quarterly data and the price-dividend ratio as predictor the adjusted $R^{2}$ is 0.01 at a 1-quarter horizon, rising to 0.39 at a 48-quarter horizon. Moving to annual data, the price-dividend ratio goes from an adjusted $R^{2}$ of 0.06 when regressing on 1-year returns to 0.33 at an 8-year horizon. When looking at this remarkable performance, we must, however, keep in mind the high persistence in the price-earnings and price-dividend ratios and the fact that we were not able to reject the unit root hypothesis for these two ratios at either quarterly or annual frequencies. Taking this into account via the Valkanov $t$-statistic, there is no evidence of significant coefficient estimates at any horizon. This goes for both $p e$ and $p d$ on quarterly and annual data.

The payout ratio de of Lamont (1998) shows only little forecasting ability at mid-range forecasting horizons. In contrast to Lamont (1998) we do not find a significant regression coefficient at a 1-quarter return horizon. Lamont's sample period runs only to 1994 and our results are in line with those of Lettau and Ludvigson (2001a) and Rangvid (2006) whose samples run to 1998 and 2003 respectively.

Moving on to tables 13 and 16 we have forecasting regressions based on the new ratios introduced in the literature. The first two ratios, price-output and price-consumption, show similar results to those obtained from the price-earnings and price-dividend ratios although the adjusted $R^{2}$ is somewhat smaller at long horizons on quarterly data. If stock prices are high relative to the level of output in the economy, lower future stock returns are predicted. The same is the case if prices are high relative to consumption. The regression coefficients only become significant at horizons of 16 quarters and up on quarterly data. Moving to annual data the adjusted $R^{2}$ for the priceoutput ratio goes from 0.01 at a 1-year horizon to 0.25 at an 8-year horizon. The results for the price-consumption ratio are much the same, which is to be expected given the fact that the correlation between the two variables was found to be 0.999 in table 6 . The two new variables are, however, outperformed by the price-dividend ratio at all horizons. As was the case for this variable, the results described in the previous section of non-stationarity and high persistence in $p y$ and $p c$ should again be kept in mind. We still do not obtain significant coefficient estimates in the sense of the Valkanov statistic. This is in line with the evidence of Rangvid (2006) when using excess returns. However, Rangvid (2006) shows that $p y$ is a significant forecasting variable for real stock returns at horizons of more than 2 years on annual data.

Moving to the labour income-consumption variables of Santos and Veronesi (2005), these are found to have some forecasting power at quarterly frequencies. The main variable, $y c_{1}$, obtains an adjusted $R^{2}$ high of 0.16 at a 16 -quarter horizon. This is slightly lower than that obtained by Santos and Veronesi using data for the period 1948-2001. The variable thus appears to have some problems fitting the market return pattern of the past years. The best performance over our sample is obtained by using compensation of employees as the labour income measure, $y c_{2}$. This variable shows an adjusted $R^{2}$ ranging from 0.04 at a 1 -quarter horizon to a high of 0.32 at a 16-quarter horizon. The variable outperforms the traditional price-dividend ratio at short horizons, but at very long horizons the adjusted $R^{2}$ of both $y c_{1}$ and $y c_{2}$ drops to virtually no forecasting ability. The regression coefficients are significantly negative at all horizons except at 48 quarters when evaluated by the traditional $t$-statistic. For $y c_{2}$ we also obtain significant regression coefficients at 16- and 24-quarter horizons using the Valkanov measure. In fact all three yc measures result in negative regression coefficients, which is in line with the underlying theory presented by Santos and Veronesi (2005). The idea of using labour income-consumption ratios to predict excess stock returns thus appears to be robust across varying choices of data series. If labour income is high relative to consumption, only a small part of consumption will be funded by returns on financial assets. This results in low correlation between the movements in consumption and financial asset returns. Hence, investors only require a small premium to hold these financial assets. Thereby, a rise in the labour income to consumption ratio implies low returns on the aggregate stock market. 
Using annual data, $y c_{1}, y c_{2}$, and $y c_{3}$ result in significantly negative coefficient estimates at all frequencies. From horizons of 5 years and up, 4 years for $y c_{2}$, all coefficient estimates are also significant according to the Valkanov corrected $t$-statistic. As was the case at quarterly horizons, the adjusted $R^{2}$ of $y c_{1}$ and $y c_{2}$ is highest at mid length horizons, whereas the forecasting ability of $y c_{3}$ continues to rise at long horizons. It results in an adjusted $R^{2}$ of 0.43 at an 8-year horizon. As has been the case for many of the variables resulting in a high adjusted $R^{2}, y c_{3}$ is nonstationary ${ }^{18}$.

The final variable in the group of new ratios investigated is the non-housing expenditure share of Piazzesi et al. (2006). This variable also provides good forecasting ability at long horizons with an adjusted $R^{2}$ of 0.19 at an 8-year horizon. However, it has virtually no power at short horizons with an adjusted $R^{2}$ of 0.003 at a 4 -quarter horizon. The regression coefficient on $n h e$ is positive at all horizons, and significantly so from a 3 -year horizon and up. This again is in line with results predicted by the theory. Non-housing expenditure shares are high during recessions when expected excess returns are also high.

The final group of predictor equations are those using the various cointegration relations presented. The first variable in table 14 and 17 is the highly acclaimed cay of Lettau and Ludvigson. Our results support previous evidence of high forecasting ability of cay on excess returns. This pattern starts at short horizons with an adjusted $R^{2}$ of 0.09 at a 2-quarter horizon moving to 0.47 at a 16-quarter horizon. Annual data shows similar performance. The adjusted $R^{2}$ is 0.13 at a 1-year horizon and rises to a high of 0.39 at a 3 -year horizon. At longer time horizons the proportion of variation in excess returns explained by cay falls slightly. cay is thus best at forecasting returns at short and intermediate horizons, in line with the findings of Lettau and Ludvigson (2005). Coefficient estimates are significantly positive at all quarterly horizons. The Valkanov statistic shows significant estimates at horizons of 8 to 36 quarters, underscoring the predictive ability of the variable at intermediate horizons. Similarly, the coefficient estimates using annual data are significantly positive in a Valkanov sense at horizons of 2 years and up.

It is slightly surprising to look at similar forecasting equations on annual returns using cay estimated by the Johansen procedure presented in table 18. As was noted in the previous section, the cointegration coefficients of cay on annual data are unstable across estimation methodologies. Using cay estimated by the Johansen procedure results in the adjusted $R^{2}$ of cay ranging from a low of -0.018 at an 8-year horizon to a high of 0.07 at a 2 -year horizon. This is thus very far from the results obtained with cay constructed based on cointegration coefficients estimated by the DLS method. These results are only obtained when estimating the cointegration relation using two lags of the first differences of the variables in the VAR. With 0,1 , or 3 lags, the resulting coefficient estimates are similar to those obtained by DLS. With quarterly data, the Johansen procedure results in a cay with approximately $2 / 3$ the forecasting power of the DLS-computed cay.

Using annual data cay still outperforms the remaining variables when forecasting 1-year excess stock returns. Moving to midrange and long annual horizons, it obtains sharp competition from the simple dividend-price ratio and the labour income-consumption ratios of Santos and Veronesi (2005). $c d y$ also provides good forecasting ability, but unlike cay this variable has a linearly increasing adjusted $R^{2}$ with increasing time horizon. Using quarterly data we find an adjusted $R^{2}$ of 0.005 at a horizon of 4 quarters and 0.22 at 24 quarters. Moving to annual data the forecasting ability continues to improve with an adjusted $R^{2}$ of an impressive 0.4 at the 8-year horizon, showing good forecasting power of $c d y$ at long-time horizons. We obtain significantly positive regression coefficients using the Valkanov statistic at horizons of 4 years to 8 years. $c d y$ is theoretically intended as a forecaster of dividend growth, but it also has a positive relation to future expected

\footnotetext{
${ }^{18}$ As noted previously, Santos and Veronesi (2005) do not log transform the labour income-consumption ratios. As a robustness test we also run the time series regression on a non log-transformed version of the 3 ratios. This makes little difference to the results.
} 
returns. Using the $c d y$ variable computed by the Johansen procedure makes little difference to the results. Compared to the more traditional dividend-based measure $p d, c d y$ is outperformed at all horizons bar the very long annual horizons.

The $l r$ variable of Julliard shows a negative relation to excess returns. Positive revisions in future labour income growth predict lower excess stock market returns. When estimated on quarterly data, the forecasting ability of $l r$ is virtually the same whether the measure is constructed using labour income, $l r_{-} y$, or compensation of employees, $l r_{-}$comp. At a 2-quarter horizon the adjusted $R^{2}$ is 0.02. Longer return horizons result in a marginal increase in the $R^{2}$ to 0.08 at a 24-quarter horizon. This is in contrast to the findings of Julliard (2005). Here an adjusted $R^{2}$ of 0.16 is found at a 4-quarter horizon. Moving to annual data the forecasting ability of the variable at short-time horizons is virtually nonexistent. $l r$ estimated with data on labour income obtains an adjusted $R^{2}$ with a high of 0.1 at an 8 year horizon. Using data on compensation of employees to construct $l r$ only explains up to $3 \%$ of the variation in excess returns. This is at a 7 - year horizon. These results must be seen in light of the very poor fit of the $\operatorname{ARIMA}(0,1,2)$ on labour income data at annual frequencies used to construct $l r$.

Our final set of variables using both annual and quarterly data is the $y_{-} l d$ and $y_{-} l s$ variables of Benzoni et al. (2006). The cointegration relation between stock market dividends and labour income $y_{-} l d$ shows a positive link to excess stock market returns, apart from at long quarterly horizons when the coefficient estimates become negative, although insignificantly so. Lower dividends relative to labour income predict higher future excess stock returns. With quarterly data frequencies $y_{-} l d$ has no forecasting power for excess stock market returns at any horizon. $y \_l s$ on the other hand provides good forecasting power at longer time horizons with an adjusted $R^{2}$ of 0.42 at a time horizon of 48-quarters. Like many of the other forecasting variables, the $y_{-} l d$ relation only has predictive power at longer time horizons. The adjusted $R^{2}$ is approximately 0.1 at horizons of 5 to 8 years when the coefficient estimate also becomes significantly positive when measured by the traditional $t$-statistic. The alternative link between the stock market and labour income $y_{-} l s$, based on a cointegration relation between labour income and the log index level of the aggregate stock market, shows higher predictive power. The adjusted $R^{2}$ goes from 0.04 at a 1-year horizon to 0.35 at an 8-year horizon, closely mimicking the performance of the price-dividend ratio. The relative performance of $y_{-} l d$ and $y_{-} l s$ is in line with that found by Benzoni et al. We must, however, remember that we cannot reject the hypothesis that $y_{-} l s$ contains a unit root, as shown in table 7 .

Finally, the housing collateral measure mymo is used to forecast excess stock market returns on annual data. This variable provides poor forecasting power at short horizons, like our other housing-based measure nhe. The adjusted $R^{2}$ does, however, grow with the time horizon and is 0.20 at an 8 -year horizon. Housing considerations have higher impact at long horizons. The regression coefficient is positive at all horizons, implying that a high value of mymo predicts high future excess returns. As mymo is constructed as the maximum housing collateral value over the sample period minus the current housing collateral value, a high mymo is equivalent to a low housing collateral value ${ }^{19}$.

In table 9 we saw that we were not able to reject the hypothesis of a unit root in mymo when estimating the relation by DLS. Alternatively, the Johansen procedure did result in a stationary variable mymo_joh. The time-series analysis using this variable, presented in table 18, shows lower predictive power reaching a maximum adjusted $R^{2}$ of 0.15 at an 8-year horizon. The regression coefficient is only significant at horizons of 6 to 8 years and the adjusted $R^{2}$ is only positive at horizons where the regressand is nonstationary.

Lustig and Nieuwerburgh (2005) restrict the cointegration coefficient on labour income to be -1

\footnotetext{
${ }^{19}$ Like Lustig and Nieuwerburgh, we find little predictive ability when using the two alternative housing collateral measures based on myfa and myrw.
} 
in their final model. Even though the coefficients estimated in table 9 are some way from this, we also estimate the long-horizon regressions with the restricted variable mymo1. As we observe, the variable still has no forecasting power at short horizons, but the adjusted $R^{2}$ rises to 0.26 at an 8 -year horizon. The pattern is similar to that found with the previous two versions of the variable, but with slightly higher forecasting power. These results are close to those found by Lustig and Nieuwerburgh (2005).

In general, univariate time-series regressions over our sample period result in very little evidence of stock return predictability when we use the Valkanov $t$-statistic. Only at long horizons is cay significant in this sense, and the labour income-consumption ratio similarly. None of the traditional predictor variables such as the price-dividend ratio and price-earnings ratio result in significant predictive ability when measured by the Valkanov statistic. There is thus an indication that stock returns are only marginally predictable over our sample period.

We do, however, observe high $R^{2}$ values for some of our variables. As noted previously, this may to some degree be due to problems of overlapping returns as we are aggregating return data over long horizons. In order to address these issues when evaluating the predictive ability of our forecaster variables, we compute the implied $R^{2}$ statistics of Hodrick (1992) resulting from VAR model estimates. Results are presented in tables 19 and 20. The performance of many of the variables is unchanged when looking at implied $R^{2}$ statistics rather than the adjusted $R^{2}$ resulting from the long-horizon regressions discussed above.

Consumption growth showed some signs of predictive ability when observing the $R^{2}$ of longhorizon regressions. These disappear when we turn to the implied $R^{2}$. Price-earnings and pricedividend ratios show similar patterns as observed when evaluating direct long-horizon regressions, although the forecasting ability of the price-earnings ratio is slightly lowered at a 48-quarter horizon. On annual data both $p e$ and $p d$ result in higher implied $R^{2}$ than the adjusted $R^{2}$ observed previously. Contrary to this, the price-output and price-consumption ratios perform better than the traditional ratios on quarterly data and worse on annual data when evaluated by the implied $R^{2}$. They are still clearly outperformed by the price-dividend and price-earnings ratios. $y_{-} l s$ also obtains a high implied $R^{2}$ at long horizons, in line with the pattern observed in the above regression analysis. Finally, the proportion of variation in stock returns explained by cay is much lower when measured by the implied $R^{2}$. However, the variable still explains higher proportions than the price-normalized variables on quarterly data. On annual data cay maintains its predictive ability at short horizons, but the price-dividend ratio performs equally well. At long horizons cay has little predictive power.

Generally, there are small differences in the magnitudes of implied and traditional adjusted $R^{2}$ statistics, but the relative performance of the predictor variables is the same. cay is best at short and midrange horizons on quarterly data, but at long horizons the price-dividend ratio explains the highest proportion of stock return variation. On annual data the price-dividend ratio is the variable to beat.

\section{VI.1.1 Alternative sample periods}

The samples of quarterly and annual data on which the estimates of the previous section were based are determined by the maximum sample period over which data is available for all our predictor variables. Some variables, however, can be computed over longer samples. Tables 21 through 28 present results of long-horizon regressions based on predictor variables measured over the maximum sample length available for each variable individually.

Table 21 presents results for $r^{e m}, d e f, p e, p d$, and $d e$ on quarterly data measured over the period 1926Q4-2005Q4. The results are similar to those observed in our main data set. Only pe shows slight differences, in that we now obtain significant coefficient estimates at all aggregation horizons and the resulting adjusted $R^{2}$ is slightly higher than the one found in our base sample. Generally 
the results of these traditional forecasting variables are relatively stable. Using annual data over the time period 1930-2005 results in similar pattern, with slight improvement in the predictive ability of pe compared to the shorter base period sample.

In table 22 results are presented for the remaining variables for which we have quarterly observations covering a longer sample period than our base case sample. However, this sample is only 4 years longer than the original sample, running from 1947Q2 through 2005Q4. Despite this short difference in sample length, some relatively large divergences in forecasting ability arise. The two new price normalized variables $p y$ and $p c$ result in significant parameter estimates at all horizons above 1 quarter, compared to the base sample where significance is obtained at horizons of 16 and more. This also reflects in the adjusted $R^{2}$. At 16 quarters it is approximately 0.23 for both variables and 0.36 at 48 quarters, compared to 0.06 and 0.12 in the base sample period. Similar patterns are observed for the three labour income-consumption ratios and the non-housing expenditure share. The predictive ability of the series thus appears to be relatively sensitive to the sample period over which forecasting regressions are run.

All the three labour income-consumption ratios are found to have high predictive power at annual frequencies for the sample 1946-2005. We can, however, not reject the hypothesis of a unit root in $y c_{1}$ and $y c_{3}$ in this sample. Hence, we should interpret these results cautiously. Santos and Veronesi (2005) note that the problem of non-rejection of the unit root hypothesis may be due to lack of power of the ADF test in short samples. We only have 60 observations in our annual time series. They find that if we adjust the sample to cover a longer period, stationarity is obtained. On the basis hereof it is argued that the measures are still valid. If we follow this procedure and perform an ADF test on all three series measured on annual data over the period 1929-2005, we can reject the hypothesis of a unit root in all cases. With this longer sample the excess returns series also become stationary at all horizons. However, estimating long-horizon time-series regressions over this period shows little evidence of forecasting ability for any of the labour income-consumption ratios. The coefficient estimates are insignificant at all horizons for all three variables and the highest obtained adjusted $R^{2}$ never rises above 0.06 . This is in sharp contrast to the strong predictive ability found for these three variables at the shorter base sample period. The performance of the labour incomeconsumption ratios suggested by Santos and Veronesi (2005) is thus very sensitive to the sample period chosen.

Estimating mymo over the sample period 1930-2005 also allows us to obtain a stationary series, unlike that observed in the 1945-2004 sample. As was the case for the three labour incomeconsumption ratios, the predictive power of the variable observed in the previous section is greatly diminished. The highest adjusted $R^{2}$ of 0.05 is achieved at a horizon of 8 years.

In addition to estimating time-series regressions over these longer sample periods, we also check the robustness of the relations observed by investigating a subsample of our original data set ending ultimo 1994. The period at the end of the last century was characterized by a high runup in stock prices which could not be explained by fundamentals such as the dividends or earnings. As noted in section II.1, empirical research in the early part of this decade found that the close link between the economic fundamentals and stock returns had been broken. To see whether this is still the case, we compare the forecasting ability from our full sample ending in ultimo 2005 to this subsample.

As can be observed in tables 29 and 32, eliminating the last 10 years of data from our sample does result in improved forecasting ability by the traditional price-dividend and price-earnings ratios. This is especially the case at the long return horizons on both quarterly and annual data. We observe higher adjusted $R^{2}$ and for $p d$ the coefficients at horizons of 24 quarters and more in our quarterly sample and 5 years and more in the annual sample become significant when evaluated by the Valkanov significance measure. We also observe higher estimated coefficient values, indicating a higher nominal effect on stock returns from a change in $p d$ over this period. The implied $R^{2}$ estimated in tables 35 and 36 also underscores this pattern. Although the value at the long end 
is much lower than the directly computed long horizon $R^{2}$, the implied $R^{2}$ is still larger than that computed over our base period sample. There are thus indications that the forecasting ability of these fundamental ratios has deteriorated over the past 10 years. However, the predictive ability found in the previous section showed that these variables were still among the strongest in the forecasting literature.

The results from the remaining price-normalized variables, $p y$ and $p c$, are very similar to those observed for $p e$ and $p d$. We observe adjusted $R^{2}$ as high as 0.86 and 0.87 for $p y$ and $p c$ respectively when forecasting excess returns at a 48-quarter horizon. Similarly, the coefficient estimates based on both quarterly and annual data are significantly negative when using the scaled $t$-statistic of Valkanov at long-return horizons. The implied $R^{2}$ is much lower than the adjusted $R^{2}$ of the direct long-horizon regression. As with the $p d$ ratio, the variables still show higher forecasting ability than in the full sample. cay also follows the pattern of better predictive ability over this subsample.

By eliminating the last 10 years of data we generally find stronger evidence of stock return predictability. We observe significant Valkanov $t$-statistics for a large group of predictor variables. The change in predictability over the past 10 years does nott seem to be specific to the forecasting variable chosen. It is a general tendency among all the variables shown to be good forecasters of stock returns.

\section{VI.1.2 Multivariate regressions}

So far we have run only univariate time-series regressions, showing good predictive ability of a number of forecasting variables. However, the question arises of whether we can say that one variable is stronger than the others. Historically the benchmark predictor variable has been the price-dividend ratio. As we have seen in previous sections, this variable still performs well in our sample. Some of the newly suggested variables appear to perform equally well. To evaluate whether this is actually the case, we run multivariate regressions of excess returns on $p d$ and the remaining forecasting variables, one at the time. These regressions will tell us whether $p d$ dominates the new ratios or wice versa.

From tables 37 and 40 we first observe that $p d$ clearly dominates $p e$. The estimated coefficient on pe is insignificant at all horizons, and the adjusted $R^{2}$ of the multivariate regressions is very close to that of the time-series regressions run with $p d$ alone. Moving to the new price-normalized ratios $p y$ and $p c$, the pattern is less clear. These two variables also performed well in univariate forecasting regressions, although $p d$ obtained a higher adjusted $R^{2}$ at all horizons. When combined with $p d, p c$ loses its significance at all horizons on annual data and at short horizons on quarterly data. Only at long horizons on quarterly data does $p c$ appear to have any predictive ability over $p d$. Menzly et al. (2004) suggest that excess stock returns should be predicted by the price-dividend ratio and the price-consumption ratio combined. We do not find support for the hypothesis of Menzly et al. (2004) that the dividend yield should by combined with the price-consumption ratio in order to forecast stock returns. Including both $p d$ and $p y$ in the time-series regression results in higher adjusted $R^{2}$ at short horizons for both quarterly and annual data. Both variables result in significant coefficients, although the sign on $p y$ has changed from negative to positive. This should be seen in the context of $p d$ obtaining larger negative coefficient estimates than in the univariate regressions. The two variables $p d$ and $p y$ are highly correlated. Moving to longer return horizons, however, $p y$ loses its significance on annual data and is thus dominated by $p d$. With quarterly data both variables remain significant and we obtain higher adjusted $R^{2}$ than in the univariate regressions.

Moving to one of the other variables that performed well in univariate regressions, cay appears to dominate $p d$ at short horizons. Including these two variables in the time-series regressions, only cay obtains significant coefficient estimates at horizons of 1 and 8 quarters and 1 year on annual 
data. At longer horizons both variables have significant forecasting power. This is in line with cay having strongest forecasting power at short and intermediate horizons.

In general the multivariate regressions show further support for the traditional $p d$ ratio as a forecasting variable for aggregate stock returns. Very few of the variables studied in this paper contribute with any additional predictive ability when combined with the price-dividend ratio.

Julliard (2005) introduced the $l r$ variable as an addition to the cay variable, implying that excess returns should be best forecast by a linear combination of cay and $l r$. Computing multivariate regressions on annual data of cay, estimated by the DLS procedure, and $l r_{-} y$ on excess stock returns shows slightly improved forecasting ability at long horizons over cay alone. On quarterly data there is no improvement over the univariate cay regressions. $l r_{-} y$ does not obtain significant coefficient estimates at any horizons ${ }^{20}$. The same is the case when using $l r_{-} c o m p$. Both our univariate and multivariate regressions have thus provided little support for the use of $l r$ in predicting excess stock returns.

\section{VI.2 Cross-sectional results}

We have now analyzed the time-series behaviour of our sample of predictor variables and found largely differing forecasting abilities when attempting to fit excess stock market returns. However, all the work so far has been carried out using returns on one single stock portfolio constructed from the aggregate market. We could construct a wide variety of stock portfolios with return patterns very different from those observed on the market portfolio. In order to fully qualify as a good forecasting variable, we want our predictor to be able to price such a cross-section of stock market portfolios as well.

To see how well the various variables perform cross-sectionally, we use the conditional C-CAPM as our asset pricing model, as stated in eq. 8. The predictor variables are then introduced, one at a time, as state variables in this model. The model is fit to the 25 Fama-French portfolios, sorted on size and the book equity to market equity ratio. Due to the relatively few annual observations in our data set, 60 time points in all, the cross-sectional analysis will only be carried out on quarterly data. For scaling reasons, consumption growth and all return series have been multiplied by 100 . Likewise some of the state variables have been scaled up by 100 . This merely implies an increase in the size of the coefficient estimates by 100 , allowing us to observe the coefficients more easily. All state variables are demeaned.

We start of by looking at risk price or $\lambda$ estimates of the conditional C-CAPM. Table 43 presents estimates based on traditional variables and new ratios as state variables. The first thing we observe is that the intercept coefficient is significant in all cases. As the models are estimated on excess stock returns, theoretically we would expect this coefficient to be zero. The variables in table 43 are thus not able to explain the equity premium puzzle.

The default premium performs just as poorly cross-sectionally as it did in our time-series analysis. None of the risk price estimates are significant when evaluated by Shanken corrected $t$-statistics. In fact neither consumption growth nor scaled consumption growth is significantly priced in any of the regressions presented in table 43. Moving to pure state variable $\lambda$ 's, these are significantly priced for a number of the variables. The price-earnings, price-dividend, and price-output ratios all result in significant positive coefficient estimates. Stocks that covary positively with these ratios thus obtain higher expected returns than stocks with negative covariation. This is in line with the empirically observed value premium. Stocks with high book equity to market equity (BE/ME) ratios, known as value stocks, tend to show higher returns than growth stocks, stocks with low BE/ME.

\footnotetext{
${ }^{20}$ The multivariate regressions are not presented in this paper, but the results are available from the author on request.
} 
The highest adjusted $R^{2}$ of 0.64 is achieved by the price-consumption ratio $p c$, closely followed by the price-output ratio and labour income-consumption ratio. These macroeconomic factors thus appear to describe the general state of the economy, which is exactly what the conditional C-CAPM requires from a scaling variable.

Next we move on to inserting the cointegration relations of our paper into the conditional CCAPM as state variables. Results are presented in table 44. Once again, very few of the variables are able to fit the equity premium puzzle. Only $c d y$ and $y \_l d$ result in insignificant estimates of the constant. As was the case in Rasmussen (2006), we find no significance of the scaled consumption factor when using cay as state variable. This is unlike results obtained by Lettau and Ludvigson (2001b). Rasmussen (2006) argues that the shorter sample period used in Lettau and Ludvigson (2001b) is the cause of this divergence. Their sample ends in 2001 unlike our sample which runs through to ultimo 2005. cay appears to be somewhat sample specific in fitting the data cross sectionally. The coefficient estimate on cay alone is significantly negative, and the adjusted $R^{2}$ is 0.59 . The $l r_{-} y$ of Julliard (2005) results in a significant coefficient estimate on scaled consumption growth when we do not apply the Shanken correction. It results in a slightly higher adjusted $R^{2}$ than cay. This may seem surprising given the relatively poor time-series performance of this variable. However, if we look at the predictive ability of our variables on excess stock returns at a 1-quarter horizon, $l r_{-} y$ obtains a significant beta estimate and the adjusted $R^{2}$ of the equation is higher than that of for example the price-dividend ratio. So as we are only looking at 1-period-ahead forecasting power cross-sectionally, the results are in line with our time-series observations.

To get a better impression of which stock portfolios are priced well by which state variables, table 45 and 46 present pricing errors for the 25 Fama-French portfolios resulting from fitting the conditional C-CAPM with varying state variables. In addition, a number of weighted pricing error measures across the 25 portfolios are presented, to show the pricing performance of the forecasting variables.

Starting with table 45 we observe a general pattern of negative pricing errors on the small growth portfolio (S1BM1) and positive pricing errors on the small value portfolio (S1BM5). This is the value spread puzzle, referred to earlier. Value stocks tend to result in higher returns than growth stocks. None of the models estimated are thus able to fit the value premium fully, but some perform better than others. Using the price-dividend ratio, price-output or price-consumption ratios only shows a value premium effect on portfolios in the first 2-size quantiles. For larger stocks the effect disappears. The hardest portfolio to fit is clearly the small growth portfolio (S1BM1). Using $y c_{3}$ to scale results in a pricing error of -1.307 , whereas the smallest pricing error for this portfolio is obtained by def with a value of -0.6. Comparably, a mid-range portfolio such as S3BM3 results in pricing errors of 0.027 when using $y c_{3}$ and -0.235 using def.

The lowest average pricing errors across portfolios are obtained by using the price-output ratio of Rangvid (2006) or the price-consumption ratio suggested by Menzly et al. (2004). These result in average pricing errors of 0.40 . Both the measures are very simply computed macroratios which appear to perform well both in time-series and cross-sectional analysis. If we compare pricing errors weighted by either the full variance-covariance matrix of returns or the moment matrix, using $p d$ to scale consumption, results in slightly smaller values than $p y$ and $p c$. With the diagonal variance matrix of returns, the weighted pricing errors are once again smaller for $p y$ and $p c$. These two variables thus appear to be slightly better than $p d$ at fitting the return pattern of the extreme portfolios, which have high variances and thereby receive smaller weights in the pricing error measure CE $E_{\text {full }}$.

Cross-sectional models estimated with cointegration-based state variables also have problems fitting the small growth portfolio (S1BM1) as we can see from table 46. Using cay_dls as scaling variable results in a pricing error of -1.354 for S1BM1 - higher than for any of the variables in table 46 . The average pricing error resulting from this model is 0.42 , which is slightly higher than 
that found when using $p y$ or $p c$ as scaling variable. However, on the three remaining pricing error measures, the cay_dls model outperforms $p y$ and $p c$. As was the case with $p d, c a y_{\_} d l s$ thus appears best at fitting the central portfolios of the Fama-French distribution and has a harder time fitting portfolios such as the small growth portfolio. Turning to the remaining state variables in table 46, the labour income growth variable $l r_{-} y$ of Julliard (2005) results in average pricing errors of similar magnitude to cay_dls. However, the same relation based on a different labour income measure as in $l r_{\text {_comp}}$. has much higher pricing errors.

All in all, the cross-sectional results imply that a number of our predictors are good state variables in a conditional model. These range from the traditional price-dividend ratio to macrobased ratios like the price-output ratio and the price-consumption ratio and finally the somewhat more complicated consumption-aggregate wealth ratio approximated by cay.

\section{VI.2.1 Alternative sample}

As was the case in our time-series analysis, we have also conducted cross-sectional estimations on a subsample ending in ultimo 1994 and one running from the second quarter of 1947 through ultimo 2005 , the longest available time period for a subsample of our forecasting variables. In the timeseries analysis, some variables were available through 1926. However, for the cross-section we need consumption data to estimate the conditional C-CAPM and this is only available form 1947 and forward.

Table 47 shows that extending the sample period backwards by 4 years gives slight improvements in the significance level of coefficients on some of the forecasting variables. In particular scaled consumption becomes significant when using $p d$ as state variable. The same is the case when using the three labour income-consumption ratios of Santos and Veronesi (2005). However, we generally observe lower adjusted $R^{2}$ than for the base case sample. This is also reflected in the observed pricing errors presented in table 49. Average pricing errors are generally larger, but the relative pattern of our best performing state variables remains the same. $p d, p y$, and $p c$ have very similar values. cay is not available over this sample period.

Ending the sample in ultimo 1994 instead of 2005 results in consumption growth and scaled consumption growth becoming significant in predicting cross-sectional returns when using $p d$ and $p y$ as state variables. For cay the significance of the state variable found in our base sample period is lost in the 1994 sample emphasizing the sensitivity of cay to the chosen sample period. In table 52 we note that de results in the lowest average pricing errors.

\section{Conclusion}

During recent years a vast number of papers on return predictability have surfaced in the finance research arena. Many have come with suggestions for variables based both on financial and macroeconomic data, which theoretically should predict stock returns. The evidence from these papers has lent a great deal of support to the idea of stock return predictability. However, when faced with this myriad of variables, one lacks a consistent comparison across these variables. This paper attempts to give such an overview. We present evidence of the time-series and cross-sectional forecasting ability of a wide selection of predictor variables suggested in the literature and compare their relative performance. The variables are based on traditional financial data such as stock prices, dividends, and earnings, but also on macroeconomic data like consumption, labour income, and housing. The series based on financial data are mostly focused on giving a description of where the stock market prices are relative to the intrinsic value of the underlying stocks, whereas macro-based series attempt to give a description of the general state of the economy, which may be relevant for the pricing of stock returns. 
Our time-series analysis shows evidence of stock return predictability of varying degrees across time horizons. Firstly, evidence of stock return predictability is not overwhelming for our base sample period running through to ultimo 2005. In the time-series analysis only very few variables obtain significant regression coefficients when we control for statistical issues of non-stationarity in both forecasting variables and returns. If we eliminate the last 10 years of data, the predictability of stock returns is somewhat stronger.

In general, the well-known empirical pattern of increasing predictability with increasing return horizons is confirmed, but with some differences across forecasting variables. At the very short horizons few variables manage to capture a great deal of the variation in excess stock returns. Traditional variables such as the relative bill rate and price-dividend ratio have some forecasting power at a 1-quarter horizon, along with new variables like the labour income-consumption ratio and cay. On annual data the proportion of variation in 1-year excess returns captured by the forecasters is slightly higher, but the variables capturing this variation are much the same as on short term quarterly returns. However, consumption growth also proves to be a good predictor, supporting the idea of using the C-CAPM as an asset pricing model to fit stock returns.

Moving to mid-range horizons the approximate consumption-aggregate wealth ratio cay of Lettau and Ludvigson (2001a) clearly outperforms the remaining variables in predicting excess stock returns. This pattern is the same whether we look at quarterly or annual data frequencies. The predictive ability of cay does, however, appear to be sensitive to the sample period over which regressions are run.

Aggregating returns over longer periods greatly increases the predictive ability of many of the forecasting variables. Generally, all the price-normalized variables especially show good forecasting power at long horizons. The most important thing does not so much appear to be which variable the price is combined with, but the fact that price enters the relation. As such, using the dividendearnings ratio has virtually no predictive power. In multivariate regressions the price-dividend ratio is found to dominate most of the remaining variables. Only cay maintains its significance at all horizons.

Housing-based measures only really obtain predictive ability at long horizons, in line with the findings of Lustig and Nieuwerburgh (2005). Housing considerations do not move markets in the short run, but may have an impact at long horizons. The labour income-consumtion ratios show strong forecasting power in our base case annual sample, but all predictive ability is lost when we increase the sample length. One should therefore be wary of using this ratio as forecasting variable.

Cross-sectionally, a number of variables perform almost equally well as state variables in the conditional C-CAPM. We have previously seen evidence supporting the use of the approximate consumption-aggregate wealth ratio cay as a state variable. This evidence is confirmed by our results. However, more simply computed variables such as the price-output or price-consumption ratio or even the traditional price-dividend ratio result in average pricing errors across our 25 test portfolios of similar or smaller magnitude than cay. There is not one variable which really pulls away from the rest of the pack. Which variable one chooses is a matter of taste. cay, however, has the disadvantage of requiring more computations to construct than the simple price ratios and it is the variable in our data set available over the shortest time-period.

All in all our research shows that there is a small group of the suggested forecasting variables which outperform the remainder in both time-series and cross-sectional estimations. This group consists of price-normalized variables such as the price-dividend, price-earnings, price-output and price-consumption ratios. Joining this group is the approximate consumption-aggregate wealth ratio cay. 


\section{References}

Baxter, M. and U. J. Jermann (1997). The international diversification puzzle is worse than you think. The American Economic Review 87(1), 170-180.

Benzoni, L., P. Collin-Dufresne, and R. S. Goldstein (2006, Jan.). Portfolio choice over the life-cycle when the stock and labor markets are cointegrated. Working paper, University of Minnesota and UCLA.

Campbell, J. Y. (1991, Mar.). A variance decomposition for stock returns. The Economic Journal 101 (405), 157-179.

Campbell, J. Y. and R. J. Shiller (1988a, Autumn). The dividend-price ratio and expectations of future dividends and discount factors. The Review of Financial Studies 1(3), 195-228.

Campbell, J. Y. and R. J. Shiller (1988b, July). Stock prices, earnings, and expected dividends. The Journal of Finance 43(3), 661-676.

Campbell, J. Y. and R. J. Shiller (2001, March). Valuation ratios and the long-run stock market outlook: An update. Cowles Foundation Discussion Paper (1295).

Campbell, J. Y. and T. Vuolteenaho (2004, Dec). Bad beta, good beta. The American Economic Review 94(5), 1-66.

Cochrane, J. H. (1996). A cross-sectional test of an investment-based asset pricing model. Journal of Political Economy 104(3), 572-621.

Fama, E. F. and K. R. French (1988). Dividend yields and expected stock returns. Journal of Financial Economics 22, 3-25.

Fama, E. F. and K. R. French (1989). Business conditions and expected returns on stocks and bonds. Journal of Financial Economics 25, 23-49.

Fama, E. F. and K. R. French (1993). Common risk factors in the returns on stocks and bonds. Journal of Financial Economics 33, 3-56.

Fama, E. F. and J. D. MacBeth (1973, May/June). Risk, return, and equilibrium: Empirical tests. Journal of Political Economy 81, 607-636.

Hodrick, R. J. (1992). Dividend yields and expected returns: Alternative procedures for inference and measurement. The Review of Financial Studies 5(3), 357-386.

Jagannathan, R. and Z. Wang (1998, Aug.). An asymptotic theory for estimating beta-pricing models using cross-sectional regression. The Journal of Finance 53, 1285-1309.

Johansen, S. (1991). Estimation and hypothesis testing of cointegration vectors in gaussian vector autoregressive models. Econometrica 59, 1551-1580.

Julliard, C. (2004, Oct.). Labor income risk and asset returns. Working Paper, Princeton University.

Lamont, O. (1998, Oct.). Earnings and expected returns. The Journal of Finance 53, 42-71.

Lettau, M. and S. Ludvigson (2001a). Resurrecting the (C)CAPM: A cross-sectional test when risk premia are time-varying. Journal of Political Economy 109(6), 1238-1287.

Lettau, M. and S. C. Ludvigson (2001b, June). Consumption, aggregate wealth, and expected stock returns. The Journal of Finance 56(3), 815-849.

Lettau, M. and S. C. Ludvigson (2004). The consumption wealth linkage. The American Economic Review 94(1), 276-299. 
Lettau, M. and S. C. Ludvigson (2005). Expected returns and expected dividend growth. Journal of Financial Economics 76, 583-626.

Lustig, H. and S. V. Nieuwerburgh (2005, June). Housing collateral, consumption insurance and risk premia: an empirical perspective. The Journal of Finance 60(3), 1167-1219.

Menzly, L., T. Santos, and P. Veronesi (2004). Understanding predictability. Journal of Political Economy 112(1), 1-47.

Piazzesi, M., M. Schneider, and S. Tuzel (2006). Housing, consumption, and asset prising. Working Paper, University of Chicago, NYU and USC.

Rangvid, J. (2006). Output and expected returns. Journal of Financial Economics 81(3), 595624.

Rasmussen, A.-S. R. (2006, Aug.). Improving the asset pricing ability of the consumption-capital asset pricing model? Unpublished.

Santos, T. and P. Veronesi (2005, March). Labor income and predictable stock returns. Working Paper, Columbia University and University of Chicago.

Shanken, J. (1992). On the estimation of beta-pricing models. Review of Financial Studies 5(1), $1-33$.

Stock, J. H. (1991, May). Confidence intervals for the largest autoregressive root in u.s. macroeconomic time series. Journal of Monetary Economics 28, 435-459.

Stock, J. H. and M. W. Watson (1993, July). A simple estimator of cointegrating vectors in higher order integrated systems. Econometrica 61(4), 783-820.

Valkanov, R. (2003). Long-horizon regressions: Theoretical results and applications. Journal of Financial Economics 68, 201-232. 
Table 1: Summary statistics for excess returns

\begin{tabular}{|c|c|c|c|c|c|c|c|c|}
\hline \multicolumn{9}{|c|}{ Panel A: Horizon h (in years) } \\
\hline & 1 & 2 & 3 & 4 & 5 & 6 & 7 & 8 \\
\hline Mean & 0.061 & 0.125 & 0.188 & 0.249 & 0.313 & 0.378 & 0.445 & 0.510 \\
\hline Std. & 0.162 & 0.227 & 0.257 & 0.284 & 0.333 & 0.371 & 0.393 & 0.421 \\
\hline Autocorr. & -0.025 & 0.374 & 0.592 & 0.762 & 0.746 & 0.771 & 0.828 & 0.858 \\
\hline $\mathrm{ADF}$ & $-8.130^{* *}$ & $-3.190^{* *}$ & $-3.741^{* *}$ & $-2.725 *$ & $-2.703^{*}$ & -2.326 & -2.137 & -2.050 \\
\hline \multicolumn{9}{|c|}{ Panel B: Horizon h (in quarters) } \\
\hline & 1 & 2 & 4 & 8 & 16 & 24 & 36 & 48 \\
\hline Mean & 0.014 & 0.029 & 0.057 & 0.114 & 0.213 & 0.318 & 0.477 & 0.605 \\
\hline Std. & 0.083 & 0.120 & 0.167 & 0.223 & 0.275 & 0.332 & 0.387 & 0.441 \\
\hline Autocorr. & 0.048 & 0.498 & 0.748 & 0.860 & 0.908 & 0.926 & 0.952 & 0.960 \\
\hline $\mathrm{ADF}$ & $-13.948 * *$ & $-7.210^{* *}$ & $-4.738^{* *}$ & $-2.995^{* *}$ & $-3.175^{* *}$ & -2.499 & -2.169 & -1.986 \\
\hline
\end{tabular}

This table presents summary statistics for excess returns computed over short and long horizons. Panel A shows annual data accumulated over horizons of 1 to 8 years for the period 1946-2005. Panel B shows quarterly data accumulated over horizons of 1 to 48 quarters for the period 1952Q1-2005Q4. The first row in each panel shows the sample mean of the series, followed by the standard deviation and the first order autocorrelation coefficient. The final row shows the result of the Augmented Dickey-Fuller (ADF) test of the unit root hypothesis. The lag length in the ADF test is chosen according to the Schwarz information criteria and a trend is included when appropriate. $*-10 \%$ significance, $* *-5 \%$ significance. 
Table 2: Summary statistics for tarditional predictor variables. Quarterly data, 1951Q4-2005Q3

\begin{tabular}{|c|c|c|c|c|c|c|c|c|c|}
\hline \multicolumn{10}{|c|}{ Panel A: Summary statistics } \\
\hline & $r^{e m}$ & $\Delta c$ & $h m l$ & $s m b$ & def & $r t b$ & pe & $p d$ & $d e$ \\
\hline Mean & (0.014 & 0.005 & 0.012 & 0.005 & (0.002 & 0.000 & 2.829 & (3.492 & -0.712 \\
\hline Std. & 0.083 & 0.004 & 0.054 & 0.054 & 0.001 & 0.002 & 0.411 & 0.388 & 0.188 \\
\hline Autocorr. & 0.048 & 0.345 & 0.141 & -0.013 & 0.927 & 0.639 & 0.980 & 0.972 & 0.949 \\
\hline $\mathrm{ADF}$ & $-14.037^{* *}$ & $-10.302^{* *}$ & $-12.709 * *$ & $-14.818 *$ & * $-2.873^{* *}$ & $-6.678^{* *}$ & -1.232 & -1.695 & $-3.403^{* *}$ \\
\hline \multicolumn{10}{|c|}{$\begin{array}{ll}\text { Panel B: Correlation matrix } \\
\end{array}$} \\
\hline & $r^{e m}$ & $\Delta c$ & $h m l$ & $s m b$ & def & $r t b$ & pe & $p d$ & $d e$ \\
\hline$r^{e m}$ & 1.000 & 0.151 & -0.392 & 0.416 & 0.093 & -0.235 & 0.077 & 0.069 & 0.052 \\
\hline$\Delta c$ & 0.151 & 1.000 & 0.015 & 0.093 & -0.164 & 0.093 & 0.141 & 0.098 & 0.022 \\
\hline$h m l$ & -0.392 & 0.015 & 1.000 & -0.149 & -0.006 & 0.053 & -0.044 & 0.011 & -0.058 \\
\hline$s m b$ & 0.416 & 0.093 & -0.149 & 1.000 & 0.121 & -0.172 & -0.008 & 0.032 & -0.004 \\
\hline def & 0.093 & -0.164 & -0.006 & 0.121 & 1.000 & -0.331 & -0.570 & -0.260 & -0.071 \\
\hline$r t b$ & -0.235 & 0.093 & 0.053 & -0.172 & -0.331 & 1.000 & 0.013 & -0.051 & -0.310 \\
\hline pe & 0.077 & 0.141 & -0.044 & -0.008 & -0.570 & 0.013 & 1.000 & 0.899 & -0.104 \\
\hline$p d$ & 0.069 & 0.098 & 0.011 & 0.032 & -0.260 & -0.051 & 0.899 & 1.000 & -0.294 \\
\hline$d e$ & 0.052 & 0.022 & -0.058 & -0.004 & -0.071 & -0.310 & -0.104 & -0.294 & 1.000 \\
\hline
\end{tabular}

This table presents summary statistics and correlations for the traditional predictor variables at quarterly frequencies for the period 1951Q4-2005Q3. Panel A shows summary statistics, starting with the sample mean of the series, followed by the standard deviation and the first order autocorrelation coefficient. The final row shows the result of the Augmented Dickey-Fuller (ADF) test of the unit root hypothesis. The lag length in the ADF test is chosen according to the Schwarz information criteria and a trend is included when appropriate. Panel B shows the correlation between the series. $r^{e m}$ is the log excess return on the CRSP VW portfolio, $c$ is $\log$ consumption, $h m l$ is the difference in returns on a high and a low BE/ME portfolio, $s m b$ is the difference in returns on portfolios of small and big stocks measured by market capitalization, def is the default premium on bonds, $r t b$ is the relative t-bill rate, $p e$ is the log price-earnings ratio on the $\mathrm{S} \& \mathrm{P} 500, p d$ is the log price-dividend ratio on the CRSP value-weighted portfolio, and de is the log dividend-earnings ratio on the $\mathrm{S} \& \mathrm{P} 500 . *-10 \%$ significance, $* *-5 \%$ significance. 
Table 3: Summary statistics for new ratio variables. Quarterly data, 1951Q4-2005Q3

\begin{tabular}{lrrrrrr}
\hline \hline \multicolumn{7}{c}{ Panel A: Summary statistics } \\
\hline \hline Mean & $p y$ & $p c$ & $y c_{1}$ & $y c_{2}$ & $y c_{3}$ & $n h e$ \\
Std. & -2.874 & -2.303 & -0.053 & 0.012 & -0.287 & -0.205 \\
Autocorr. & 0.595 & 0.588 & 0.032 & 0.030 & 0.020 & 0.014 \\
ADF & 0.975 & 0.975 & 0.960 & 0.959 & 0.970 & 0.981 \\
\hline \hline \multicolumn{7}{c}{ Panel B: Correlation matrix } \\
\hline -1.079 & -1.036 & -1.803 & -2.183 & -1.469 & -2.158 \\
\hline \hline$p y$ & $p y$ & $p c$ & $y c_{1}$ & $y c_{2}$ & $y c_{3}$ & $n h e$ \\
$p c$ & 1.000 & 0.999 & 0.186 & -0.096 & -0.220 & -0.105 \\
$y c_{1}$ & 0.999 & 1.000 & 0.195 & -0.076 & -0.212 & -0.102 \\
$y c_{2}$ & 0.186 & 0.195 & 1.000 & 0.767 & 0.674 & -0.651 \\
$y c_{3}$ & -0.096 & -0.076 & 0.767 & 1.000 & 0.644 & -0.459 \\
$n h e$ & -0.220 & -0.212 & 0.674 & 0.644 & 1.000 & -0.330 \\
\hline \hline
\end{tabular}

This table presents summary statistics and correlations for the new ratio predictor variables at quarterly frequencies for the period 1951Q4-2005Q3. Panel A shows summary statistics, starting with the sample mean of the series, followed by the standard deviation and the first order autocorrelation coefficient. The final row shows the result of the Augmented Dickey-Fuller (ADF) test of the unit root hypothesis. The lag length in the ADF test is chosen according to the Schwarz information criteria and a trend is included when appropriate. Panel B shows the correlation between the series. $p y$ is the log price-output ratio, $p c$ is the $\log$ price-consumption ratio, $y c_{1}$ is the log labour income-consumption ratio, $y c_{2}$ is the $\log$ compensation of employees-consumption ratio, $y c_{3}$ is the log labour income-compensation of employees ratio, and $n h e$ is the log non-housing consumption share. $*-10 \%$ significance, $* *-5 \%$ significance. 
Table 4: Summary statistics for cointegration relation variables. Quarterly data, 1951Q4-2005Q3

\begin{tabular}{|c|c|c|c|c|c|c|c|c|}
\hline \multicolumn{9}{|c|}{ Panel A: Summary statistics } \\
\hline & cay_dls & cay_joh & $c d y \_d l s$ & $c d y_{-} j o h$ & $l r_{-} y$ & lr_comp. & $y \_l d$ & $y_{-} l s$ \\
\hline Mean & -0.012 & -0.000 & -0.007 & 0.001 & 0.000 & & 0.004 & 4.620 \\
\hline Std. & & & & & 0.001 & & 0.410 & 0.374 \\
\hline & & & 0.896 & & 0.477 & 0.370 & 0.980 & 0.968 \\
\hline & -3.331 & -3.331 & -3.203 & -3.203 & $-7.847^{* *}$ & $-9.888^{* *}$ & -2.722 & -1.682 \\
\hline \multicolumn{9}{|c|}{ Panel B: Correlation matrix } \\
\hline & cay_dls & cay_joh & $c d y \_d l s$ & $c d y_{-} j o h$ & $l r_{-} y$ & $l r_{-}$comp. & $y \_l d$ & $y_{-} l s$ \\
\hline$a y \_d l s$ & 1.000 & 0.861 & 0.362 & 0.266 & -0.347 & -0.268 & -0.099 & 0.299 \\
\hline & 0.861 & & & & -0.3 & 73 & -0.109 & 0.578 \\
\hline$y-000$ & 0.362 & 0.218 & & 0.974 & -0.174 & -0. & 0.210 & 0.120 \\
\hline$c d y_{-} j o h$ & 0.266 & 0.232 & & 00 & -0.145 & -0.137 & 0.284 & 0.254 \\
\hline$l r \_y$ & -0.347 & -0.314 & -0.174 & .145 & 1.000 & 0.761 & 0.086 & -0.181 \\
\hline lr_comp. & -0.268 & -0.273 & -0.146 & -0.1 & 0.761 & 1.000 & 0.059 & -0.182 \\
\hline$y \_l d$ & -0.099 & -0.109 & & & 0.086 & 0.059 & 1.000 & 0.532 \\
\hline$y_{-} l s$ & 0.299 & 0.578 & 0.120 & 0.254 & -0.181 & -0.182 & 0.532 & 1.000 \\
\hline
\end{tabular}

This table presents summary statistics and correlations for predictor variables based on cointegration relations at quarterly frequencies for the period 1951Q4-2005Q3. Panel A shows summary statistics, starting with the sample mean of the series, followed by the standard deviation and the first order autocorrelation coefficient. The final row shows the result of the Augemented Dickey-Fuller (ADF) test of the unit root hypothesis. The lag length in the ADF test is chosen according to the Schwarz information criteria and a trend is included when appropriate. Panel B shows the correlation between the series. cay is the approximate consumption-aggregate wealth ratio, $c d y$ is the cointegration relation between consumption, dividends and labour income. $d l s$ implies that the relation has been computed by dynamic least squares and $j o h$ by the Johansen (1991) procedure. $l r_{-} y$ is the long run labour income growth relation of Julliard (2005) computed using log labour income and $l r_{-}$comp is the same relation using log compensation of employees instead of log labour income. $y_{-} l d$ is based on a cointegration relation between labour income and dividends and $y_{-} l s$ is the cointegration relation between labour income and the log level of the CRSP value-weighted stock index. $*-10 \%$ significance, $* *-5 \%$ significance. 
Table 5: Summary statistics for traditional variables. Annual data, 1945-2004

\begin{tabular}{|c|c|c|c|c|c|c|c|c|}
\hline \multicolumn{9}{|c|}{ Panel A: Summary statistics } \\
\hline & $r^{e m}$ & $\Delta c$ & $h m l$ & $s m b$ & $d e f$ & pe & $p d$ & $d e$ \\
\hline Mean & 0.066 & 0.021 & 0.058 & 0.027 & 0.009 & 2.774 & 3.415 & -0.697 \\
\hline Std. & 0.165 & 0.013 & 0.131 & 0.134 & 0.004 & 0.412 & 0.407 & 0.191 \\
\hline Autocorr. & -0.043 & 0.262 & -0.146 & 0.244 & 0.787 & 0.910 & 0.931 & 0.563 \\
\hline $\mathrm{ADF}$ & $-7.829^{* *}$ & $-5.765^{* *}$ & $-8.787^{* *}$ & $-5.833^{* *}$ & -2.609 & -1.409 & -1.064 & $-4.184^{* *}$ \\
\hline \multicolumn{9}{|c|}{ Panel B: Correlation matrix } \\
\hline & $r^{e m}$ & $\Delta c$ & $h m l$ & $s m b$ & $d e f$ & pe & $p d$ & $d e$ \\
\hline$r^{e m}$ & 1.000 & 0.019 & -0.105 & 0.302 & $\overline{-0.057}$ & 0.150 & -0.089 & 0.055 \\
\hline$\Delta c$ & 0.019 & 1.000 & 0.110 & 0.013 & -0.274 & 0.171 & 0.132 & 0.040 \\
\hline$h m l$ & -0.105 & 0.110 & 1.000 & 0.003 & 0.086 & -0.072 & 0.001 & -0.002 \\
\hline$s m b$ & 0.302 & 0.013 & 0.003 & 1.000 & 0.148 & -0.005 & 0.021 & 0.019 \\
\hline def & -0.057 & -0.274 & 0.086 & 0.148 & 1.000 & -0.442 & -0.121 & -0.098 \\
\hline pe & 0.150 & 0.171 & -0.072 & -0.005 & -0.442 & 1.000 & 0.882 & -0.076 \\
\hline$p d$ & -0.089 & 0.132 & 0.009 & 0.021 & -0.121 & 0.882 & 1.000 & -0.248 \\
\hline$d e$ & 0.055 & 0.040 & -0.002 & 0.019 & -0.098 & -0.076 & -0.248 & 1.000 \\
\hline
\end{tabular}

This table presents summary statistics and correlations for the traditional predictor variables at annual frequencies for the period 1945-2004. Panel A shows summary statistics, starting with the sample mean of the series, followed by the standard deviation and the first order autocorrelation coefficient. The final row shows the result of the Augmented Dickey-Fuller (ADF) test of the unit root hypothesis. The lag length in the ADF test is chosen according to the Schwarz information criteria and a trend is included when appropriate. Panel B shows the correlation between the series. $*-10 \%$ significance, $* *-5 \%$ significance. $r^{e m}$ is the log excess return on the CRSP VW portfolio, $c$ is log consumption, $h m l$ is the difference in returns on a high and a low $\mathrm{BE} / \mathrm{ME}$ portfolio, $s m b$ is the difference in returns on portfolios of small and big stocks measured by market capitalization, def is the default premium on bonds, pe is the log price-earnings ratio on the $\mathrm{S} \& \mathrm{P} 500, p d$ is the log price-dividend ratio on the CRSP value-weighted portfolio, and de is the log dividend-earnings ratio on the S\&P 500. $*-10 \%$ significance, $* *-5 \%$ significance. 
Table 6: Summary statistics for new ratio variables. Annual data, 1945-2004

\begin{tabular}{|c|c|c|c|c|c|c|}
\hline \multicolumn{7}{|c|}{ Panel A: Summary statistics } \\
\hline & py & $p c$ & $y c_{1}$ & $y c_{2}$ & $y c_{3}$ & nhe \\
\hline Mean & $\overline{-2.993}$ & -2.423 & -0.062 & $\overline{0.003}$ & $\overline{-0.294}$ & $\overline{-0.199}$ \\
\hline Std. & 0.696 & 0.693 & 0.042 & 0.043 & 0.026 & 0.023 \\
\hline Autocorr. & 0.923 & 0.926 & 0.864 & 0.753 & 0.916 & 0.918 \\
\hline $\mathrm{ADF}$ & -1.263 & -0.998 & -0.943 & $-5.140 * *$ & -1.537 & $-3.069 * *$ \\
\hline \multicolumn{7}{|c|}{ Panel B: Correlation matrix } \\
\hline & py & $p c$ & $y c_{1}$ & $y c_{2}$ & $y c_{3}$ & nhe \\
\hline py & 1.000 & 0.999 & 0.440 & 0.279 & 0.230 & -0.531 \\
\hline$p c$ & 0.999 & 1.000 & 0.458 & 0.306 & 0.243 & -0.533 \\
\hline$y c_{1}$ & 0.440 & 0.458 & 1.000 & 0.875 & 0.778 & -0.736 \\
\hline$y c_{2}$ & 0.279 & 0.306 & 0.875 & 1.000 & 0.730 & -0.588 \\
\hline$y c_{3}$ & 0.230 & 0.243 & 0.778 & 0.730 & 1.000 & -0.675 \\
\hline nhe & -0.531 & -0.533 & -0.736 & -0.588 & -0.675 & 1.000 \\
\hline
\end{tabular}

This table presents summary statistics and correlations for the new ratio predictor variables at annual frequencies for the period 1945-2004. Panel A shows summary statistics, starting with the sample mean of the series, followed by the standard deviation and the first order autocorrelation coefficient. The final row shows the result of the Augmented Dickey-Fuller (ADF) test of the unit root hypothesis. The lag length in the ADF test is chosen according to the Schwarz information criteria and a trend is included when appropriate. Panel B shows the correlation between the series. $p y$ is the $\log$ price-output ratio, $p c$ is the $\log$ price-consumption ratio, $y c_{1}$ is the log labour income-consumption ratio, $y c_{2}$ is the log compensation of employees-consumption ratio, $y c_{3}$ is the log labour income-compensation of employees ratio, and nhe is the log non-housing consumption share. $*-10 \%$ significance, $* *-5 \%$ significance. 
Table 7: Summary statistics for cointegration relation variables. Annual data, 1945-2004

\begin{tabular}{|c|c|c|c|c|c|c|c|}
\hline & cay_dls & $c d y \_d l s$ & $l r_{-} y$ & lr_comp. & $y \_l d$ & $y_{-} l s$ & mymo_dls \\
\hline Mean & -0.017 & -0.005 & -0.000 & -0.000 & 0.000 & 4.964 & 0.358 \\
\hline Std. & 0.021 & 0.030 & 0.011 & 0.013 & 0.534 & 0.391 & 0.179 \\
\hline Autocorr. & 0.490 & 0.683 & 0.404 & 0.001 & 0.893 & 0.891 & 0.881 \\
\hline $\mathrm{ADF}$ & $-5.104 * *$ & -3.410 & $-5.122 * *$ & $-7.839 * *$ & $-3.450 *$ & -1.652 & -2.118 \\
\hline \multicolumn{8}{|c|}{ Correlation matrix } \\
\hline & cay_dls & $c d y \_d l s$ & $l r_{-} y$ & lr_comp. & $y \_l d$ & $y \_l s$ & mymo_dls \\
\hline$c a y \_d l s$ & 1.000 & 0.559 & -0.305 & -0.167 & -0.029 & 0.331 & 0.108 \\
\hline$c d y \_d l s$ & 0.559 & 1.000 & -0.485 & -0.311 & 0.395 & 0.283 & 0.383 \\
\hline$l r_{-} y$ & -0.305 & -0.485 & 1.000 & 0.795 & -0.234 & -0.316 & -0.394 \\
\hline$l r_{-} c o m p$. & -0.167 & -0.311 & 0.795 & 1.000 & -0.177 & -0.231 & -0.309 \\
\hline$y \_l d$ & -0.029 & 0.394 & -0.234 & -0.177 & 1.000 & 0.599 & 0.174 \\
\hline$y \_l s$ & 0.331 & 0.283 & -0.316 & -0.231 & 0.599 & 1.000 & 0.613 \\
\hline mymo_dls & 0.108 & 0.383 & -0.394 & -0.309 & 0.174 & 0.613 & 1.000 \\
\hline
\end{tabular}

This table presents summary statistics and correlations for predictor variables based on cointegration relations at annual frequencies for the period 1945-2004. The cointegration relations are estimated by DLS. Panel A shows summary statistics, starting with the sample mean of the series, followed by the standard deviation and the first order autocorrelation coefficient. The final row shows the result of the Augmented Dickey-Fuller (ADF) test of the unit root hypothesis. The lag length in the ADF test is chosen according to the Schwarz information criteria and a trend is included when apropriate. Panel B shows the correlation between the series. cay is the approximate consumption-aggregate wealth ratio, $c d y$ is the cointegration relation between consumption, dividends and labour income. dls implies the relation has been computed by dynamic least squares. $l r_{-} y$ is the long run labour income growth relation of Julliard (2005) computed using log labour income and $l r_{-} c o m p$ is the same relation using log compensation of employees instead of log labour income. $y \_l d$ is based on a cointegration relation between labour income and dividends, and $y \_l s$ is the cointegration relation between labour income and the log level of the CRSP value-weighted stock index. mymo is a housing collateral measure developed from a cointegration relation between aggregate labour income and the value of outstanding mortgages in the US. $*-10 \%$ significance, $* *-5 \%$ significance. 
Table 8: Summary statistics for cointegration relation variables. Annual data, 1945-2004

\begin{tabular}{lcrrr}
\hline \hline \multicolumn{5}{c}{ Panel A: Summary statistics } \\
\hline & cay_joh & $c d y_{-}$joh & mymo_joh & mymo_1 \\
\hline \hline Mean & -0.003 & 0.002 & 0.298 & 0.276 \\
Std. & 0.0412 & 0.035 & 0.182 & 0.174 \\
Autocorr. & 0.759 & 0.702 & 0.812 & 0.834 \\
ADF & -5.104 & -3.410 & -2.118 & -1.580 \\
\hline \hline \multicolumn{5}{c}{ Panel B: Correlation matrix } \\
\hline cay_joh & cdy_joh & mymo_joh & mymo_1 \\
\hline \hline cay_joh & 1.000 & -0.065 & -0.017 & -0.017 \\
cdy_joh & -0.065 & 1.000 & 0.587 & 0.638 \\
mymo_joh & -0.017 & 0.587 & 1.000 & 0.983 \\
mymo_1 & -0.017 & 0.638 & 0.983 & 1.000 \\
\hline
\end{tabular}

This table presents summary statistics and correlations for predictor variables based on cointegration relations at annual frequencies for the period 1945-2004. The first three variables are based on relations estimated by the Johansen (1991) procedure. The last variable is estimated using DLS, but imposing restrictions on the cointegration coefficients. Panel A shows summary statistics, starting with the sample mean of the series, followed by the standard deviation and the first order autocorrelation coefficient. The final row shows the result of the Augmented Dickey-Fuller (ADF) test of the unit root hypothesis. The lag length in the ADF test is chosen according to the Schwarz information criteria and a trend is included when apropriate. Panel B shows the correlation between the series. cay is the approximate consumptionaggregate wealth ratio, $c d y$ is the cointegration relation between consumption, dividends and labour income. mymo is a housing collateral measure developed from a cointegration relation between aggregate labour income and the value of outstanding mortgages in the US. joh indicates that the cointegration coefficients of the relations have been estimated by the Johansen (1991) procedure. mymo_1 is based on the same relation as mymo, but with the cointegration coefficient on aggregate labour income restricted to -1 . $*-10 \%$ significance, $* *-5 \%$ significance. 
Table 9: Cointegration coefficients

\begin{tabular}{|c|c|c|c|c|c|c|c|c|}
\hline \multicolumn{9}{|c|}{ Panel A: Annual data, 1945-2004 } \\
\hline & $c$ & $m o$ & intercept & trend & $a$ & $\frac{d}{d}$ & $y$ & $A D F$ \\
\hline cay_dls & 1 & & $\begin{array}{l}-0.457 \\
(0.081)\end{array}$ & & $\begin{array}{l}-0.258 \\
(0.030)\end{array}$ & & $\begin{array}{l}-0.664 \\
(0.031)\end{array}$ & $-5.104^{* *}$ \\
\hline cay_joh & 1 & & -0.301 & & $\begin{array}{c}-0.583 \\
(0.108)\end{array}$ & & $\begin{array}{l}-0.288 \\
(0.112)\end{array}$ & $-5.104^{* *}$ \\
\hline$c d y \_d l s$ & 1 & & $\begin{array}{l}-1.769 \\
(0.192)\end{array}$ & & & $\begin{array}{l}-0.119 \\
(0.022)\end{array}$ & $\begin{array}{l}-0.747 \\
(0.035)\end{array}$ & -3.410 \\
\hline$c d y_{-} j o h$ & 1 & & -1.901 & & & $\begin{array}{c}-0.151 \\
(0.029)\end{array}$ & $\begin{array}{l}-0.709 \\
(0.048)\end{array}$ & -3.410 \\
\hline mymo_dls & & 1 & $\begin{array}{l}2.245 \\
(5.113)\end{array}$ & $\begin{array}{l}-0.011 \\
(0.015)\end{array}$ & & & $\begin{array}{l}-1.198 \\
(0.629)\end{array}$ & -2.118 \\
\hline mymo_joh & & 1 & 8.325 & $\begin{array}{c}-0.011 \\
(0.008)\end{array}$ & & & $\begin{array}{c}-1.650 \\
(0.509)\end{array}$ & -2.118 \\
\hline \multicolumn{9}{|c|}{ "Panel B: Quarterly data, 1951Q4-2005Q3 } \\
\hline & $c$ & $m o$ & intercept & trend & $a$ & $d$ & $y$ & $A D F$ \\
\hline cay_dls & 1 & & $\begin{array}{l}-0.435 \\
(0.056)\end{array}$ & & $\begin{array}{l}-0.236 \\
(0.018)\end{array}$ & & $\begin{array}{c}-0.693 \\
(0.018)\end{array}$ & -3.331 \\
\hline cay_joh & 1 & & -0.378 & & $\begin{array}{c}-0.344 \\
(0.052)\end{array}$ & & $\begin{array}{l}-0.569 \\
(0.056)\end{array}$ & -3.331 \\
\hline$c d y \_d l s$ & 1 & & $\begin{array}{l}-2.098 \\
(0.106)\end{array}$ & & & $\begin{array}{l}-0.174 \\
(0.011)\end{array}$ & $\begin{array}{l}-0.675 \\
(0.019)\end{array}$ & -3.203 \\
\hline$c d y_{-} j o h$ & 1 & & -2.338 & & & $\begin{array}{l}-0.206 \\
(0.027)\end{array}$ & $\begin{array}{l}-0.626 \\
(0.044)\end{array}$ & -3.203 \\
\hline mymo_dls & & 1 & $\begin{array}{l}-4.960 \\
(2.669)\end{array}$ & $\begin{array}{l}-0.007 \\
(0.001)\end{array}$ & & & $\begin{array}{c}-0.328 \\
(0.267)\end{array}$ & -2.118 \\
\hline mymo_joh & & 1 & 8.838 & $\begin{array}{c}-0.003 \\
(0.003)\end{array}$ & & & $\begin{array}{l}-1.705 \\
(0.779)\end{array}$ & -2.118 \\
\hline
\end{tabular}

This table presents estimates of the cointegration coefficients of the variables cay, cdy, and mymo. Standard errors are in parentheses. The cointegration relations are estimated by the dynamic least squares $(D L S)$ procedure of Stock and Watson (1993) and the Johansen (Joh) procedure of Johansen (1991). The final column shows the ADF test statistic for a unit root in the series resulting from the estimated cointegration relation. Panel A shows results based on annual data for the period 1945-2004 and panel B based on quarterly data for 1951Q4-2005Q3. 
Table 10: ARIMA models for lr estimates. Annual and quarterly data

\begin{tabular}{|c|c|c|c|c|}
\hline \multicolumn{5}{|c|}{ Panel A: Annual data } \\
\hline & & intercept & $m a(1)$ & $m a(2)$ \\
\hline$\overline{\text { Compensation of }}$ & employees & $\begin{array}{l}0.019 \\
(0.005)\end{array}$ & $\begin{array}{l}0.438 \\
(0.167)\end{array}$ & $\begin{array}{l}-0.004 \\
(0.090)\end{array}$ \\
\hline Labour income & & $\begin{array}{l}0.021 \\
(0.004)\end{array}$ & $\begin{array}{l}0.254 \\
(0.195)\end{array}$ & $\begin{array}{l}0.216 \\
(0.114)\end{array}$ \\
\hline \multicolumn{5}{|c|}{ Panel B: Quarterly data } \\
\hline & & intercept & $m a(1)$ & $m a(2)$ \\
\hline$\overline{\text { Compensation of }}$ & employees & $\begin{array}{l}0.005 \\
(0.001)\end{array}$ & $\begin{array}{l}0.319 \\
(0.127)\end{array}$ & $\begin{array}{l}\begin{array}{l}0.197 \\
(0.070)\end{array}\end{array}$ \\
\hline Labour income & & $\begin{array}{l}0.006 \\
(0.001)\end{array}$ & $\begin{array}{l}0.036 \\
(0.110)\end{array}$ & $\begin{array}{l}0.086 \\
(0.062)\end{array}$ \\
\hline
\end{tabular}

This table presents estimates of the parameters in ARIMA(0,1,2) models run on log compensation of employees and log labour income. Standard errors are in parentheses. Panel A shows estimates on annual data for 1945-2004 and panel B on quarterly data for the period 1951Q4-2005Q3. 
Table 11: Valkanov statistic parameter estimates

\begin{tabular}{|c|c|c|c|c|}
\hline & \multicolumn{2}{|c|}{ Quarterly } & \multicolumn{2}{|c|}{ Annual } \\
\hline & $c$ & $\delta$ & $c$ & $\delta$ \\
\hline e_rm & -222.00 & 0.287 & -225.00 & 0.402 \\
\hline$\Delta c$ & -140.00 & 0.189 & -160.00 & 0.061 \\
\hline def & -13.14 & 0.056 & -10.40 & -0.077 \\
\hline$r t b$ & -75.00 & -0.152 & & \\
\hline pe & 0.91 & 0.936 & 0.59 & 0.935 \\
\hline$p d$ & -1.10 & 0.961 & 1.13 & 0.601 \\
\hline de & -20.00 & 0.017 & -31.38 & 0.001 \\
\hline py & 1.18 & 0.992 & 0.86 & 0.981 \\
\hline$p c$ & 1.20 & 0.997 & 1.20 & 0.988 \\
\hline$y c_{1}$ & -2.30 & -0.037 & 1.26 & -0.050 \\
\hline$y c_{2}$ & -6.16 & -0.122 & -50.00 & -0.161 \\
\hline$y c_{3}$ & 0.36 & -0.005 & 0.075 & -0.016 \\
\hline nhe & -5.91 & 0.210 & -15.73 & 0.200 \\
\hline cay_dls & -19.00 & -0.508 & -110.00 & -0.374 \\
\hline cay_joh & -19.00 & -0.687 & -50.00 & -0.813 \\
\hline$c d y \_d l s$ & -17.35 & -0.149 & -20.00 & -0.413 \\
\hline$c d y_{-} j o h$ & -17.35 & -0.186 & -20.00 & -0.477 \\
\hline$l r_{-} y$ & -115.00 & 0.058 & -125.00 & 0.034 \\
\hline$l r_{-} c o m p$. & -140.00 & 0.063 & -210.00 & -0.016 \\
\hline$y \_l d$ & -8.60 & -0.322 & -18.19 & -0.643 \\
\hline$y \_l s$ & -0.99 & -0.993 & -0.70 & -0.986 \\
\hline mymo_dls & & & -5.52 & -0.267 \\
\hline mymo_joh & & & -5.52 & -0.293 \\
\hline mymo_1 & & & -0.14 & -0.290 \\
\hline
\end{tabular}

This table presents estimates of the two nuisance parameters $c$ and $\delta$ used to determine critical values for the rescaled t-statistic of Valkanov (2003). $\delta$ is the correlation between the innovations in returns and innovations in the forecasting variable. $c$ is a measure of the deviation from unity in the largest autoregressive root of the forecasting variable. It is computed using the methodology of Stock (1991). 
Table 12: Quarterly univariate long-horizon regressions, 1952Q1-2005Q4

\begin{tabular}{|c|c|c|c|c|c|c|c|c|}
\hline \multicolumn{9}{|c|}{ Horizon h (in quarters) } \\
\hline & 1 & 2 & 4 & 8 & 16 & 24 & 36 & 48 \\
\hline \multirow[t]{4}{*}{$r^{e m}$} & 0.048 & -0.003 & -0.048 & -0.230 & -0.226 & -0.322 & 0.032 & -0.147 \\
\hline & $(0.061)$ & $(0.095)$ & $(0.128)$ & $(0.186)$ & $(0.202)$ & $(0.245)$ & $(0.313)$ & $(0.354)$ \\
\hline & $\{0.047\}$ & $\{-0.002\}$ & $\{-0.024\}$ & $\{-0.087\}$ & $\{-0.068\}$ & $\{-0.078\}$ & $\{0.006\}$ & $\{-0.027\}$ \\
\hline & {$[-0.002]$} & {$[-0.005]$} & {$[-0.004]$} & {$[0.002]$} & {$[-0.000]$} & {$[0.001]$} & {$[-0.006]$} & {$[-0.005]$} \\
\hline \multirow[t]{4}{*}{$\Delta c$} & -1.370 & -1.791 & -7.316 & -12.379 & -13.222 & -23.658 & -25.101 & -21.635 \\
\hline & $(1.231)$ & $(2.396)$ & $(3.085)^{* *}$ & $(5.405)^{* *}$ & $(4.851)^{* *}$ & $(6.138)^{* *}$ & $(8.325)^{* *}$ & $(8.323)^{* *}$ \\
\hline & $\{-0.074\}$ & $\{-0.067\}$ & $\{-0.200\}$ & $\{-0.259\}$ & $\{-0.225\}$ & $\{-0.348\}$ & $\{-0.321\}$ & $\{-0.244\}$ \\
\hline & {$[0.001]$} & {$[-0.000]$} & [0.034] & [0.059] & [0.044] & {$[0.104]$} & [0.089] & {$[0.051]$} \\
\hline \multirow[t]{4}{*}{$d e f$} & 6.208 & 9.013 & 9.902 & -9.413 & -9.365 & 20.181 & 57.133 & 118.603 \\
\hline & $(6.441)$ & $(11.265)$ & $(17.506)$ & $(20.039)$ & $(32.232)$ & $(30.591)$ & $(41.102)$ & $(50.547)^{* *}$ \\
\hline & $\{0.077\}$ & $\{0.077\}$ & $\{0.061\}$ & $\{-0.044\}$ & $\{-0.036\}$ & $\{0.065\}$ & $\{0.163\}$ & $\{0.313\}$ \\
\hline & [0.001] & [0.001] & {$[-0.001]$} & {$[-0.003]$} & {$[-0.004]$} & {$[-0.001]$} & [0.021] & {$[0.085]$} \\
\hline \multirow[t]{4}{*}{$r t b$} & -8.215 & -13.173 & -22.660 & -13.924 & -11.221 & -17.362 & -25.800 & -25.437 \\
\hline & $(2.759)^{* *}$ & $(5.359)^{* *}$ & $(10.636)^{* *}$ & $(10.069)^{* *}$ & $(12.913)$ & $(15.680)$ & $(18.887)$ & $(18.673)$ \\
\hline & $\{-0.189\}$ & $\{-0.210\}$ & $\{-0.263\}$ & $\{-0.119\}$ & $\{-0.078\}$ & $\{-0.099\}$ & $\{-0.131\}$ & $\{-0.116\}$ \\
\hline & {$[0.030]$} & {$[0.038]$} & {$[0.061]$} & {$[0.009]$} & {$[0.001]$} & {$[0.005]$} & {$[0.012]$} & {$[0.007]$} \\
\hline \multirow[t]{4}{*}{ pe } & -0.018 & -0.039 & -0.077 & -0.141 & -0.224 & -0.310 & -0.481 & -0.807 \\
\hline & $(0.015)$ & $(0.029)$ & $(0.050)$ & $(0.079)^{*}$ & $(0.086)^{* *}$ & $(0.081)^{* *}$ & $(0.133)^{* *}$ & $(0.153)^{* *}$ \\
\hline & $\{-0.091\}$ & $\{-0.134\}$ & $\{-0.193\}$ & $\{-0.266\}$ & $\{-0.352\}$ & $\{-0.383\}$ & $\{-0.448\}$ & $\{-0.718\}$ \\
\hline & {$[0.004]$} & {$[0.013]$} & {$[0.031]$} & {$[0.062]$} & {$[0.107]$} & {$[0.125]$} & {$[0.164]$} & {$[0.339]$} \\
\hline \multirow[t]{4}{*}{$p d$} & -0.026 & -0.055 & -0.106 & -0.920 & -0.324 & -0.477 & -0.841 & -1.304 \\
\hline & $(0.016)$ & $(0.031)^{*}$ & $(0.055)^{*}$ & $(0.091)^{* *}$ & $(0.095)^{* *}$ & $(0.103)^{* *}$ & $(0.198)^{* *}$ & $(0.241)^{* *}$ \\
\hline & $\{-0.124\}$ & $\{-0.178\}$ & $\{-0.251\}$ & $\{-0.346\}$ & $\{-0.474\}$ & $\{-0.509\}$ & $\{-0.604\}$ & $\{-0.805\}$ \\
\hline & {$[0.011]$} & {$[0.026]$} & {$[0.056]$} & {$[0.104]$} & {$[0.181]$} & {$[0.203]$} & {$[0.265]$} & {$[0.392]$} \\
\hline \multirow[t]{4}{*}{$d e$} & 0.021 & 0.038 & 0.086 & 0.246 & 0.352 & 0.538 & -0.056 & -0.515 \\
\hline & $(0.031)$ & $(0.060)$ & $(0.106)$ & $(0.187)$ & $(0.209)^{*}$ & $(0.231)^{* *}$ & $(0.289)$ & $(0.322)$ \\
\hline & $\{0.048\}$ & $\{0.058\}$ & $\{0.094\}$ & $\{0.197\}$ & $\{0.230\}$ & $\{0.275\}$ & $\{-0.023\}$ & $\{-0.178\}$ \\
\hline & {$[-0.002]$} & {$[-0.001]$} & {$[0.004]$} & {$[0.033]$} & {$[0.046]$} & {$[0.066]$} & {$[-0.005]$} & {$[0.025]$} \\
\hline
\end{tabular}

This table presents OLS beta parameter estimates for univariate regressions of excess returns on the traditional predictor variables. Excess returns are measured at quarterly frequencies for the period 1952Q12005Q4 and cumulated for up to 48 periods. In parentheses, below the parameter estimates, are NeweyWest (1987) corrected standard errors, the $t / \sqrt{T}$ test of Valkanov (2003) in curly brackets, and adjusted $R^{2}$ statistics in square brackets. $r^{e m}$ is the log excess return on the CRSP VW portfolio, $c$ is log consumption, def is the default premium on bonds, $r t b$ is the relative t-bill rate, $p e$ is the log price-earnings ratio on the $\mathrm{S} \& \mathrm{P} 500, p d$ is the log price-dividend ratio on the CRSP value-weighted portfolio, and $d e$ is the $\log$ dividend-earnings ratio on the S\&P 500. $*-10 \%$ significance, $* *-5 \%$ significance. 
Table 13: Quarterly univariate long-horizon regressions, 1952Q1-2005Q4

\begin{tabular}{lllllllll}
\hline \hline & \multicolumn{7}{c}{ Horizon h (in quarters) } & \\
\hline & 1 & 2 & 4 & 8 & 16 & 24 & 36 & 48 \\
\hline \hline$p y$ & -0.011 & -0.023 & -0.048 & -0.097 & -0.165 & -0.201 & -0.237 & -0.422 \\
& $(0.010)$ & $(0.020)$ & $(0.037)$ & $(0.063)$ & $(0.075)^{* *}$ & $(0.083)^{* *}$ & $(0.129)^{*}$ & $(0.185)^{* *}$ \\
& $\{-0.080\}$ & $\{-0.116\}$ & $\{-0.171\}$ & $\{-0.258\}$ & $\{-0.353\}$ & $\{-0.320\}$ & $\{-0.256\}$ & $\{-0.362\}$ \\
& {$[0.002]$} & {$[0.009]$} & {$[0.024]$} & {$[0.058]$} & {$[0.107]$} & {$[0.089]$} & {$[0.057]$} & {$[0.112]$} \\
$p c$ & -0.012 & -0.025 & -0.052 & -0.102 & -0.175 & -0.217 & -0.263 & -0.451 \\
& $(0.010)$ & $(0.020)$ & $(0.037)$ & $(0.063)$ & $(0.074)^{* *}$ & $(0.081)^{* *}$ & $(0.132)^{* *}$ & $(0.189)^{* *}$ \\
& $\{-0.086\}$ & $\{-0.124\}$ & $\{-0.181\}$ & $\{-0.269\}$ & $\{-0.372\}$ & $\{-0.344\}$ & $\{-0.281\}$ & $\{-0.381\}$ \\
& {$[0.003]$} & {$[0.011]$} & {$[0.027]$} & {$[0.063]$} & {$[0.118]$} & {$[0.102]$} & {$[0.069]$} & {$[0.123]$} \\
$y c_{1}$ & -0.331 & -0.591 & -1.042 & -1.975 & -3.515 & -3.430 & -2.616 & 0.186 \\
& $(0.174)^{*}$ & $(0.336)^{*}$ & $(0.596)^{*}$ & $(0.784)^{* *}$ & $(0.861)^{* *}$ & $(1.027)^{* *}$ & $(1.430)^{*}$ & $(1.906)$ \\
& $\{-0.129\}$ & $\{-0.159\}$ & $\{-0.203\}$ & $\{-0.293\}$ & $\{-0.439\}$ & $\{-0.350\}$ & $\{-0.229\}$ & $\{0.014\}$ \\
& {$[0.012]$} & {$[0.020]$} & {$[0.035]$} & {$[0.075]$} & {$[0.159]$} & {$[0.106]$} & {$[0.045]$} & {$[-0.006]$} \\
$y c_{2}$ & -0.597 & -1.108 & -1.844 & -3.082 & -5.087 & -5.329 & -4.177 & -2.006 \\
& $(0.180)^{* *}$ & $(0.355)^{* *}$ & $(0.643)^{* *}$ & $(0.864)^{* *}$ & $(0.884)^{* *}$ & $(1.283)^{* *}$ & $(1.517)^{* *}$ & $(1.902)$ \\
& $\{-0.220\}$ & $\{-0.287\}$ & $\{-0.126\}$ & $\{-0.461\}$ & $\{-0.695\}^{* *}$ & $\{-0.579\}^{*}$ & $\{-0.369\}$ & $\{-0.145\}$ \\
& {$[0.042]$} & {$[0.072]$} & {$[0.106]$} & {$[0.173]$} & {$[0.324]$} & {$[0.249]$} & {$[0.116]$} & {$[0.015]$} \\
$y c_{3}$ & -0.397 & -0.780 & -1.590 & -3.129 & -5.019 & -6.534 & -9.072 & -7.633 \\
& $(0.265)$ & $(0.489)$ & $(0.889)^{*}$ & $(1.362)^{* *}$ & $(1.655)^{* *}$ & $(1.976)^{* *}$ & $(2.381)^{* *}$ & $(2.708)^{* *}$ \\
& $\{-0.097\}$ & $\{-0.132\}$ & $\{-0.195\}$ & $\{-0.297\}$ & $\{-0.405\}$ & $\{-0.451\}$ & $\{-0.566\}^{*}$ & $\{-0.399\}$ \\
& {$[0.005]$} & {$[0.013]$} & {$[0.033]$} & {$[0.077]$} & {$[0.138]$} & {$[0.166]$} & {$[0.241]$} & {$[0.134]$} \\
$n h e$ & 0.276 & 0.545 & 1.007 & 2.231 & 3.124 & 2.750 & 1.854 & -0.727 \\
& $(0.379)$ & $(0.714)$ & $(1.258)$ & $(1.814)$ & $(2.290)$ & $(2.924)$ & $(3.649)$ & $(4.822)$ \\
& $\{0.048\}$ & $\{0.066\}$ & $\{0.087\}$ & $\{0.146\}$ & $\{0.168\}$ & $\{0.124\}$ & $\{0.074\}$ & $\{-0.026\}$ \\
& {$[-0.002]$} & {$[-0.000]$} & {$[0.003]$} & {$[0.016]$} & {$[0.023]$} & {$[0.010]$} & {$[-0.000]$} & {$[-0.005]$} \\
\hline \hline
\end{tabular}

This table presents OLS beta parameter estimates for univariate regressions of excess returns on the new ratios. Excess returns are measured at quarterly frequencies for the period 1952Q1-2005Q4 and cumulated for up to 48 periods. In parentheses, below the parameter estimates, are Newey-West (1987) corrected standard errors, the $t / \sqrt{T}$ test of Valkanov (2003) in curly brackets, and adjusted $R^{2}$ statistics in square brackets. $p y$ is the $\log$ price-output ratio, $p c$ is the log price-consumption ratio, $y c_{1}$ is the $\log \operatorname{labour}$ income-consumption ratio, $y c_{2}$ is the log compensation of employees-consumption ratio, $y c_{3}$ is the $\log$ labour income-compensation of employees ratio, and nhe is the log non-housing consumption share. $*-10 \%$ significance, $* *-5 \%$ significance. 
Table 14: Quarterly univariate long-horizon regressions, 1952Q1-2005Q4

\begin{tabular}{|c|c|c|c|c|c|c|c|c|}
\hline \multicolumn{9}{|c|}{ Horizon h (in quarters) } \\
\hline & 1 & 2 & 4 & 8 & 16 & 24 & 36 & 48 \\
\hline \multirow[t]{4}{*}{ cay_dls } & 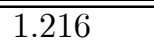 & 2.330 & 4.342 & 7.925 & $\begin{array}{l}12.171 \\
\end{array}$ & 14.532 & 14.624 & 13.215 \\
\hline & $(0.349)^{* *}$ & $(0.666)^{* *}$ & $(1.191)^{* *}$ & $(1.568)^{* *}$ & $(1.490)^{* *}$ & $(1.958)^{* *}$ & $(3.128)^{* *}$ & $(3.332)^{* *}$ \\
\hline & $\{0.239\}$ & $\{0.322\}$ & $\{0.446\}$ & $\{0.658\}^{*}$ & $\{0.937\}^{* *}$ & $\{0.882\}^{* *}$ & $\{0.668\}^{*}$ & $\{0.457\}$ \\
\hline & {$[0.050]$} & [0.090] & [0.163] & {$[0.301]$} & {$[0.467]$} & {$[0.437]$} & {$[0.307]$} & {$[0.170]$} \\
\hline \multirow[t]{4}{*}{ cay_joh } & 0.736 & 1.453 & 2.763 & 4.895 & 6.985 & 8.788 & 9.517 & 10.841 \\
\hline & $(0.248)^{* *}$ & $(0.475)^{* *}$ & $(0.857)^{* *}$ & $(1.260)^{* *}$ & $(1.393)^{* *}$ & $(1.892)^{* *}$ & $(3.109)^{* *}$ & $(3.186)^{* *}$ \\
\hline & $\{0.187\}$ & $\{0.257\}$ & $\{0.360\}$ & $\{0.500\}$ & $\{0.610\}^{*}$ & $\{0.609\}^{*}$ & $\{0.501\}$ & $\{0.485\}$ \\
\hline & [0.029] & {$[0.058]$} & {$[0.112]$} & [0.198] & {$[0.269]$} & [0.269] & {$[0.198]$} & {$[0.187]$} \\
\hline \multirow[t]{4}{*}{$c d y \_d l s$} & 0.332 & 0.544 & 1.044 & 3.281 & 7.019 & 10.775 & 11.335 & 12.390 \\
\hline & $(0.359)$ & $(0.671)$ & $(1.287)$ & $(1.869)^{*}$ & $(1.961)^{* *}$ & $(2.608)^{* *}$ & $(3.314)^{* *}$ & $(3.686)^{* *}$ \\
\hline & $\{0.065\}$ & $\{0.073\}$ & $\{0.098\}$ & $\{0.233\}$ & $\{0.427\}$ & $\{0.541\}^{* *}$ & $\{0.493\}^{*}$ & $\{0.474\}^{*}$ \\
\hline & {$[-0.000]$} & {$[0.001]$} & [0.005] & {$[0.047]$} & {$[0.151]$} & {$[0.224]$} & {$[0.193]$} & {$[0.180]$} \\
\hline \multirow[t]{4}{*}{$c d y_{-} j o h$} & 0.173 & 0.264 & 0.544 & 2.264 & 5.175 & 8.178 & 8.559 & 10.663 \\
\hline & $(0.311)$ & $(0.585)$ & $(1.153)$ & $(1.703)$ & $(1.793)^{* *}$ & $(2.725)^{* *}$ & $(3.537)^{* *}$ & $(3.381)^{* *}$ \\
\hline & $\{0.038\}$ & $\{0.040\}$ & $\{0.057\}$ & $\{0.178\}$ & $\{0.341\}$ & $\{0.443\}^{*}$ & $\{0.404\}$ & $\{0.461\}^{*}$ \\
\hline & {$[-0.003]$} & {$[-0.003]$} & {$[-0.001]$} & {$[0.026]$} & {$[0.101]$} & {$[0.161]$} & {$[0.137]$} & {$[0.172]$} \\
\hline \multirow[t]{4}{*}{$l r_{-} y$} & -8.987 & -13.584 & -27.537 & -36.223 & -48.623 & -72.778 & -89.657 & -81.044 \\
\hline & $(5.006)^{*}$ & $(7.421)^{*}$ & $(10.263)^{* *}$ & $(16.594)^{* *}$ & $(16.893)^{* *}$ & $(21.977)^{* *}$ & $(30.610)^{* *}$ & $(31.119)^{* *}$ \\
\hline & $\{-0.144\}$ & $\{-0.150\}$ & $\{-0.222\}$ & $\{-0.220\}$ & $\{-0.241\}$ & $\{-0.306\}$ & $\{-0.334\}$ & $\{-0.266\}$ \\
\hline & {$[0.016]$} & {$[0.018]$} & {$[0.043]$} & {$[0.042]$} & {$[0.051]$} & {$[0.082]$} & {$[0.096]$} & {$[0.061]$} \\
\hline \multirow[t]{4}{*}{$l r_{-} c o m p$. } & -2.139 & -4.352 & -8.364 & -9.778 & -11.444 & -20.351 & -20.952 & -19.160 \\
\hline & $(1.060)^{* *}$ & $(2.586)^{* *}$ & $(2.639)^{* *}$ & $(4.222)^{* *}$ & $(4.634)^{* *}$ & $(5.963)^{* *}$ & $(8.386)^{* *}$ & $(8.506)^{* *}$ \\
\hline & $\{-0.125\}$ & $\{-0.177\}$ & $\{-0.248\}$ & $\{-0.217\}$ & $\{-0.208\}$ & $\{-0.314\}$ & $\{-0.279\}$ & $\{-0.225\}$ \\
\hline & {$[0.011]$} & {$[0.026]$} & {$[0.054]$} & {$[0.041]$} & {$[0.037]$} & {$[0.086]$} & {$[0.068]$} & {$[0.043]$} \\
\hline \multirow[t]{4}{*}{$y \_l d$} & 0.003 & 0.006 & 0.017 & 0.051 & 0.099 & 0.058 & -0.085 & -0.097 \\
\hline & $(0.014)$ & $(0.026)$ & $(0.051)$ & $(0.090)$ & $(0.122)$ & $(0.143)$ & $(0.183)$ & $(0.228)$ \\
\hline & $\{0.013\}$ & $\{0.019\}$ & $\{0.040\}$ & $\{0.090\}$ & $\{0.141\}$ & $\{0.067\}$ & $\{-0.078\}$ & $\{-0.072\}$ \\
\hline & {$[-0.005]$} & {$[-0.004]$} & {$[-0.003]$} & {$[0.003]$} & {$[0.015]$} & {$[-0.001]$} & {$[0.001]$} & {$[-0.001]$} \\
\hline \multirow[t]{4}{*}{$y_{-} l s$} & 0.023 & 0.049 & 0.098 & 0.184 & 0.286 & 0.405 & 0.631 & 0.982 \\
\hline & $(0.016)$ & $(0.031)$ & $(0.054)^{*}$ & $(0.087)^{* *}$ & $(0.093)^{* *}$ & $(0.097)^{* *}$ & $(0.152)^{* *}$ & $(0.159)^{* *}$ \\
\hline & $\{0.104\}$ & $\{0.154\}$ & $\{0.223\}$ & $\{0.321\}$ & $\{0.419\}$ & $\{0.471\}$ & $\{0.559\}$ & $\{0.858\}$ \\
\hline & {$[0.006]$} & [0.019] & [0.043] & {$[0.090]$} & {$[0.146]$} & {$[0.179]$} & {$[0.236]$} & {$[0.424]$} \\
\hline
\end{tabular}

This table presents OLS beta parameter estimates for univariate regressions of excess returns on variables based on cointegration relations. Excess returns are measured at quarterly frequencies for the period 1952Q1-2005Q4 and cumulated for up to 48 periods. In parentheses, below the parameter estimates, are Newey-West (1987) corrected standard errors, the $t / \sqrt{T}$ test of Valkanov (2003) in curly brackets, and adjusted $R^{2}$ statistics in square brackets. cay is the approximate consumption-aggregate wealth ratio, $c d y$ is the cointegration relation between consumption, dividends, and labour income. $d l s$ implies that the relation has been computed by dynamic least squares and $j o h$ by the Johansen (1991) procedure. $l r \_y$ is the long-run labour income growth relation of Julliard (2005) computed using log labour income and lr_comp is the same relation using log compensation of employees instead of log labour income. $y \_l d$ is based on a cointegration relation between labour income and dividends and $y \_l s$ is the cointegration relation between labour income and the log level of the CRSP value-weighted stock index. $*-10 \%$ significance, $* *-5 \%$ significance. 
Table 15: Annual univariate long-horizon regressions, 1946-2005

\begin{tabular}{cllllllll}
\hline \hline & \multicolumn{7}{c}{ Horizon h (in years) } \\
\hline & 1 & 2 & 3 & 4 & 5 & 6 & 7 & 8 \\
\hline \hline$r^{e m}$ & -0.044 & -0.254 & -0.261 & 0.057 & 0.015 & -0.142 & -0.038 & 0.063 \\
& $(0.111)$ & $(0.119)$ & $(0.099)$ & $(0.187)$ & $(0.254)$ & $(0.230)$ & $(0.207)$ & $(0.266)$ \\
& $\{-0.044\}$ & $\{-0.186\}$ & $\{-.167\}$ & $\{0.032\}$ & $\{0.007\}$ & $\{-0.059\}$ & $\{-0.015\}$ & $\{0.023\}$ \\
& {$[-0.015]$} & {$[0.018]$} & {$[0.011]$} & {$[-0.017]$} & {$[-0.019]$} & {$[-0.015]$} & {$[-0.019]$} & {$[-0.019]$} \\
$\Delta c$ & -3.734 & -6.704 & -6.555 & -6.858 & -9.128 & -9.994 & -11.466 & -10.245 \\
& $(1.583)^{* *}$ & $(2.256)^{* *}$ & $(2.239)^{* *}$ & $(2.858)^{* *}$ & $(3.726)^{* *}$ & $(4.515)^{* *}$ & $(4.602)^{* *}$ & $(5.820)^{*}$ \\
& $\{-0.307\}$ & $\{-0.873\}$ & $\{-0.347\}$ & $\{-0.328\}$ & $\{-0.379\}$ & $\{-0.374\}$ & $\{-0.413\}$ & $\{-0.339\}$ \\
& {$[0.073]$} & {$[0.133]$} & {$[0.095]$} & {$[0.084]$} & {$[0.113]$} & {$[0.110]$} & {$[0.134]$} & {$[0.089]$} \\
def & 0.329 & -6.662 & -10.263 & -10.906 & -7.726 & -8.771 & -5.566 & -4.916 \\
& $(4.323)$ & $(4.994)$ & $(6.205)$ & $(7.771)$ & $(7.793)$ & $(7.911)$ & $(9.058)$ & $(10.393)$ \\
& $\{0.008\}$ & $\{-0.114\}$ & $\{-0.156\}$ & $\{-0.150\}$ & $\{-0.091\}$ & $\{-0.093\}$ & $\{-0.056\}$ & $\{-0.047\}$ \\
& {$[-0.017]$} & {$[-0.004]$} & {$[0.007]$} & {$[0.005]$} & {$[-0.010]$} & {$[-0.010]$} & {$[-0.016]$} & {$[-0.017]$} \\
$p e$ & -0.084 & -0.162 & -0.208 & -0.265 & -0.349 & -0.416 & -0.456 & -0.539 \\
& $(0.047)^{*}$ & $(0.086)^{*}$ & $(0.111)^{*}$ & $(0.120)^{* *}$ & $(0.132)^{* *}$ & $(0.162)^{* *}$ & $(0.199)^{* *}$ & $(0.241)^{* *}$ \\
& $\{-0.215\}$ & $\{-0.300\}$ & $\{-0.344\}$ & $\{-0.407\}$ & $\{-0.458\}$ & $\{-0.477\}$ & $\{-0.461\}$ & $\{-0.485\}$ \\
& {$[0.029]$} & {$[0.069]$} & {$[0.093]$} & {$[0.131]$} & {$[0.163]$} & {$[0.176]$} & {$[0.165]$} & {$[0.181]$} \\
$p d$ & -0.109 & -0.198 & -0.268 & -0.365 & -0.493 & -0.626 & -0.725 & -0.856 \\
& $(0.048)^{* *}$ & $(0.085)^{* *}$ & $(0.103)^{* *}$ & $(0.108)^{* *}$ & $(0.130)^{* *}$ & $(0.174)^{* *}$ & $(0.218)^{* *}$ & $(0.258)^{* *}$ \\
& $\{-0.281\}$ & $\{-0.370\}$ & $\{-0.448\}$ & $\{-0.570\}$ & $\{-0.647\}$ & $\{-0.690\}$ & $\{-0.697\}$ & $\{-0.715\}$ \\
& {$[0.059]$} & {$[0.109]$} & {$[0.158]$} & {$[0.238]$} & {$[0.290]$} & {$[0.318]$} & {$[0.323]$} & {$[0.334]$} \\
$d e$ & 0.019 & 0.123 & 0.154 & 0.202 & 0.410 & 0.484 & 0.403 & 0.313 \\
& $(0.089)$ & $(0.209)$ & $(0.262)$ & $(0.244)$ & $(0.241)$ & $(0.276)$ & $(1.269)$ & $(0.325)$ \\
& $\{0.022\}$ & $\{0.099\}$ & $\{0.107\}$ & $\{0.129\}$ & $\{0.224\}$ & $\{0.227\}$ & $\{0.170\}$ & $\{0.122\}$ \\
& {$[-0.017]$} & {$[-0.007]$} & {$[-0.006]$} & {$[-0.001]$} & {$[0.032]$} & {$[0.033]$} & {$[0.010]$} & {$[-0.004]$} \\
\hline
\end{tabular}

This table presents OLS beta parameter estimates for univariate regressions of excess returns on the traditional predictor variables. Excess returns are measured at annual frequencies for the period 1946-2005 and cumulated for up to 8 periods. In parentheses, below the parameter estimates, are Newey-West (1987) corrected t-statistics, the $t / \sqrt{T}$ test of Valkanov (2003) in curly brackets, and adjusted $R^{2}$ statistics in square brackets. $r^{e m}$ is the log excess return on the CRSP VW portfolio, $c$ is $\log$ consumption, def is the default premium on bonds, $p e$ is the log price-earnings ratio on the $\mathrm{S} \& \mathrm{P} 500$, and $p d$ is the log price-dividend ratio on the CRSP value-weighted portfolio, and de is the log dividend-earnings ratio on the S\&P 500 * $* 10 \%$ significance, $* *-5 \%$ significance. 
Table 16: Annual univariate long-horizon regressions, 1946-2005

\begin{tabular}{|c|c|c|c|c|c|c|c|c|}
\hline \multicolumn{9}{|c|}{ Horizon h (in years) } \\
\hline & 1 & 2 & 3 & 4 & 5 & 6 & 7 & 8 \\
\hline \multirow[t]{4}{*}{ py } & -0.041 & -0.090 & -0.135 & -0.189 & $\begin{array}{c}-0.250 \\
\end{array}$ & $\begin{array}{l}-0.299 \\
\end{array}$ & -0.331 & $\begin{array}{c}-0.377 \\
\end{array}$ \\
\hline & $(0.030)$ & $(0.054)^{*}$ & $(0.070)^{*}$ & $(0.075)^{* *}$ & $(0.082)^{* *}$ & $(0.099)^{* *}$ & $(0.123)^{* *}$ & $(0.146)^{* *}$ \\
\hline & $\{-0.176\}$ & $\{-0.277\}$ & $\{-0.370\}$ & $\{-0.489\}$ & $\{-0.553\}$ & $\{-0.578\}$ & $\{-0.570\}$ & $\{-0.581\}$ \\
\hline & {$[0.014]$} & {$[0.057]$} & {$[0.109]$} & {$[0.184]$} & {$[0.227]$} & {$[0.244]$} & {$[0.238]$} & {$[0.245]$} \\
\hline \multirow[t]{4}{*}{$p c$} & -0.043 & -0.094 & -0.141 & -0.197 & -0.260 & -0.310 & -0.345 & -0.394 \\
\hline & (0.030) & $(0.053)^{*}$ & $(0.068)^{* *}$ & $(0.073)^{* *}$ & $(0.080)^{* *}$ & $(0.097)^{* *}$ & $(0.120)^{* *}$ & $(0.144)^{* *}$ \\
\hline & $\{-0.184\}$ & $\{-0.288\}$ & $\{-0.387\}$ & $\{-0.509\}$ & $\{-0.577\}$ & $\{-0.605\}$ & $\{-0.599\}$ & $\{-0.612\}$ \\
\hline & {$[0.017]$} & {$[0.063]$} & {$[0.119]$} & {$[0.198]$} & {$[0.243]$} & {$[0.262]$} & {$[0.257]$} & {$[0.266]$} \\
\hline \multirow[t]{4}{*}{$y c_{1}$} & -0.796 & -1.715 & -2.695 & -3.528 & -3.905 & -4.340 & -4.702 & -4.943 \\
\hline & $(0.358)^{* *}$ & $(0.571)^{* *}$ & $(0.719)^{* *}$ & $(0.849)^{* *}$ & $(0.982)^{* *}$ & $(1.171)^{* *}$ & $(1.368)^{* *}$ & $(1.489)^{* *}$ \\
\hline & $\{-0.205\}$ & $\{-0.323\}$ & $\{-0.469\}$ & $\{-0.584\}^{*}$ & $\{-0.544\}^{*}$ & $\{-0.548\}^{*}$ & $\{-0.570\}^{*}$ & $\{-0.564\}^{*}$ \\
\hline & {$[0.025]$} & {$[0.082]$} & {$[0.171]$} & {$[0.247]$} & {$[0.221]$} & {$[0.223]$} & {$[0.238]$} & {$[0.223]$} \\
\hline \multirow[t]{4}{*}{$y c_{2}$} & -1.084 & -2.039 & -2.991 & -3.873 & -4.461 & -4.787 & -4.953 & -5.217 \\
\hline & $(0.389)^{* *}$ & $(0.562)^{* *}$ & $(0.594)^{* *}$ & $(0.759)^{* *}$ & $(0.979)^{* *}$ & $(1.144)^{* *}$ & $(1.200)^{* *}$ & $(1.200)^{* *}$ \\
\hline & $\{-0.299\}$ & $\{-0.420\}$ & $\{-0.588\}^{* *}$ & $\{-0.751\}^{* *}$ & $\{-0.737\}^{* *}$ & $\{-0.700\}^{* *}$ & $\{-0.682\}^{* *}$ & $\{-0.676\}^{* *}$ \\
\hline & [0.069] & [0.140] & {$[0.250]$} & {$[0.357]$} & {$[0.348]$} & {$[0.324]$} & {$[0.323]$} & {$[0.309]$} \\
\hline \multirow[t]{4}{*}{$y c_{3}$} & -1.101 & -2.378 & -3.865 & -5.452 & -6.715 & -7.980 & -9.199 & -10.459 \\
\hline & $(0.622)^{*}$ & $(1.119)^{* *}$ & $(1.469)^{* *}$ & $(1.788)^{* *}$ & $(2.001)^{* *}$ & $(2.188)^{* *}$ & $(2.301)^{* *}$ & $(2.385)^{* *}$ \\
\hline & $\{-0.174\}$ & $\{-0.274\}$ & $\{-0.413\}$ & $\{-0.565\}^{*}$ & $\{-0.609\}^{*}$ & $\{-0.676\}^{* *}$ & $\{-0.780\}^{* *}$ & $\{-0.875\}^{* *}$ \\
\hline & {$[0.014]$} & {$[0.056]$} & {$[0.135]$} & {$[0.235]$} & {$[0.264]$} & {$[0.309]$} & {$[0.376]$} & {$[0.432]$} \\
\hline \multirow[t]{4}{*}{ nhe } & 0.577 & 1.593 & 2.850 & 4.195 & 5.460 & 6.467 & 7.206 & 7.961 \\
\hline & $(0.744)$ & $(1.257)$ & $(1.600)^{*}$ & $(1.781)^{* *}$ & $(1.995)^{* *}$ & $(2.258)^{* *}$ & $(2.514)^{* *}$ & $(2.720)^{* *}$ \\
\hline & $\{0.080\}$ & $\{0.159\}$ & $\{0.259\}$ & $\{0.358\}$ & $\{0.407\}$ & $\{0.442\}^{*}$ & $\{0.475\}^{*}$ & $\{0.501\}^{*}$ \\
\hline & {$[-0.011]$} & {$[0.008]$} & {$[0.048]$} & {$[0.101]$} & {$[0.131]$} & {$[0.153]$} & {$[0.174]$} & {$[0.191]$} \\
\hline
\end{tabular}

This table presents OLS beta parameter estimates for univariate regressions of excess returns on the new ratios. Excess returns are measured at annual frequencies for the period 1946-2005 and cumulated for up to 8 periods. In parentheses, below the parameter estimates, are Newey-West (1987) corrected standard errors, the $t / \sqrt{T}$ test of Valkanov (2003) in curly brackets, and adjusted $R^{2}$ statistics in square brackets. $p y$ is the $\log$ price-output ratio, $p c$ is the $\log$ price-consumption ratio, $y c_{1}$ is the log labour income-consumption ratio, $y c_{2}$ is the $\log$ compensation of employees-consumption ratio, $y c_{3}$ is the log labour income-compensation of employees ratio, and nhe is the log non-housing consumption share. $*-10 \%$ significance, $* *-5 \%$ significance. 
Table 17: Annual univariate long-horizon regressions, 1946-2005

\begin{tabular}{|c|c|c|c|c|c|c|c|c|}
\hline \multicolumn{9}{|c|}{ Horizon $\mathrm{h}$ (in years) } \\
\hline & 1 & 2 & 3 & 4 & 5 & 6 & 7 & 8 \\
\hline \multirow[t]{4}{*}{$\overline{c a y \_d l s}$} & 2.971 & 5.952 & 7.937 & 8.396 & 9.079 & 10.084 & 10.309 & 10.415 \\
\hline & $(0.961)^{* *}$ & $(1.856)^{* *}$ & $(2.187)^{* *}$ & $(2.243)^{* *}$ & $(2.875)^{* *}$ & $(3.733)^{* *}$ & $(2.229)^{* *}$ & $(4.036)^{* *}$ \\
\hline & $\{0.404\}$ & $\{0.628\}^{* *}$ & $\{0.803\}^{* *}$ & $\{0.760\}^{* *}$ & $\{0.678\}^{* *}$ & $\{0.677\}^{* *}$ & $\{0.621\}^{* *}$ & $\{0.573\}^{* *}$ \\
\hline & {$[0.129]$} & {$[0.277]$} & {$[0.390]$} & {$[0.363]$} & {$[0.310]$} & {$[0.309]$} & {$[0.272]$} & {$[0.239]$} \\
\hline \multirow[t]{4}{*}{$c d y \_d l s$} & 0.551 & 1.941 & 3.368 & 4.323 & 5.355 & 6.920 & 7.805 & 8.842 \\
\hline & $(0.505)$ & $(1.025)^{*}$ & $(1.201)^{* *}$ & $(1.222)^{* *}$ & $(1.479)^{* *}$ & $(2.149)^{* *}$ & $(2.284)^{* *}$ & $(1.887)^{* *}$ \\
\hline & $\{0.101\}$ & $\{0.260\}$ & $\{0.421\}$ & $\{0.508\}^{*}$ & $\{0.542\}^{* *}$ & $\{0.660\}^{* *}$ & $\{0.734\}^{* *}$ & $\{0.819\}^{* *}$ \\
\hline & {$[-0.007]$} & {$[0.049]$} & [0.140] & {$[0.197]$} & {$[0.219]$} & {$[0.298]$} & {$[0.346]$} & {$[0.399]$} \\
\hline \multirow[t]{4}{*}{$l r \_y$} & -1.107 & -2.411 & -3.862 & -6.849 & -8.801 & -10.707 & -11.738 & -12.823 \\
\hline & $(2.288)$ & $(3.063)$ & $(3.141)$ & $(3.488)^{* *}$ & $(4.139)^{* *}$ & $(4.755)^{* *}$ & $(4.730)^{* *}$ & $(6.229)^{* *}$ \\
\hline & $\{-0.075\}$ & $\{-0.117\}$ & $\{-0.168\}$ & $\{-0.279\}$ & $\{-0.310\}$ & $\{-0.345\}$ & $\{-0.361\}$ & $\{-0.370\}$ \\
\hline & {$[-0.011]$} & {$[-0.003]$} & {$[0.011]$} & {$[0.058]$} & {$[0.074]$} & [0.093] & {$[0.102]$} & [0.107] \\
\hline \multirow[t]{4}{*}{ lr_comp. } & -0.807 & -2.149 & -1.608 & -2.753 & -5.792 & -7.154 & -7.860 & -7.627 \\
\hline & $(1.674)$ & $(2.600)$ & $(2.152)$ & $(2.478)$ & $(3.123)^{*}$ & $(3.512)^{* *}$ & $(2.954)^{* *}$ & $(4.913)$ \\
\hline & $\{-0.062\}$ & $\{-0.119\}$ & $\{-0.079\}$ & $\{-0.124\}$ & $\{-0.226\}$ & $\{-0.215\}$ & $\{-0.266\}$ & $\{-0.240\}$ \\
\hline & {$[-0.013]$} & {$[-0.003]$} & {$[-0.011]$} & {$[-0.002]$} & [0.033] & {$[0.028]$} & {$[0.051]$} & {$[0.038]$} \\
\hline \multirow[t]{4}{*}{$y \_l d$} & 0.016 & 0.058 & 0.107 & 0.167 & 0.221 & 0.256 & 0.265 & 0.289 \\
\hline & $(0.036)$ & $(0.069)$ & $(0.097)$ & $(0.111)$ & $(0.121)^{*}$ & $(0.135)^{*}$ & $(0.157)^{*}$ & $(0.180)$ \\
\hline & $\{0.051\}$ & $\{0.132\}$ & $\{0.216\}$ & $\{0.315\}$ & $\{0.359\}$ & $\{0.375\}$ & $\{0.358\}$ & $\{0.358\}$ \\
\hline & {$[-0.014]$} & {$[0.000]$} & {$[0.029]$} & {$[0.077]$} & {$[0.101]$} & {$[0.111]$} & {$[0.101]$} & {$[0.100]$} \\
\hline \multirow[t]{4}{*}{$y \_l s$} & 0.095 & 0.196 & 0.269 & 0.346 & 0.457 & 0.553 & 0.626 & 0.727 \\
\hline & $(0.047)^{* *}$ & $(0.082)^{* *}$ & $(0.103)^{* *}$ & $(0.106)^{* *}$ & $(0.117)^{* *}$ & $(0.151)^{* *}$ & $(0.191)^{* *}$ & $(0.218)^{* *}$ \\
\hline & $\{0.233\}$ & $\{0.353\}$ & $\{0.439\}$ & $\{0.530\}$ & $\{0.623\}$ & $\{0.679\}$ & $\{0.695\}$ & $\{0.742\}$ \\
\hline & {$[0.037]$} & [0.099] & {$[0.152]$} & {$[0.211]$} & {$[0.274]$} & {$[0.311]$} & {$[0.321]$} & {$[0.352]$} \\
\hline \multirow[t]{4}{*}{ mymo_dls } & -0.029 & 0.011 & 0.095 & 0.241 & 0.434 & 0.618 & 0.814 & 1.029 \\
\hline & $(0.064)$ & $(0.105)$ & $(0.145)$ & $(0.182)$ & $(0.231)^{*}$ & $(0.284)^{* *}$ & $(0.334)^{* *}$ & $(0.375)^{* *}$ \\
\hline & $\{-0.032\}$ & $\{0.009\}$ & $\{0.066\}$ & $\{0.154\}$ & $\{0.242\}$ & $\{0.319\}$ & $\{0.413\}$ & $\{0.512\}^{*}$ \\
\hline & {$[-0.016]$} & {$[-0.017]$} & {$[-0.013]$} & {$[0.006]$} & {$[0.040]$} & {$[0.079]$} & {$[0.134]$} & {$[0.199]$} \\
\hline
\end{tabular}

$\overline{\text { This table presents OLS beta parameter estimates for univariate regressions of excess returns on variables }}$ based on cointegration relations. Excess returns are measured at annual frequencies for the period 1946-2005 and cumulated for up to 8 periods. In parentheses, below the parameter estimates, are Newey-West (1987) corrected t-statistics, the $t / \sqrt{T}$ test of Valkanov (2003) in curly brackets, and adjusted $R^{2}$ statistics in square brackets. cay is the approximate consumption-aggregate wealth ratio, $c d y$ is the cointegration relation between consumption, dividends, and labour income. $d l s$ implies that the relation has been computed by dynamic least squares. $l r_{-} y$ is the long-run labour income growth relation of Julliard (2005) computed using log labour income and $l r_{-}$comp is the same relation using log compensation of employees instead of log labour income. $y \_l d$ is based on a cointegration relation between labour income and dividends, and $y \_l s$ is the cointegration relation between labour income and the log level of the CRSP value-weighted stock index. mymo is a housing collateral measure developed from a cointegration relation between aggregate labour income and the value of outstanding mortgages in the US. $*-10 \%$ significance, $* *-5 \%$ significance. 
Table 18: Annual univariate long-horizon regressions, 1946-2005

\begin{tabular}{|c|c|c|c|c|c|c|c|c|}
\hline \multicolumn{9}{|c|}{ Horizon h (in years) } \\
\hline & 1 & 2 & 3 & 4 & 5 & 6 & 7 & 8 \\
\hline \multirow[t]{4}{*}{$\overline{c a y \_j o h}$} & $\overline{0.884}$ & 1.606 & $\overline{c 1.729}$ & 1.368 & $\overline{1.479}$ & 1.528 & $\overline{0.883}$ & $\overline{0.439}$ \\
\hline & $(0.345)^{* *}$ & $(0.721)^{* *}$ & $(1.078)$ & (1.257) & $(1.399)$ & $(1.536)$ & $(1.669)$ & $(1.820)$ \\
\hline & $\{0.228\}$ & $\{0.301\}$ & $\{0.287\}$ & $\{0.202\}$ & $\{0.187\}$ & $\{0.172\}$ & $\{0.089\}$ & $\{0.041\}$ \\
\hline & {$[0.034]$} & {$[0.070]$} & {$[0.062]$} & {$[0.023]$} & {$[0.017]$} & {$[0.012]$} & {$[-0.011]$} & {$[-0.018]$} \\
\hline \multirow[t]{4}{*}{$c d y_{-} j o h$} & 0.397 & 1.570 & 2.795 & 3.675 & 4.611 & 5.871 & 6.531 & 7.370 \\
\hline & $(0.392)$ & $(0.849)^{*}$ & $(1.039)^{* *}$ & $(1.012)^{* *}$ & $(1.238)^{* *}$ & $(1.824)^{* *}$ & $(1.933)^{* *}$ & $(1.587)^{* *}$ \\
\hline & $\{0.085\}$ & $\{0.244\}$ & $\{0.403\}$ & $\{0.500\}$ & $\{0.546\}$ & $\{0.657\}^{*}$ & $\{0.712\}^{* *}$ & $\{0.648\}^{* *}$ \\
\hline & {$[-0.010]$} & {$[0.042]$} & {$[0.129]$} & {$[0.192]$} & {$[0.222]$} & {$[0.296]$} & {$[0.332]$} & {$[0.379]$} \\
\hline \multirow[t]{4}{*}{ mymo_joh } & -0.079 & -0.069 & 0.006 & 0.142 & 0.304 & 0.486 & 0.681 & 0.886 \\
\hline & $(0.066)$ & $(0.118)$ & $(0.170)$ & $(0.202)$ & $(0.225)$ & $(0.260)^{*}$ & $(0.308)^{* *}$ & $(0.353)^{* *}$ \\
\hline & $\{-0.088\}$ & $\{-0.055\}$ & $\{0.004\}$ & $\{0.091\}$ & $\{0.170\}$ & $\{0.249\}$ & $\{0.341\}$ & $\{0.432\}$ \\
\hline & {$[-0.009]$} & {$[-0.014]$} & {$[-0.018]$} & {$[-0.009]$} & [0.011] & [0.043] & [0.091] & {$[0.146]$} \\
\hline \multirow[t]{4}{*}{ mymo_1 } & -0.018 & 0.049 & 0.170 & 0.356 & 0.563 & 0.771 & 0.985 & 1.208 \\
\hline & $(0.077)$ & $(0.140)$ & $(0.196)$ & $(0.219)$ & $(0.243)^{* *}$ & $(0.292)^{* *}$ & $(0.348)^{* *}$ & $(0.385)^{* *}$ \\
\hline & $\{-0.019\}$ & $\{0.037\}$ & $\{0.115\}$ & $\{0.223\}$ & $\{0.310\}$ & $\{0.395\}$ & $\{0.500\}$ & $\{0.606\}^{*}$ \\
\hline & {$[-0.017]$} & {$[-0.016]$} & {$[-0.004]$} & [0.032] & {$[0.074]$} & [0.123] & [0.190] & {$[0.262]$} \\
\hline
\end{tabular}

This table presents OLS beta parameter estimates for univariate regressions of excess returns on variables based on cointegration relations. Excess returns are measured at annual frequencies for the period 1946-2005 and cumulated for up to 8 periods. In parentheses, below the parameter estimates, are Newey-West (1987) corrected standard errors, the $t / \sqrt{T}$ test of Valkanov (2003) in curly brackets, and adjusted $R^{2}$ statistics in square brackets. cay is the approximate consumption-aggregate wealth ratio, $c d y$ is the cointegration relation between consumption, dividends, and labour income. joh implies that the relation has been computed by the Johansen (1991) procedure. mymo is a housing collateral measure developed from a cointegration relation between aggregate labour income and the value of outstanding mortgages in the US. mymo_1 is based on the same relation as mymo, but with the cointegration coefficient on aggregate labour income restricted to -1 . $*-10 \%$ significance, $* *-5 \%$ significance. 
Table 19: Implied long-horizon $R^{2}, 1952 \mathrm{Q} 1-2005 \mathrm{Q} 4$

\begin{tabular}{|c|c|c|c|c|c|c|c|c|}
\hline \multicolumn{9}{|c|}{ Horizon h (in quarters) } \\
\hline & 1 & 2 & 4 & 8 & 16 & 24 & 36 & 48 \\
\hline$\overline{\Delta c}$ & $\overline{0.005}$ & 0.005 & $\overline{0.003}$ & $\overline{0.002}$ & $\overline{0.001}$ & 0.001 & $\overline{0.000}$ & $\overline{0.000}$ \\
\hline def & 0.006 & 0.010 & 0.018 & 0.029 & 0.035 & 0.034 & 0.028 & 0.023 \\
\hline$r t b$ & 0.035 & 0.045 & 0.046 & 0.031 & 0.017 & 0.011 & 0.007 & 0.006 \\
\hline pe & 0.007 & 0.016 & 0.034 & 0.068 & 0.130 & 0.181 & 0.241 & 0.280 \\
\hline$p d$ & 0.012 & 0.025 & 0.054 & 0.108 & 0.201 & 0.275 & 0.353 & 0.395 \\
\hline$d e$ & 0.003 & 0.006 & 0.011 & 0.020 & 0.032 & 0.039 & 0.044 & 0.045 \\
\hline py & 0.004 & 0.008 & 0.017 & 0.036 & 0.072 & 0.106 & 0.153 & 0.196 \\
\hline$p c$ & 0.004 & 0.009 & 0.021 & 0.043 & 0.086 & 0.127 & 0.185 & 0.237 \\
\hline$y c_{1}$ & 0.014 & 0.025 & 0.046 & 0.078 & 0.115 & 0.130 & 0.134 & 0.128 \\
\hline$y c_{2}$ & 0.042 & 0.078 & 0.134 & 0.204 & 0.263 & 0.276 & 0.267 & 0.247 \\
\hline$y c_{3}$ & 0.007 & 0.013 & 0.024 & 0.044 & 0.071 & 0.087 & 0.099 & 0.102 \\
\hline nhe & 0.000 & 0.001 & 0.001 & 0.003 & 0.005 & 0.006 & 0.008 & 0.009 \\
\hline cay_dls & 0.057 & 0.102 & 0.177 & 0.246 & 0.245 & 0.201 & 0.146 & 0.112 \\
\hline cay_joh & 0.036 & 0.070 & 0.133 & 0.216 & 0.263 & 0.242 & 0.189 & 0.147 \\
\hline$c d y \_d l s$ & 0.004 & 0.007 & 0.013 & 0.018 & 0.020 & 0.018 & 0.013 & 0.011 \\
\hline$c d y_{-} j o h$ & 0.001 & 0.003 & 0.005 & 0.008 & 0.009 & 0.009 & 0.007 & 0.006 \\
\hline$l r_{-} y$ & 0.020 & 0.023 & 0.018 & 0.009 & 0.005 & 0.003 & 0.002 & 0.002 \\
\hline$l r_{-} c o m p$. & 0.015 & 0.015 & 0.010 & 0.005 & 0.002 & 0.002 & 0.001 & 0.001 \\
\hline$y \_l d$ & 0.000 & 0.000 & 0.000 & 0.000 & 0.000 & 0.001 & 0.001 & 0.001 \\
\hline$y_{-} l s$ & 0.010 & 0.021 & 0.045 & 0.090 & 0.166 & 0.222 & 0.273 & 0.292 \\
\hline
\end{tabular}

This table presents implied $h$-period $R^{2}$ statistics from first order vector autoregressions (VAR) run on $r^{e m}$ and the respective predictor variables. Data is quarterly for the period 1951Q4 to 2005Q3. 
Table 20: Implied long-horizon $R^{2}, 1946-2005$

\begin{tabular}{|c|c|c|c|c|c|c|c|c|}
\hline \multicolumn{9}{|c|}{ "Horizon h (in years) } \\
\hline & 1 & 2 & 3 & 4 & 5 & 6 & 7 & 8 \\
\hline$\overline{\Delta c}$ & $\overline{0.059}$ & $\overline{0.050}$ & $\overline{0.038}$ & $\overline{0.032}$ & $\overline{0.027}$ & $\overline{0.023}$ & $\overline{0.021}$ & 0.018 \\
\hline def & 0.000 & 0.000 & 0.000 & 0.000 & 0.000 & 0.000 & 0.000 & 0.000 \\
\hline pe & 0.052 & 0.100 & 0.146 & 0.186 & 0.223 & 0.255 & 0.284 & 0.309 \\
\hline$p d$ & 0.090 & 0.171 & 0.238 & 0.297 & 0.348 & 0.393 & 0.431 & 0.464 \\
\hline$d e$ & 0.005 & 0.006 & 0.007 & 0.007 & 0.006 & 0.006 & 0.005 & 0.005 \\
\hline py & 0.024 & 0.046 & 0.066 & 0.086 & 0.105 & 0.124 & 0.142 & 0.159 \\
\hline$p c$ & 0.029 & 0.055 & 0.080 & 0.104 & 0.128 & 0.152 & 0.175 & 0.198 \\
\hline$y c_{1}$ & 0.013 & 0.022 & 0.027 & 0.030 & 0.032 & 0.032 & 0.032 & 0.032 \\
\hline$y c_{2}$ & 0.018 & 0.027 & 0.029 & 0.029 & 0.028 & 0.026 & 0.024 & 0.023 \\
\hline$y c_{3}$ & 0.035 & 0.067 & 0.087 & 0.104 & 0.117 & 0.127 & 0.135 & 0.142 \\
\hline nhe & 0.002 & 0.005 & 0.007 & 0.009 & 0.010 & 0.011 & 0.012 & 0.013 \\
\hline$c a y \_d l s$ & 0.112 & 0.134 & 0.125 & 0.108 & 0.091 & 0.078 & 0.067 & 0.059 \\
\hline$c d y \_d l s$ & 0.011 & 0.015 & 0.016 & 0.017 & 0.017 & 0.017 & 0.016 & 0.015 \\
\hline$l r_{-} y$ & 0.006 & 0.006 & 0.005 & 0.004 & 0.003 & 0.002 & 0.002 & 0.002 \\
\hline$l r_{-} c o m p$. & 0.004 & 0.002 & 0.001 & 0.001 & 0.001 & 0.001 & 0.001 & 0.000 \\
\hline$y \_l d$ & 0.002 & 0.002 & 0.002 & 0.002 & 0.003 & 0.003 & 0.003 & 0.003 \\
\hline$y \_l s$ & 0.050 & 0.095 & 0.135 & 0.170 & 0.201 & 0.229 & 0.253 & 0.273 \\
\hline mymo_dls & 0.000 & 0.000 & 0.001 & 0.001 & 0.001 & 0.001 & 0.001 & 0.001 \\
\hline cay_joh & 0.039 & 0.070 & 0.091 & 0.101 & 0.103 & 0.101 & 0.096 & 0.089 \\
\hline$c d y_{-} j o h$ & 0.007 & 0.011 & 0.012 & 0.013 & 0.013 & 0.013 & 0.013 & 0.012 \\
\hline mymo_joh & 0.001 & 0.002 & 0.002 & 0.003 & 0.003 & 0.003 & 0.003 & 0.003 \\
\hline mymo_1 & 0.000 & 0.000 & 0.000 & 0.000 & 0.000 & 0.000 & 0.000 & 0.000 \\
\hline
\end{tabular}

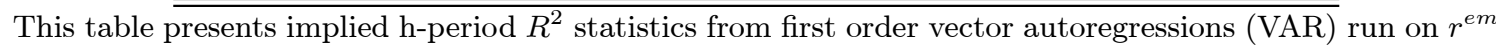
and the respective predictor variables. Data is annual for the period 1945 to 2004. 
Table 21: Quarterly univariate long-horizon regressions, 1926Q4-2005Q4

\begin{tabular}{lllllllll}
\hline \hline & \multicolumn{7}{c}{ Horizon h (in quarters) } \\
\hline & 1 & 2 & 4 & 8 & 16 & 24 & 36 & 48 \\
\hline \hline$r^{e m}$ & -0.049 & -0.033 & -0.005 & -0.109 & -0.301 & -0.451 & -0.131 & -0.086 \\
& $(0.098)$ & $(0.134)$ & $(0.160)$ & $(0.225)$ & $(0.218)$ & $(0.183)$ & $(0.225)$ & $(0.288)$ \\
& $\{-0.048\}$ & $\{-0.024\}$ & $\{-0.002\}$ & $\{-0.039\}$ & $\{-0.083\}$ & $\{-0.118\}$ & $\{-0.031\}$ & $\{-0.016\}$ \\
& {$[-0.001]$} & {$[-0.003]$} & {$[-0.003]$} & {$[-0.002]$} & {$[0.004]$} & {$[0.010]$} & {$[-0.003]$} & {$[-0.003]$} \\
def & 3.300 & 2.671 & 10.031 & 16.587 & 35.358 & 30.959 & 27.087 & 79.028 \\
& $(5.974)$ & $(9.866)$ & $(14.800)$ & $(16.067)$ & $(26.595)$ & $(18.828)$ & $(22.037)$ & $(25.178)^{* *}$ \\
& $\{0.054\}$ & $\{0.032\}$ & $\{0.082\}$ & $\{0.097\}$ & $\{0.164\}$ & $\{0.137\}$ & $\{0.108\}$ & $\{0.262\}$ \\
& {$[-0.000]$} & {$[-0.002]$} & {$[0.003]$} & {$[0.006]$} & {$[0.023]$} & {$[0.015]$} & {$[0.008]$} & {$[0.061]$} \\
$p e$ & -0.042 & -0.078 & -0.171 & -0.325 & -0.513 & -0.582 & -0.824 & -1.233 \\
& $(0.017)^{* *}$ & $(0.029)^{* *}$ & $(0.053)^{* *}$ & $(0.092)^{* *}$ & $(0.117)^{* *}$ & $(0.114)^{* *}$ & $(0.166)^{* *}$ & $(0.183)^{* *}$ \\
& $\{-0.154\}$ & $\{-0.212\}$ & $\{-0.323\}$ & $\{-0.460\}$ & $\{-0.586\}$ & $\{-0.598\}$ & $\{-0.707\}$ & $\{-0.906\}$ \\
& {$[0.020]$} & {$[0.040]$} & {$[0.092]$} & {$[0.173]$} & {$[0.254]$} & {$[0.262]$} & {$[0.333]$} & {$[0.451]$} \\
$p d$ & -0.025 & -0.046 & -0.103 & -0.207 & -0.400 & -0.583 & -0.917 & -1.324 \\
& $(0.018)$ & $(0.032)$ & $(0.056)^{*}$ & $(0.081)^{* *}$ & $(0.099)^{* *}$ & $(0.109)^{* *}$ & $(0.165)^{* *}$ & $(0.183)^{* *}$ \\
& $\{-0.097\}$ & $\{-0.130\}$ & $\{-0.199\}$ & $\{-0.290\}$ & $\{-0.434\}$ & $\{-0.576\}$ & $\{-0.729\}$ & $\{-0.820\}$ \\
& {$[0.006]$} & {$[0.014]$} & {$[0.035]$} & {$[0.075]$} & {$[0.157]$} & {$[0.248]$} & {$[0.346]$} & {$[0.402]$} \\
$d e$ & -0.014 & -0.028 & -0.026 & 0.052 & 0.147 & 0.247 & 0.098 & 0.252 \\
& $(0.038)$ & $(0.071)$ & $(0.124)$ & $(0.162)$ & $(0.201)$ & $(0.134)$ & $(0.152)$ & $(0.209)$ \\
& $\{-0.036\}$ & $\{-0.050\}$ & $\{-0.031\}$ & $\{0.044\}$ & $\{0.098\}$ & $\{0.153\}$ & $\{0.053\}$ & $\{0.107\}$ \\
& {$[-0.002]$} & {$[-0.001]$} & {$[-0.002]$} & {$[-0.001]$} & {$[0.006]$} & {$[0.020]$} & {$[-0.001]$} & {$[0.008]$} \\
\hline \hline
\end{tabular}

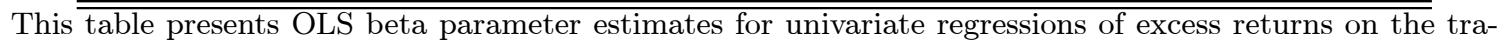
ditional predictor variables. Excess returns are measured at quarterly frequencies for the period 1926Q42005Q4 and cumulated for up to 48 periods. In parentheses, below the parameter estimates, are Newey-West (1987) corrected standard errors, the $t / \sqrt{T}$ test of Valkanov (2003) in curly brackets, and adjusted $R^{2}$ statistics in square brackets. $r^{e m}$ is the log excess return on the CRSP VW portfolio, def is the default premium on bonds, pe is the log price-earnings ratio on the $\mathrm{S} \& \mathrm{P} 500, p d$ is the log price-dividend ratio on the CRSP value-weighted portfolio, and de is the log dividend-earnings ratio on the $\mathrm{S} \& \mathrm{P} 500 . *-10 \%$ significance, $* *-5 \%$ significance. 
Table 22: Quarterly univariate long-horizon regressions, 1947Q2-2005Q4

\begin{tabular}{|c|c|c|c|c|c|c|c|c|}
\hline \multicolumn{9}{|c|}{ Horizon h (in quarters) } \\
\hline & 1 & 2 & 4 & 8 & 16 & 24 & 36 & 48 \\
\hline \multirow[t]{4}{*}{$\overline{\Delta \Delta c}$} & -1.273 & -1.599 & $\begin{array}{c}-5.806 \\
\end{array}$ & -10.828 & -12.498 & -21.358 & -24.003 & -23.647 \\
\hline & $(0.974)$ & $(1.895)$ & $(2.582)^{* *}$ & $(4.474)^{* *}$ & $(4.225)^{* *}$ & $(6.083)^{* *}$ & $(7.911)^{* *}$ & $(8.360)^{* *}$ \\
\hline & $\{-0.077\}$ & $\{-0.067\}$ & $\{-0.176\}$ & $\{-0.249\}$ & $\{-0.224\}$ & $\{-0.310\}$ & $\{-0.297\}$ & $\{-0.258\}$ \\
\hline & {$[0.002]$} & [0.000] & {$[0.026]$} & [0.055] & {$[0.044]$} & [0.084] & [0.077] & {$[0.058]$} \\
\hline \multirow[t]{4}{*}{$r t b$} & -8.120 & -13.020 & -22.524 & -13.403 & -9.040 & -15.600 & -22.931 & -21.071 \\
\hline & $(2.754)^{* *}$ & $(5.344)^{* *}$ & $(10.658)^{* *}$ & $(10.129)$ & $(13.200)$ & $(15.415)$ & $(18.880)$ & $(18.176)$ \\
\hline & $\{-0.183\}$ & $\{-0.204\}$ & $\{-0.254\}$ & $\{-0.110\}$ & $\{-0.058\}$ & $\{-0.077\}$ & $\{-0.096\}$ & $\{-0.078\}$ \\
\hline & {$[0.029]$} & [0.036] & [0.057] & [0.008] & {$[-0.001]$} & {$[0.001]$} & [0.004] & {$[0.001]$} \\
\hline \multirow[t]{4}{*}{$p y$} & -0.012 & -0.025 & -0.052 & -0.106 & -0.213 & -0.305 & -0.444 & -0.644 \\
\hline & $(0.008)$ & $(0.015)^{*}$ & $(0.028)^{*}$ & $(0.048)^{* *}$ & $(0.055)^{* *}$ & $(0.070)^{* *}$ & $(0.107)^{* *}$ & $(0.132)^{* *}$ \\
\hline & $\{-0.101\}$ & $\{-0.147\}$ & $\{-0.217\}$ & $\{-0.329\}$ & $\{-0.538\}$ & $\{-0.569\}$ & $\{-0.601\}$ & $\{-0.741\}$ \\
\hline & {$[0.006]$} & [0.017] & {$[0.041]$} & [0.095] & {$[0.223]$} & [0.243] & [0.264] & {$[0.354]$} \\
\hline \multirow[t]{4}{*}{$p c$} & -0.013 & -0.027 & -0.054 & -0.109 & -0.219 & -0.316 & -0.462 & -0.657 \\
\hline & $(0.008)$ & $(0.015)^{*}$ & $(0.028)^{*}$ & $(0.048)^{* *}$ & $(0.053)^{* *}$ & $(0.068)^{* *}$ & $(0.104)^{* *}$ & $(0.127)^{* *}$ \\
\hline & $\{-0.106\}$ & $\{-0.154\}$ & $\{-0.225\}$ & $\{-0.339\}$ & $\{-0.558\}$ & $\{-0.597\}$ & $\{-0.635\}$ & $\{-0.771\}$ \\
\hline & {$[0.007]$} & {$[0.019]$} & {$[0.044]$} & {$[0.100]$} & {$[0.236]$} & {$[0.261]$} & {$[0.286]$} & {$[0.372]$} \\
\hline \multirow[t]{4}{*}{$y c_{1}$} & -0.255 & -0.481 & -0.895 & -1.778 & -3.748 & -4.558 & -5.175 & -4.195 \\
\hline & $(0.128)^{*}$ & $(0.242)^{* *}$ & $(0.436)$ & $(0.615)^{* *}$ & $(0.597)^{* *}$ & $(0.874)^{* *}$ & $(1.102)^{* *}$ & $(1.657)^{* *}$ \\
\hline & $\{-0.127\}$ & $\{-0.166\}$ & $\{-0.223\}$ & $\{-0.337\}$ & $\{-0.605\}^{*}$ & $\{-0.578\}^{*}$ & $\{-0.556\}^{*}$ & $\{-0.376\}$ \\
\hline & {$[0.012]$} & {$[0.023]$} & {$[0.044]$} & {$[0.099]$} & {$[0.267]$} & {$[0.249]$} & {$[0.234]$} & {$[0.120]$} \\
\hline \multirow[t]{4}{*}{$y c_{2}$} & -0.367 & -0.716 & -1.274 & -2.302 & -4.252 & -5.447 & -5.917 & -5.636 \\
\hline & $(0.135)^{* *}$ & $(0.257)^{* *}$ & $(0.450)^{* *}$ & $(0.606)^{* *}$ & $(0.554)^{* *}$ & $(0.814)^{* *}$ & $(0.893)^{* *}$ & $(1.224)^{* *}$ \\
\hline & $\{-0.189\}$ & $\{-0.259\}$ & $\{-0.337\}$ & $\{-0.478\}$ & $\{-0.804\}^{* *}$ & $\{-0.825\}^{* *}$ & $\{-0.729\}^{* *}$ & $\{-0.570\}^{*}$ \\
\hline & {$[0.031]$} & {$[0.059]$} & {$[0.099]$} & {$[0.183]$} & {$[0.392]$} & {$[0.404]$} & {$[0.346]$} & {$[0.243]$} \\
\hline \multirow[t]{4}{*}{$y c_{3}$} & -0.358 & -0.725 & -1.523 & -3.113 & -5.998 & -8.355 & -11.525 & -11.485 \\
\hline & $(0.211)^{*}$ & $(0.386)^{*}$ & $(0.695)^{* *}$ & $(1.030)^{* *}$ & $(1.162)^{* *}$ & $(1.624)^{* *}$ & $(1.872)^{* *}$ & $(2.229)^{* *}$ \\
\hline & $\{-0.106\}$ & $\{-0.148\}$ & $\{-0.225\}$ & $\{-0.353\}$ & $\{-0.581\}$ & $\{-0.672\}^{* *}$ & $\{-0.860\}^{* *}$ & $\{-0.710\}^{* *}$ \\
\hline & [0.007] & [0.017] & {$[0.044]$} & [0.108] & {$[0.251]$} & {$[0.310]$} & {$[0.425]$} & {$[0.334]$} \\
\hline \multirow[t]{4}{*}{ nhe } & 0.303 & 0.637 & 1.256 & 2.665 & 5.571 & 7.400 & 9.198 & 9.217 \\
\hline & $(0.242)$ & $(0.455)$ & $(0.797)$ & $(1.137)^{* *}$ & $(1.268)^{* *}$ & $(1.946)^{* *}$ & $(2.250)^{* *}$ & $(3.040)^{* *}$ \\
\hline & $\{0.072\}$ & $\{0.105\}$ & $\{0.149\}$ & $\{0.239\}$ & $\{0.414\}$ & $\{0.444\}$ & $\{0.478\}$ & $\{0.416\}$ \\
\hline & {$[0.001]$} & {$[0.007]$} & {$[0.018]$} & {$[0.050]$} & {$[0.144]$} & {$[0.162]$} & {$[0.184]$} & {$[0.144]$} \\
\hline
\end{tabular}

This table presents OLS beta parameter estimates for univariate regressions of excess returns on the traditional predictor variables and new ratios. Excess returns are measured at quarterly frequencies for the period 1947Q2-2005Q4 and cumulated for up to 48 periods. In parentheses, below the parameter estimates, are Newey-West (1987) corrected standard errors, the $t / \sqrt{T}$ test of Valkanov (2003) in curly brackets, and adjusted $R^{2}$ statistics in square brackets. $r^{e m}$ is the log excess return on the CRSP VW portfolio, $c$ is $\log$ consumption, $r t b$ is the relative t-bill rate, $p y$ is the $\log$ price-output ratio, $p c$ is the log price-consumption ratio, $y c_{1}$ is the log labour income-consumption ratio, $y c_{2}$ is the log compensation of employees-consumption ratio, $y c_{3}$ is the log labour income-compensation of employees ratio, and nhe is the log non-housing consumption share. $*-10 \%$ significance, $* *-5 \%$ significance. 
Table 23: Quarterly univariate long-horizon regressions, 1947Q2-2005Q4

\begin{tabular}{lllllllll}
\hline \hline & \multicolumn{7}{c}{ Horizon h (in quarters) } \\
\hline & 1 & 2 & 4 & 8 & 16 & 24 & 36 & 48 \\
\hline \hline lr_y & -5.282 & -4.886 & -14.809 & -24.951 & -38.308 & -58.773 & -66.815 & -58.865 \\
& $(7.978)$ & $(11.386)$ & $(14.618)$ & $(22.288)$ & $(27.989)$ & $(44.148)$ & $(54.664)$ & $(49.474)$ \\
& $\{-0.046\}$ & $\{-0.029\}$ & $\{-0.063\}$ & $\{-0.079\}$ & $\{-0.094\}$ & $\{-0.114\}$ & $\{-0.112\}$ & $\{-0.087\}$ \\
& {$[-0.002]$} & {$[-0.003]$} & {$[-0.000]$} & {$[0.002]$} & {$[0.004]$} & {$[0.008]$} & {$[0.007]$} & {$[0.002]$} \\
lr_comp & -1.228 & -2.917 & -5.892 & -7.148 & -7.329 & -13.481 & -13.507 & -14.086 \\
& $(0.992)$ & $(1.656)^{*}$ & $(2.618)^{* *}$ & $(3.917)^{*}$ & $(4.982)$ & $(7.352)^{*}$ & $(9.265)$ & $(9.315)$ \\
& $\{-0.080\}$ & $\{-0.132\}$ & $\{-0.193\}$ & $\{-0.173\}$ & $\{-0.139\}$ & $\{-0.202\}$ & $\{-0.173\}$ & $\{-0.159\}$ \\
& {$[0.002]$} & {$[0.013]$} & {$[0.032]$} & {$[0.025]$} & {$[0.015]$} & {$[0.035]$} & {$[0.024]$} & {$[0.019]$} \\
$y \_l d$ & 0.008 & 0.017 & 0.038 & 0.099 & 0.200 & 0.258 & 0.244 & 0.335 \\
& $(0.011)$ & $(0.021)$ & $(0.040)$ & $(0.068)$ & $(0.093)^{* *}$ & $(0.121)^{* *}$ & $(0.164)$ & $(0.201)^{*}$ \\
& $\{0.044\}$ & $\{0.067\}$ & $\{0.104\}$ & $\{0.203\}$ & $\{0.326\}$ & $\{0.323\}$ & $\{0.265\}$ & $\{0.272\}$ \\
& {$[-0.002]$} & {$[0.000]$} & {$[0.006]$} & {$[0.036]$} & {$[0.093]$} & {$[0.091]$} & {$[0.050]$} & {$[0.064]$} \\
$y \_l s$ & 0.026 & 0.056 & 0.112 & 0.212 & 0.364 & 0.550 & 0.827 & 1.130 \\
& $(0.014)^{*}$ & $(0.027)^{* *}$ & $(0.047)^{* *}$ & $(0.076)^{* *}$ & $(0.085)^{* *}$ & $(0.111)^{* *}$ & $(0.155)^{* *}$ & $(0.158)^{* *}$ \\
& $\{0.120\}$ & $\{0.178\}$ & $\{0.258\}$ & $\{0.375\}$ & $\{0.534\}$ & $\{0.636\}$ & $\{0.779\}$ & $\{1.073\}^{* *}$ \\
& {$[0.010]$} & {$[0.027]$} & {$[0.059]$} & {$[0.120]$} & {$[0.220]$} & {$[0.287]$} & {$[0.377]$} & {$[0.536]$} \\
\hline \hline
\end{tabular}

This table presents OLS beta parameter estimates for univariate regressions of excess returns on variables based on cointegration relations. Excess returns are measured at quarterly frequencies for the period 1947Q2-2005Q4 and cumulated for up to 48 periods. In parentheses, below the parameter estimates, are Newey-West (1987) corrected standard errors, the $t / \sqrt{T}$ test of Valkanov (2003) in curly brackets, and adjusted $R^{2}$ statistics in square brackets. $l r_{-} y$ is the long-run labour income growth relation of Julliard (2005) computed using log labour income and lr_comp is the same relation using log compensation of employees instead of log labour income. $y_{-} l d$ is based on a cointegration relation between labour income and dividends and $y \_l s$ is the cointegration relation between labour income and the log level of the CRSP value-weighted stock index. $*-10 \%$ significance, $* *-5 \%$ significance. 
Table 24: Annual univariate long-horizon regressions, 1930-2005

\begin{tabular}{lllllllll}
\hline \hline & \multicolumn{7}{c}{ Horizon h (in years) } \\
\hline & 1 & 2 & 3 & 4 & 5 & 6 & 7 & 8 \\
\hline \hline$r^{e m}$ & 0.091 & -0.068 & -0.159 & -0.244 & -0.323 & -0.357 & -0.245 & -0.159 \\
& $(0.136)$ & $(0.166)$ & $(0.129)$ & $(0.173)$ & $(0.189)$ & $(0.166)$ & $(0.166)$ & $(0.191)$ \\
& $\{0.091\}$ & $\{-0.047\}$ & $\{-0.091\}$ & $\{-0.125\}$ & $\{-0.160\}$ & $\{-0.176\}$ & $\{-0.118\}$ & $\{-0.073\}$ \\
& {$[-0.005]$} & {$[-0.011]$} & {$[-0.005]$} & {$[0.002]$} & {$[0.012]$} & {$[0.017]$} & {$[0.000]$} & {$[-0.009]$} \\
$\Delta c$ & -1.012 & -1.938 & -3.899 & -4.313 & -5.018 & -5.486 & -4.955 & -3.594 \\
& $(1.379)$ & $(1.644)$ & $(1.529)^{* *}$ & $(1.595)$ & $(1.635)^{* *}$ & $(1.818)^{* *}$ & $(2.118)^{* *}$ & $(2.171)$ \\
& $\{-0.112\}$ & $\{-0.162\}$ & $\{-0.316\}$ & $\{-0.313\}$ & $\{-0.338\}$ & $\{-0.348\}$ & $\{-0.292\}$ & $\{-0.197\}$ \\
& {$[-0.001]$} & {$[0.013]$} & {$[0.080]$} & {$[0.079]$} & {$[0.092]$} & {$[0.098]$} & {$[0.067]$} & {$[0.024]$} \\
def & 2.602 & 3.884 & 6.459 & 8.769 & 8.401 & 6.902 & 7.667 & 6.083 \\
& $(2.966)$ & $(5.433)$ & $(7.562)$ & $(8.316)$ & $(7.295)$ & $(7.225)$ & $(7.533)$ & $(8.123)$ \\
& $\{0.089\}$ & $\{0.091\}$ & $\{0.129\}$ & $\{0.159\}$ & $\{0.147\}$ & $\{0.121\}$ & $\{0.133\}$ & $\{0.101\}$ \\
& {$[-0.005]$} & {$[-0.005]$} & {$[0.003]$} & {$[0.012]$} & {$[0.008]$} & {$[0.001]$} & {$[0.004]$} & {$[-0.004]$} \\
$p e$ & -0.143 & -0.293 & -0.394 & -0.480 & -0.532 & -0.565 & -0.601 & -0.683 \\
& $(0.053)^{* *}$ & $(0.104)^{* *}$ & $(0.139)^{* *}$ & $(0.156)^{* *}$ & $(0.153)^{* *}$ & $(0.162)^{* *}$ & $(0.184)^{* *}$ & $(0.214)^{* *}$ \\
& $\{-0.292\}$ & $\{-0.424\}$ & $\{-0.486\}$ & $\{-0.546\}$ & $\{-0.585\}$ & $\{-0.609\}$ & $\{-0.600\}$ & $\{-0.632\}$ \\
& {$[0.068]$} & {$[0.144]$} & {$[0.185]$} & {$[0.224]$} & {$[0.250]$} & {$[0.266]$} & {$[0.260]$} & {$[0.281]$} \\
$p d$ & -0.104 & -0.197 & -0.281 & -0.379 & -0.483 & -0.604 & -0.699 & -0.847 \\
& $(0.050)^{* *}$ & $(0.086)^{* *}$ & $(0.111)^{* *}$ & $(0.129)^{* *}$ & $(0.141)^{* *}$ & $(0.167)^{* *}$ & $(0.199)^{* *}$ & $(0.228)^{* *}$ \\
& $\{-0.214\}$ & $\{-0.275\}$ & $\{-0.329\}$ & $\{-0.398\}$ & $\{-0.482\}$ & $\{-0.583\}$ & $\{-0.628\}$ & $\{-0.706\}$ \\
& {$[0.032]$} & {$[0.060]$} & {$[0.088]$} & {$[0.128]$} & {$[0.182]$} & {$[0.248]$} & {$[0.279]$} & {$[0.329]$} \\
de & -0.015 & 0.076 & 0.108 & 0.148 & 0.250 & 0.278 & 0.227 & 0.207 \\
& $(0.102)$ & $(0.167)$ & $(0.196)$ & $(0.214)$ & $(0.175)$ & $(0.151)^{*}$ & $(0.163)$ & $(0.152)$ \\
& $\{-0.021\}$ & $\{0.068\}$ & $\{0.081\}$ & $\{0.101\}$ & $\{0.166\}$ & $\{0.181\}$ & $\{0.142\}$ & $\{0.124\}$ \\
& {$[-0.013]$} & {$[-0.009]$} & {$[-0.007]$} & {$[-0.003]$} & {$[0.014]$} & {$[0.019]$} & {$[0.006]$} & {$[0.001]$} \\
\hline \hline
\end{tabular}

This table presents OLS beta parameter estimates for univariate regressions of excess returns on the traditional predictor variables. Excess returns are measured at annual frequencies for the period 1930-2005 and cumulated for up to 8 periods. In parentheses, below the parameter estimates, are Newey-West (1987) corrected standard errors, the $t / \sqrt{T}$ test of Valkanov (2003) in curly brackets, and adjusted $R^{2}$ statistics in square brackets. $r^{e m}$ is the log excess return on the CRSP VW portfolio, $c$ is log consumption, def is the default premium on bonds, $p e$ is the log price-earnings ratio on the $\mathrm{S} \& \mathrm{P} 500, p d$ is the log price-dividend ratio on the CRSP value-weighted portfolio, and de is the log dividend-earnings ratio on the S\&P 500 . $*-10 \%$ significance, $* *-5 \%$ significance. 
Table 25: Annual univariate long-horizon regressions, 1930-2005

\begin{tabular}{lllllllll}
\hline \hline & \multicolumn{7}{c}{ Horizon h (in years) } \\
\hline & 1 & 2 & 3 & 4 & 5 & 6 & 7 & 8 \\
\hline \hline$p y$ & -0.026 & -0.062 & -0.103 & -0.155 & -0.197 & -0.232 & -0.257 & -0.289 \\
& $(0.032)$ & $(0.054)$ & $(0.064)$ & $(0.067)^{* *}$ & $(0.070)^{* *}$ & $(0.079)^{* *}$ & $(0.093)^{* *}$ & $(0.111)^{* *}$ \\
& $\{-0.106\}$ & $\{-0.176\}$ & $\{-0.267\}$ & $\{-0.397\}$ & $\{-0.466\}$ & $\{-0.526\}$ & $\{-0.535\}$ & $\{-0.536\}$ \\
& {$[-0.002]$} & {$[0.018]$} & {$[0.056]$} & {$[0.127]$} & {$[0.171]$} & {$[0.210]$} & {$[0.216]$} & {$[0.217]$} \\
$p c$ & -0.021 & -0.055 & -0.095 & -0.145 & -0.185 & -0.216 & -0.235 & -0.261 \\
& $(0.033)$ & $(0.054)$ & $(0.063)$ & $(0.066)^{* *}$ & $(0.069)^{* *}$ & $(0.077)^{* *}$ & $(0.091)^{* *}$ & $(0.063)^{* *}$ \\
& $\{-0.091\}$ & $\{-0.159\}$ & $\{-0.254\}$ & $\{-0.305\}$ & $\{-0.453\}$ & $\{-0.507\}$ & $\{-0.507\}$ & $\{-0.309\}$ \\
& {$[-0.005]$} & {$[0.012]$} & {$[0.049]$} & {$[0.120]$} & {$[0.163]$} & {$[0.198]$} & {$[0.198]$} & {$[0.198]$} \\
$y c_{1}$ & 0.186 & 0.218 & -0.057 & -0.392 & -0.529 & -0.634 & -0.565 & -0.428 \\
& $(0.392)$ & $(0.637)$ & $(0.669)$ & $(0.594)$ & $(0.566)$ & $(0.564)$ & $(0.609)$ & $(0.653)$ \\
& $\{0.087\}$ & $\{0.070\}$ & $\{-0.017\}$ & $\{-0.112\}$ & $\{-0.140\}$ & $\{-0.162\}$ & $\{-0.138\}$ & $\{-0.096\}$ \\
& {$[-0.006]$} & {$[-0.009]$} & {$[-0.014]$} & {$[-0.001]$} & {$[0.006]$} & {$[0.012]$} & {$[0.005]$} & {$[-0.005]$} \\
$y c_{2}$ & 0.139 & 0.146 & -0.061 & -0.315 & -0.413 & -0.442 & -0.371 & -0.282 \\
& $(0.293)$ & $(0.470)$ & $(0.488)$ & $(0.446)$ & $(0.450)$ & $(0.457)$ & $(0.476)$ & $(0.501)$ \\
& $\{0.086\}$ & $\{0.063\}$ & $\{-0.024\}$ & $\{-0.121\}$ & $\{-0.147\}$ & $\{-0.151\}$ & $\{-0.121\}$ & $\{-0.085\}$ \\
& {$[-0.006]$} & {$[-0.010]$} & {$[-0.013]$} & {$[0.001]$} & {$[0.008]$} & {$[0.009]$} & {$[0.000]$} & {$[-0.007]$} \\
$y c_{3}$ & 0.387 & 0.548 & 0.001 & -0.726 & -1.124 & -1.575 & -1.802 & -1.897 \\
& $(0.694)$ & $(0.464)$ & $(1.305)$ & $(1.245)$ & $(1.276)$ & $(1.234)$ & $(1.318)$ & $(1.550)$ \\
& $\{0.107\}$ & $\{0.105\}$ & $\{0.000\}$ & $\{-0.123\}$ & $\{-0.177\}$ & $\{-0.243\}$ & $\{-0.268\}$ & $\{-0.261\}$ \\
& {$[-0.002]$} & {$[-0.002]$} & {$[-0.014]$} & {$[0.001]$} & {$[0.017]$} & {$[0.044]$} & {$[0.055]$} & {$[0.052]$} \\
$n h e$ & -0.060 & 0.298 & 1.177 & 2.235 & 3.113 & 4.001 & 4.650 & 5.203 \\
& $(0.822)$ & $(1.373)$ & $(1.571)$ & $(1.663)$ & $(1.784)^{*}$ & $(1.815)^{* *}$ & $(1.922)^{* *}$ & $(2.151)^{* *}$ \\
& $\{-0.009\}$ & $\{0.032\}$ & $\{0.115\}$ & $\{0.215\}$ & $\{0.281\}$ & $\{0.357\}$ & $\{0.404\}$ & $\{0.421\}$ \\
& {$[-0.013]$} & {$[-0.013]$} & {$[-0.000]$} & {$[0.032]$} & {$[0.062]$} & {$[0.103]$} & {$[0.131]$} & {$[0.141]$} \\
\hline \hline
\end{tabular}

This table presents OLS beta parameter estimates for univariate regressions of excess returns on the new ratios. Excess returns are measured at annual frequencies for the period 1930-2005 and cumulated for up to 8 periods. In parentheses, below the parameter estimates, are Newey-West (1987) corrected standard errors, the $t / \sqrt{T}$ test of Valkanov (2003) in curly brackets, and adjusted $R^{2}$ statistics in square brackets. $r^{e m}$ is the $\log$ excess return on the CRSP VW portfolio, $c$ is log consumption, def is the default premium on bonds, $r t b$ is the relative t-bill rate, $p e$ is the log price-earnings ratio on the $\mathrm{S} \& \mathrm{P} 500, p d$ is the log price-dividend ratio on the CRSP value-weighted portfolio, $d e$ is the log dividend-earnings ratio on the $\mathrm{S} \& \mathrm{P} 500, y c_{1}$ is the $\log$ labour income-consumption ratio, $y c_{2}$ is the log compensation of employees-consumption ratio, $y c_{3}$ is the log labour income-compensation of employees ratio, and nhe is the log non-housing consumption share. $*-10 \%$ significance, $* *-5 \%$ significance. 
Table 26: Annual univariate long-horizon regressions, 1930-2005

\begin{tabular}{|c|c|c|c|c|c|c|c|c|}
\hline \multicolumn{9}{|c|}{ Horizon h (in years) } \\
\hline & 1 & 2 & 3 & 4 & 5 & 6 & 7 & 8 \\
\hline \multirow[t]{4}{*}{$\overline{l l r \_y}$} & 0.066 & -0.147 & -0.568 & -0.557 & -0.764 & -1.404 & -1.636 & -0.877 \\
\hline & $(0.476)$ & $(0.642)$ & (1.142) & (1.321) & (1.351) & $(1.264)$ & $(1.256)$ & $(1.326)$ \\
\hline & $\{0.015\}$ & $\{-0.024\}$ & $\{-0.084\}$ & $\{-0.074\}$ & $\{-0.092\}$ & $\{-0.160\}$ & $\{-0.179\}$ & $\{-0.089\}$ \\
\hline & {$[-0.014]$} & {$[-0.013]$} & {$[-0.007]$} & {$[-0.009]$} & {$[-0.006]$} & {$[0.011]$} & {$[0.017]$} & {$[-0.007]$} \\
\hline \multirow[t]{4}{*}{$l r_{-} \_c o m p$} & -0.634 & -0.165 & -0.367 & -0.903 & -1.503 & -1.797 & -2.082 & -1.066 \\
\hline & $(0.696)$ & $(1.104)$ & $(1.563)$ & (1.988) & $(1.722)$ & $(1.762)$ & $(1.807)$ & $(2.090)$ \\
\hline & $\{-0.107\}$ & $\{-0.021\}$ & $\{-0.041\}$ & $\{-0.090\}$ & $\{-0.136\}$ & $\{-0.152\}$ & $\{-0.170\}$ & $\{-0.081\}$ \\
\hline & {$[-0.002]$} & {$[-0.014]$} & {$[-0.013]$} & {$[-0.006]$} & {$[0.004]$} & {$[0.009]$} & {$[0.014]$} & {$[-0.009]$} \\
\hline \multirow[t]{4}{*}{$y \_l d$} & -0.000 & 0.018 & 0.051 & 0.100 & 0.134 & 0.162 & 0.174 & 0.186 \\
\hline & $(0.041)$ & $(0.069)$ & $(0.079)$ & $(0.080)$ & $(0.083)$ & $(0.087)^{*}$ & $(0.097)^{*}$ & $(0.112)^{*}$ \\
\hline & $\{-0.000\}$ & $\{0.045\}$ & $\{0.115\}$ & $\{0.219\}$ & $\{0.274\}$ & $\{0.321\}$ & $\{0.323\}$ & $\{0.315\}$ \\
\hline & {$[-0.014]$} & {$[-0.012]$} & {$[-0.000]$} & [0.033] & [0.058] & [0.083] & [0.084] & {$[0.079]$} \\
\hline \multirow[t]{4}{*}{$y \_l s$} & 0.140 & 0.286 & 0.367 & 0.447 & 0.538 & 0.603 & 0.680 & 0.796 \\
\hline & $(0.043)^{* *}$ & $(0.077)^{* *}$ & $(0.095)^{* *}$ & $(0.103)^{* *}$ & $(0.109)^{* *}$ & $(0.129)^{* *}$ & $(0.156)^{* *}$ & $(0.173)^{* *}$ \\
\hline & $\{0.274\}$ & $\{0.400\}$ & $\{0.486\}$ & $\{0.599\}$ & $\{0.688\}$ & $\{0.751\}$ & $\{0.791\}$ & $\{0.855\}$ \\
\hline & {$[0.059]$} & {$[0.130]$} & {$[0.184]$} & {$[0.259]$} & {$[0.318]$} & {$[0.358]$} & {$[0.383]$} & {$[0.421]$} \\
\hline \multirow[t]{4}{*}{ mymo_dls } & 0.058 & 0.084 & 0.057 & 0.037 & 0.071 & 0.117 & 0.198 & 0.287 \\
\hline & $(0.102)$ & $(0.165)$ & $(0.177)$ & $(0.163)$ & $(0.159)$ & $(0.162)$ & $(0.168)$ & $(0.182)$ \\
\hline & $\{0.100\}$ & $\{0.102\}$ & $\{0.063\}$ & $\{0.039\}$ & $\{0.071\}$ & $\{0.113\}$ & $\{0.184\}$ & $\{0.252\}$ \\
\hline & {$[-0.003]$} & {$[-0.003]$} & {$[-0.010]$} & {$[-0.012]$} & {$[-0.009]$} & {$[-0.001]$} & {$[0.020]$} & {$[0.047]$} \\
\hline
\end{tabular}

This table presents OLS beta parameter estimates for univariate regressions of excess returns on variables based on cointegration relations. Excess returns are measured at annual frequencies for the period 19302005 and cumulated for up to 8 periods. In parentheses, below the parameter estimates, are Newey-West (1987) corrected standard errors, the $t / \sqrt{T}$ test of Valkanov (2003) in curly brackets, and adjusted $R^{2}$ statistics in square brackets. $d l s$ implies that the relation has been computed by dynamic least squares. $l r_{-} y$ is the long-run labor income growth relation of Julliard (2005) computed using log labour income and $l r_{\_} c o m p$ is the same relation using log compensation of employees instead of log labour income. $y_{-} l d$ is based on a cointegration relation between labour income and dividends and $y \_l s$ is the cointegration relation between labour income and the log level of the CRSP value-weighted stock index. mymo is a housing collateral measure developed from a cointegration relation between aggregate labor income and the value of outstanding mortgages in the US. $*-10 \%$ significance, $* *-5 \%$ significance. 
Table 27: Implied long-horizon $R^{2}$, 1926Q4-2005Q4 and 1947Q2-2005Q4

\begin{tabular}{lrrrrrrrr}
\hline \hline \multicolumn{7}{c}{ Horizon h (in quarters) } \\
\hline \hline$\Delta c$ & 1 & 2 & 4 & 8 & 16 & 24 & 36 & 48 \\
\hline def & 0.006 & 0.005 & 0.003 & 0.001 & 0.001 & 0.000 & 0.000 & 0.000 \\
$r t b$ & 0.003 & 0.005 & 0.009 & 0.013 & 0.016 & 0.015 & 0.013 & 0.010 \\
$p e$ & 0.033 & 0.043 & 0.043 & 0.029 & 0.016 & 0.010 & 0.007 & 0.005 \\
$p d$ & 0.024 & 0.046 & 0.085 & 0.153 & 0.252 & 0.313 & 0.351 & 0.350 \\
$d e$ & 0.010 & 0.018 & 0.034 & 0.062 & 0.109 & 0.145 & 0.180 & 0.197 \\
$p y$ & 0.002 & 0.003 & 0.006 & 0.011 & 0.018 & 0.022 & 0.026 & 0.027 \\
$p c$ & 0.005 & 0.010 & 0.021 & 0.044 & 0.088 & 0.132 & 0.194 & 0.253 \\
$y c_{1}$ & 0.005 & 0.010 & 0.023 & 0.047 & 0.095 & 0.141 & 0.206 & 0.266 \\
$y c_{2}$ & 0.010 & 0.018 & 0.033 & 0.054 & 0.074 & 0.079 & 0.076 & 0.068 \\
$y c_{3}$ & 0.021 & 0.039 & 0.071 & 0.115 & 0.161 & 0.176 & 0.176 & 0.166 \\
nhe & 0.006 & 0.011 & 0.020 & 0.036 & 0.054 & 0.062 & 0.066 & 0.064 \\
$l r_{-} y$ & 0.002 & 0.001 & 0.002 & 0.003 & 0.005 & 0.007 & 0.008 & 0.008 \\
$l r_{-}$comp. & 0.002 & 0.001 & 0.000 & 0.000 & 0.000 & 0.000 & 0.000 & 0.000 \\
$y \_l d$ & 0.000 & 0.006 & 0.004 & 0.002 & 0.001 & 0.001 & 0.000 & 0.000 \\
$y \_l s$ & 0.012 & 0.025 & 0.054 & 0.108 & 0.198 & 0.263 & 0.319 & 0.336 \\
\hline \hline
\end{tabular}

This table presents implied h-period $R^{2}$ statistics from first order vector autoregressions (VAR) run on $r^{e m}$ and the respective predictor variable. Estimates for the variables def, pe, $p d$, and de are based on quarterly data for the period 1926Q3-2005Q3. The remaining VAR's are run on data covering the period 1947Q1-2005Q3.

Table 28: Implied long-horizon $R^{2}, 1930-2005$

\begin{tabular}{lrrrrrrrr}
\hline \hline & \multicolumn{1}{c}{ Horizon h (in years) } \\
\hline & 1 & 2 & 3 & 4 & 5 & 6 & 7 & 8 \\
\hline \hline$\Delta c$ & 0.011 & 0.013 & 0.011 & 0.009 & 0.007 & 0.006 & 0.005 & 0.004 \\
$d e f$ & 0.008 & 0.016 & 0.022 & 0.027 & 0.029 & 0.029 & 0.029 & 0.027 \\
$p e$ & 0.087 & 0.176 & 0.278 & 0.375 & 0.458 & 0.523 & 0.572 & 0.604 \\
$p d$ & 0.052 & 0.100 & 0.153 & 0.203 & 0.248 & 0.288 & 0.323 & 0.352 \\
$d e$ & 0.011 & 0.007 & 0.006 & 0.005 & 0.004 & 0.004 & 0.003 & 0.003 \\
$p y$ & 0.006 & 0.017 & 0.029 & 0.042 & 0.056 & 0.070 & 0.085 & 0.100 \\
$p c$ & 0.004 & 0.012 & 0.021 & 0.031 & 0.041 & 0.052 & 0.063 & 0.074 \\
$y c_{1}$ & 0.004 & 0.007 & 0.010 & 0.012 & 0.014 & 0.016 & 0.017 & 0.018 \\
$y c_{2}$ & 0.004 & 0.007 & 0.009 & 0.011 & 0.013 & 0.015 & 0.016 & 0.017 \\
$y c_{3}$ & 0.003 & 0.005 & 0.006 & 0.008 & 0.009 & 0.010 & 0.011 & 0.012 \\
nhe & 0.000 & 0.000 & 0.000 & 0.000 & 0.000 & 0.000 & 0.000 & 0.000 \\
$l r_{-} y$ & 0.000 & 0.000 & 0.000 & 0.000 & 0.000 & 0.000 & 0.000 & 0.000 \\
$l r_{-}$comp. & 0.010 & 0.007 & 0.005 & 0.004 & 0.003 & 0.002 & 0.002 & 0.002 \\
y_ld & 0.000 & 0.000 & 0.000 & 0.000 & 0.000 & 0.000 & 0.000 & 0.000 \\
y_ls & 0.073 & 0.154 & 0.245 & 0.332 & 0.409 & 0.472 & 0.523 & 0.560 \\
mymo_dls & 0.005 & 0.009 & 0.012 & 0.015 & 0.017 & 0.019 & 0.021 & 0.023 \\
\hline \hline
\end{tabular}

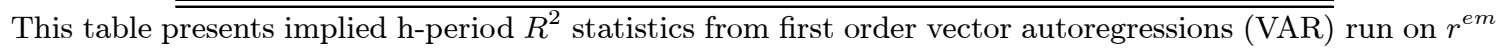
and the respective predictor variable. Data is annual for the period 1929 to 2004 . 
Table 29: Quarterly univariate long-horizon regressions, 1952Q1-1994Q4

\begin{tabular}{|c|c|c|c|c|c|c|c|c|}
\hline \multicolumn{9}{|c|}{ 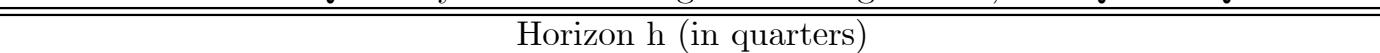 } \\
\hline & 1 & 2 & 4 & 8 & 16 & 24 & 36 & 48 \\
\hline \multirow[t]{4}{*}{$\bar{r}^{e m}$} & 0.089 & -0.025 & -0.120 & -0.426 & -0.272 & -0.162 & 0.125 & -0.110 \\
\hline & $(0.067)$ & $(0.111)$ & $(0.149)$ & $(0.148)^{* *}$ & $(0.210)$ & $(0.273)$ & $(0.369)$ & $(0.425)$ \\
\hline & $\{0.127\}$ & $\{-0.017\}$ & $\{-0.060\}$ & $\{-0.171\}$ & $\{-0.094\}$ & $\{-0.043\}$ & $\{0.026\}$ & $\{-0.020\}$ \\
\hline & {$[0.002]$} & {$[-0.006]$} & {$[-0.002]$} & {$[0.023]$} & [0.003] & {$[-0.005]$} & {$[-0.007]$} & {$[-0.008]$} \\
\hline \multirow[t]{4}{*}{$\Delta c$} & -1.323 & -1.544 & -6.765 & -10.898 & -8.621 & -19.555 & -21.273 & -30.385 \\
\hline & $(1.305)$ & $(2.558)$ & $(3.154)^{* *}$ & $(5.541)^{*}$ & $(4.829)^{*}$ & $(6.558)^{* *}$ & $(7.921)^{* *}$ & $(7.949)^{* *}$ \\
\hline & $\{-0.079\}$ & $\{-0.062\}$ & $\{-0.206\}$ & $\{-0.266\}$ & $\{-0.176\}$ & $\{-0.312\}$ & $\{-0.279\}$ & $\{-0.367\}$ \\
\hline & {$[0.000]$} & {$[-0.002]$} & [0.035] & [0.061] & [0.024] & {$[0.083]$} & {$[0.067]$} & [0.113] \\
\hline \multirow[t]{4}{*}{ def } & 8.842 & 13.202 & 12.839 & -7.392 & -2.790 & 22.926 & 50.470 & 80.949 \\
\hline & $(6.623)$ & $(11.562)$ & $(18.155)$ & $(20.000)$ & $(31.372)$ & $(33.319)$ & $(44.718)$ & $(49.996)$ \\
\hline & $\{0.121\}$ & $\{0.123\}$ & $\{0.088\}$ & $\{-0.040\}$ & $\{-0.013\}$ & $\{0.085\}$ & $\{0.156\}$ & $\{0.218\}$ \\
\hline & {$[0.009]$} & {$[0.009]$} & {$[0.002]$} & {$[-0.005]$} & {$[-0.006]$} & {$[0.000]$} & {$[0.017]$} & {$[0.038]$} \\
\hline \multirow[t]{4}{*}{$r t b$} & -10.298 & -16.925 & -29.217 & -16.717 & -13.994 & -13.786 & -20.637 & -19.161 \\
\hline & $(2.675)^{* *}$ & $(5.074)^{* *}$ & $(9.840)^{* *}$ & $(9.701)^{*}$ & (13.021) & (14.075) & (17.836) & (19.947) \\
\hline & $\{-0.260\}$ & $\{-0.291\}$ & $\{-0.383\}$ & $\{-0.165\}$ & $\{-0.117\}$ & $\{-0.089\}$ & $\{-0.110\}$ & $\{-0.090\}$ \\
\hline & [0.059] & [0.074] & [0.124] & {$[0.021]$} & {$[0.007]$} & [0.001] & [0.005] & {$[0.000]$} \\
\hline \multirow[t]{4}{*}{$p e$} & -0.030 & -0.064 & -0.120 & -0.185 & -0.251 & -0.450 & -0.688 & -0.906 \\
\hline & $(0.019)$ & $(0.035)^{*}$ & $(0.056)^{* *}$ & $(0.078)^{* *}$ & $(0.085)^{* *}$ & $(0.117)^{* *}$ & $(0.135)^{* *}$ & $(0.136)^{* *}$ \\
\hline & $\{-0.119\}$ & $\{-0.174\}$ & $\{-0.241\}$ & $\{-0.296\}$ & $\{-0.352\}$ & $\{-0.522\}$ & $\{-0.732\}$ & $\{-0.925\}$ \\
\hline & {$[0.008]$} & {$[0.024]$} & {$[0.050]$} & {$[0.076]$} & {$[0.106]$} & {$[0.211]$} & {$[0.347]$} & {$[0.461]$} \\
\hline \multirow{4}{*}{$p d$} & -0.079 & -0.170 & -0.324 & -0.558 & -0.756 & -1.096 & -1.516 & -1.762 \\
\hline & $(0.026)$ & $(0.052)^{* *}$ & $(0.088)^{* *}$ & $(0.147)^{* *}$ & $(0.148)^{* *}$ & $(0.181)^{* *}$ & $(0.168)^{* *}$ & $(0.154)^{* *}$ \\
\hline & $\{-0.214\}$ & $\{-0.318\}$ & $\{-0.466\}$ & $\{-0.672\}$ & $\{-0.834\}$ & $\{-1.052\}^{* *}$ & $\{-1.435\}^{* *}$ & $\{-1.804\}^{* *}$ \\
\hline & {$[0.038]$} & {$[0.087]$} & {$[0.175]$} & {$[0.309]$} & {$[0.409]$} & {$[0.526]$} & {$[0.674]$} & {$[0.766]$} \\
\hline \multirow[t]{4}{*}{$d e$} & 0.057 & 0.089 & 0.136 & 0.194 & 0.122 & 0.043 & -0.270 & -0.760 \\
\hline & $(0.040)$ & $(0.074)$ & $(0.119)$ & $(0.138)$ & $(0.240)$ & $(0.286)$ & $(0.368)$ & $(0.437)^{*}$ \\
\hline & $\{0.104\}$ & $\{0.112\}$ & $\{0.127\}$ & $\{0.142\}$ & $\{0.069\}$ & $\{0.018\}$ & $\{-0.095\}$ & $\{-0.249\}$ \\
\hline & {$[0.005]$} & {$[0.007]$} & {$[0.019]$} & {$[0.014]$} & {$[-0.002]$} & {$[-0.006]$} & {$[0.002]$} & {$[0.051]$} \\
\hline
\end{tabular}

This table presents OLS beta parameter estimates for univariate regressions of excess returns on the traditional predictor variables. Excess returns are measured at quarterly frequencies for the period 1952Q11994Q4 and cumulated for up to 48 periods. In parentheses, below the parameter estimates, are NeweyWest (1987) corrected standard errors, the $t / \sqrt{T}$ test of Valkanov (2003) in curly brackets, and adjusted $R^{2}$ statistics in square brackets. $r^{e m}$ is the log excess return on the CRSP VW portfolio, $c$ is log consumption, def is the default premium on bonds, $r t b$ is the relative t-bill rate, $p e$ is the log price-earnings ratio on the $\mathrm{S} \& \mathrm{P} 500, p d$ is the log price-dividend ratio on the CRSP value-weighted portfolio, and de is the $\log$ dividend-earnings ratio on the $\mathrm{S} \& \mathrm{P} 500 . *-10 \%$ significance, $* *-5 \%$ significance. 
Table 30: Quarterly univariate long-horizon regressions, 1952Q1-1994Q4

\begin{tabular}{|c|c|c|c|c|c|c|c|c|}
\hline \multicolumn{9}{|c|}{ Horizon h (in quarters) } \\
\hline & 1 & 2 & 4 & 8 & 16 & 24 & 36 & 48 \\
\hline \multirow[t]{4}{*}{$p y$} & -0.032 & -0.068 & -0.134 & -0.257 & -0.417 & -0.693 & -1.139 & -1.427 \\
\hline & $(0.014)^{* *}$ & $(0.028)^{* *}$ & $(0.050)^{* *}$ & $(0.079)^{* *}$ & $(0.090)^{* *}$ & $(0.131)^{* *}$ & $(0.114)^{* *}$ & \\
\hline & $\{-0.143\}$ & $\{-0.207\}$ & $\{-0.307\}$ & $\{-0.468\}$ & $\{-0.653\}$ & $\{-0.880\}$ & $\{-1.431\}^{* *}$ & $\{-2.460\}^{* *}$ \\
\hline & [0.015] & [0.036] & [0.082] & [0.177] & [0.297] & {$[0.436]$} & {$[0.673]$} & [0.859] \\
\hline \multirow[t]{4}{*}{$p c$} & -0.035 & -0.075 & -0.146 & -0.272 & -0.435 & -0.719 & -1.167 & -1.434 \\
\hline & $(0.015)$ & $(0.029)^{* *}$ & $(0.051)^{* *}$ & $(0.080)^{* *}$ & $(0.089)^{* *}$ & $(0.131)^{* *}$ & $(0.111)^{* *}$ & $(0.058)^{* *}$ \\
\hline & $\{-0.157\}$ & $\{-0.226\}$ & $\{-0.329\}$ & $\{-0.491\}$ & $\{-0.685\}$ & $\{-0.931\}$ & $\{-1.533\}^{* *}$ & $\{-2.542\}^{* *}$ \\
\hline & {$[0.019]$} & {$[0.044]$} & {$[0.093]$} & {$[0.191]$} & {$[0.318]$} & {$[0.464]$} & {$[0.702]$} & {$[0.867]$} \\
\hline \multirow[t]{4}{*}{$y c_{1}$} & -0.346 & -0.605 & -1.083 & -2.012 & -3.231 & -3.352 & -2.550 & -0.816 \\
\hline & $(0.183)^{*}$ & $(0.360)^{*}$ & $(0.637)^{*}$ & $(0.803)^{* *}$ & $(0.863)^{* *}$ & $(1.047)^{* *}$ & $(1.512)^{*}$ & $(1.9$ \\
\hline & $\{-0.146\}$ & $\{-0.173\}$ & $\{-0.233\}$ & $\{-0.357\}$ & $\{-0.536\}^{*}$ & $\{-0.414\}$ & $\{-0.250\}$ & $\{-0.070\}$ \\
\hline & [0.015] & [0.024] & [0.046] & [0.109] & {$[0.220]$} & {$[0.142]$} & [0.053] & {$[-0.003]$} \\
\hline \multirow[t]{4}{*}{$y c_{2}$} & -0.510 & -0.927 & -1.474 & -2.314 & -4.103 & -4.810 & -4.270 & -2.180 \\
\hline & $(0.196)^{* *}$ & $(0.388)^{* *}$ & $(0.706)^{* *}$ & $(0.896)^{* *}$ & $(0.877)^{* *}$ & $(1.274)^{* *}$ & $(1.668)^{* *}$ & (1.97 \\
\hline & $\{-0.204\}$ & $\{-0.253\}$ & $\{-0.299\}$ & $\{-0.375\}$ & $\{-0.630\}$ & $\{-0.557\}$ & $\{-0.387\}$ & $\{-0.171\}$ \\
\hline & {$[0.035]$} & {$[0.055]$} & {$[0.077]$} & {$[0.119]$} & {$[0.282]$} & {$[0.234]$} & {$[0.126]$} & {$[0.021]$} \\
\hline \multirow[t]{4}{*}{$y c_{3}$} & -0.442 & -0.868 & -1.798 & -3.653 & -6.150 & -7.658 & -7.268 & -4.555 \\
\hline & $(0.280)$ & $(0.509)^{*}$ & $(0-909)^{* *}$ & $(1.343)^{* *}$ & $(1.499)^{* *}$ & $(1.996)^{* *}$ & $(2.814)^{* *}$ & (3.906) \\
\hline & $\{-0.117\}$ & $\{-0.156\}$ & $\{-0.244\}$ & $\{-0.414\}$ & $\{-0.671\}^{* *}$ & $\{-0.593\}^{*}$ & $\{-0.420\}$ & $\{-0.217\}$ \\
\hline & {$[0.008]$} & {$[0.018]$} & {$[0.051]$} & {$[0.143]$} & {$[0.308]$} & {$[0.258]$} & {$[0.146]$} & {$[0.038]$} \\
\hline \multirow[t]{4}{*}{ nhe } & 0.364 & 0.710 & 1.355 & 2.964 & 4.906 & 5.062 & 5.440 & 5.543 \\
\hline & & & $(1.278)$ & $(1.777)^{*}$ & $(2.130)^{* *}$ & $(2.874)^{*}$ & (3.799) & $(5.360)$ \\
\hline & $\{-0.071\}$ & $\{0.093\}$ & $\{0.133\}$ & $\{0.235\}$ & $\{0.348\}$ & $\{0.272\}$ & $\{0.236\}$ & $\{0.209\}$ \\
\hline & {$[-0.001]$} & {$[0.003]$} & {$[0.012]$} & {$[0.047]$} & [0.103] & {$[0.063]$} & {$[0.046]$} & [0.035] \\
\hline
\end{tabular}

This table presents OLS beta parameter estimates for univariate regressions of excess returns on the new ratios. Excess returns are measured at quarterly frequencies for the period 1952Q1-1994Q4 and cumulated for up to 48 periods. In parentheses, below the parameter estimates, are Newey-West (1987) corrected standard errors, the $t / \sqrt{T}$ test of Valkanov (2003) in curly brackets, and adjusted $R^{2}$ statistics in square brackets. $\quad p y$ is the $\log$ price-output ratio, $p c$ is the $\log$ price-consumption ratio, $y c_{1}$ is the $\log \operatorname{labour}$ income-consumption ratio, $y c_{2}$ is the log compensation of employees-consumption ratio, $y c_{3}$ is the $\log$ labour income-compensation of employees ratio, and nhe is the log non-housing consumption share. $*-10 \%$ significance, $* *-5 \%$ significance. 
Table 31: Quarterly univariate long-horizon regressions, 1952Q1-1994Q4

\begin{tabular}{|c|c|c|c|c|c|c|c|c|}
\hline \multicolumn{9}{|c|}{ Horizon h (in quarters) } \\
\hline & 1 & 2 & 4 & 8 & 16 & 24 & 36 & 48 \\
\hline \multirow[t]{4}{*}{$\overline{c \text { cay_dls }}$} & 1.967 & 3.921 & 7.058 & 10.777 & 11.011 & 16.348 & 18.976 & 17.113 \\
\hline & $(0.452)^{* *}$ & $(0.878)^{* *}$ & $(1.449)^{* *}$ & $(1.700)^{* *}$ & $(1.604)^{* *}$ & $(2.737)^{* *}$ & $(2.919)^{* *}$ & $(3.773)^{* *}$ \\
\hline & $\{0.324\}$ & $\{0.455\}$ & $\{0.655\}^{*}$ & $\{0.887\}^{* *}$ & $\{0.731\}^{* *}$ & $\{0.903\}^{* *}$ & $\{0.828\}^{* *}$ & $\{0.589\}$ \\
\hline & {$[0.091]$} & [0.168] & {$[0.299]$} & {$[0.440]$} & {$[0.347]$} & {$[0.449]$} & {$[0.406]$} & {$[0.255]$} \\
\hline \multirow[t]{4}{*}{$c d y \_d l s$} & 0.627 & 1.024 & 1.659 & 3.925 & 7.280 & 10.850 & 14.362 & 14.609 \\
\hline & $(0.386)$ & $(0.711)$ & (1.269) & $(1.898)^{* *}$ & $(2.038)^{* *}$ & $(3.030)^{* *}$ & $(3.501)^{* *}$ & $(3.882)^{* *}$ \\
\hline & $\{0.114\}$ & $\{0.126\}$ & $\{0.149\}$ & $\{0.285\}$ & $\{0.497\}$ & $\{0.603\}$ & $\{0.693\}$ & $\{0.622\}$ \\
\hline & {$[0.007]$} & {$[0.010]$} & {$[0.016]$} & {$[0.070]$} & {$[0.195]$} & {$[0.264]$} & {$[0.323]$} & {$[0.276]$} \\
\hline \multirow[t]{4}{*}{$l r \_y$} & -9.167 & -11.457 & -23.541 & -34.535 & -34.167 & -56.540 & -76.478 & -89.215 \\
\hline & $(4.898)^{*}$ & $(7.775)$ & $(10.323)^{* *}$ & $(17.527)^{*}$ & $(16.295)^{* *}$ & $(21.909)^{* *}$ & $(28.729)^{* *}$ & $(32.722)^{* *}$ \\
\hline & $\{-0.165\}$ & $\{-0.139\}$ & $\{-0.213\}$ & $\{-0.242\}$ & $\{-0.207\}$ & $\{-0.267\}$ & $\{-0.302\}$ & $\{-0.320\}$ \\
\hline & {$[0.021]$} & {$[0.013]$} & {$[0.038]$} & {$[0.050]$} & {$[0.035]$} & {$[0.061]$} & {$[0.078]$} & {$[0.087]$} \\
\hline \multirow[t]{4}{*}{$l r_{-} c o m p$. } & -2.325 & -4.338 & -8.872 & -10.673 & -8.514 & -16.296 & -17.192 & -23.103 \\
\hline & $(1.043)^{* *}$ & $(1.679)^{* *}$ & $(2.354)^{*}$ & $(4.286)^{* *}$ & $(4.859)^{*}$ & $(6.283)^{* *}$ & $(8.036)^{* *}$ & $(9.030)^{* *}$ \\
\hline & $\{-0.161\}$ & $\{-0.205\}$ & $\{-0.317\}$ & $\{-0.291\}$ & $\{-0.196\}$ & $\{-0.294\}$ & $\{-0.257\}$ & $\{-0.319\}$ \\
\hline & {$[0.020]$} & {$[0.035]$} & {$[0.087]$} & {$[0.073]$} & {$[0.031]$} & {$[0.075]$} & {$[0.056]$} & {$[0.087]$} \\
\hline \multirow[t]{4}{*}{$y \_l d$} & 0.011 & 0.022 & 0.047 & 0.104 & 0.197 & 0.344 & 0.635 & 1.072 \\
\hline & $(0.016)$ & $(0.031)$ & $(0.057)$ & (0.091) & $(0.126)$ & $(0.186)^{*}$ & $(0.297)^{* *}$ & $(0.403)^{* *}$ \\
\hline & $\{0.046\}$ & $\{0.062\}$ & $\{0.096\}$ & $\{0.163\}$ & $\{0.252\}$ & $\{0.302\}$ & $\{0.401\}$ & $\{0.579\}$ \\
\hline & {$[-0.004]$} & {$[-0.002]$} & {$[0.003]$} & {$[0.020]$} & {$[0.054]$} & {$[0.079]$} & {$[0.134]$} & {$[0.248]$} \\
\hline \multirow[t]{4}{*}{$y \_l s$} & 0.031 & 0.068 & 0.125 & 0.202 & 0.255 & 0.449 & 0.700 & 0.934 \\
\hline & $(0.019)$ & $(0.035)^{*}$ & $(0.053)^{* *}$ & $(0.080)^{* *}$ & $(0.095)^{* *}$ & $(0.138)^{* *}$ & $(0.143)^{* *}$ & $(0.135)^{* *}$ \\
\hline & $\{0.115\}$ & $\{0.174\}$ & $\{0.240\}$ & $\{0.314\}$ & $\{0.351\}$ & $\{0.511\}$ & $\{0.739\}$ & $\{1.013\}^{* *}$ \\
\hline & {$[0.007]$} & {$[0.024]$} & {$[0.050]$} & {$[0.085]$} & {$[0.105]$} & {$[0.204]$} & {$[0.352]$} & {$[0.507]$} \\
\hline
\end{tabular}

This table presents OLS beta parameter estimates for univariate regressions of excess returns on variables based on cointegration relations. Excess returns are measured at quarterly frequencies for the period 1952Q1-1994Q4 and cumulated for up to 48 periods. In parentheses, below the parameter estimates, are Newey-West (1987) corrected standard errors, the $t / \sqrt{T}$ test of Valkanov (2003) in curly brackets, and adjusted $R^{2}$ statistics in square brackets. cay is the approximate consumption-aggregate wealth ratio, $c d y$ is the cointegration relation between consumption, dividends and labour income. $d l s$ implies that the relation has been computed by dynamic least squares. $l r_{-} y$ is the long-run labour income growth relation of Julliard (2005) computed using log labour income and $l r_{-}$comp is the same relation using log compensation of employees instead of log labour income. $y_{-} l d$ is based on a cointegration relation between labour income and dividends and $y \_l s$ is the cointegration relation between labour income and the log level of the CRSP value-weighted stock index. $*-10 \%$ significance, $* *-5 \%$ significance. 
Table 32: Annual univariate long-horizon regressions, 1946-1994

\begin{tabular}{|c|c|c|c|c|c|c|c|c|}
\hline \multicolumn{9}{|c|}{ Horizon h (in years) } \\
\hline & 1 & 2 & 3 & 4 & 5 & 6 & 7 & 8 \\
\hline \multirow[t]{4}{*}{$\overline{r^{e m}}$} & $\begin{array}{l}-0.109 \\
\end{array}$ & $\begin{array}{l}-0.382 \\
\end{array}$ & -0.269 & $\overline{0.089}$ & $\overline{0.163}$ & 0.035 & $\overline{0.120}$ & $\overline{0.143}$ \\
\hline & $(0.128)$ & $(0.099)^{* *}$ & $(0.097)^{* *}$ & $(0.206)$ & $(0.273)$ & $(0.247)$ & $(0.216)$ & $(0.286)$ \\
\hline & $\{-0.110\}$ & $\{-0.300\}$ & $\{-0.192\}$ & $\{0.056\}$ & $\{0.083\}$ & $\{0.015\}$ & $\{0.048\}$ & $\{0.053\}$ \\
\hline & {$[-0.009]$} & {$[0.065]$} & {$[0.016]$} & {$[-0.019]$} & {$[-0.016]$} & {$[-0.024]$} & {$[-0.022]$} & {$[-0.022]$} \\
\hline \multirow[t]{4}{*}{$\Delta c$} & -3.373 & -5.357 & -4.712 & -5.274 & -7.727 & -8.775 & -10.872 & -9.700 \\
\hline & $(1.772)^{*}$ & $(2.453)^{* *}$ & $(1.977)^{* *}$ & $(2.402)^{* *}$ & $(3.875)^{*}$ & $(4.917)^{*}$ & $(4.906)^{* *}$ & $(5.864)$ \\
\hline & $\{-0.302\}$ & $\{-0.363\}$ & $\{-0.292\}$ & $\{-0.283\}$ & $\{-0.347\}$ & $\{-0.341\}$ & $\{-0.369\}$ & $\{-0.318\}$ \\
\hline & {$[0.068]$} & {$[0.102]$} & {$[0.062]$} & {$[0.056]$} & {$[0.092]$} & {$[0.088]$} & {$[0.121]$} & {$[0.073]$} \\
\hline \multirow[t]{4}{*}{ def } & 0.278 & -7.107 & -10.735 & -11.063 & -9.544 & -11.479 & -10.014 & -10.445 \\
\hline & $(3.573)$ & $(5.008)$ & $(8.240)$ & $(10.544)$ & $(12.066)$ & $(14.144)$ & $(16.536)$ & $(19.524)$ \\
\hline & $\{0.007\}$ & $\{-0.137\}$ & $\{-0.196\}$ & $\{-0.181\}$ & $\{-0.128\}$ & $\{-0.133\}$ & $\{-0.107\}$ & $\{-0.102\}$ \\
\hline & {$[-0.021]$} & {$[-0.002]$} & {$[0.017]$} & {$[0.011]$} & {$[-0.006]$} & {$[-0.005]$} & {$[-0.012]$} & {$[-0.014]$} \\
\hline \multirow[t]{4}{*}{ pe } & -0.136 & -0.235 & -0.262 & -0.321 & -0.457 & -0.584 & -0.668 & -0.774 \\
\hline & $(0.051)^{* *}$ & $(0.108)^{* *}$ & $(0.133)^{*}$ & $(0.155)^{* *}$ & $(0.198)^{* *}$ & $(0.254)^{* *}$ & $(0.275)^{* *}$ & $(0.285)^{* *}$ \\
\hline & $\{-0.277\}$ & $\{-0.359\}$ & $\{-0.371\}$ & $\{-0.409\}$ & $\{-0.496\}$ & $\{-0.562\}$ & $\{-0.603\}$ & $\{-0.665\}$ \\
\hline & {$[0.055]$} & [0.100] & [0.106] & [0.130] & {$[0.186]$} & [0.231] & {$[0.258]$} & {$[0.300]$} \\
\hline \multirow[t]{4}{*}{$p d$} & -0.280 & -0.481 & -0.627 & -0.766 & -1.006 & -1.195 & -1.327 & -1.467 \\
\hline & $(0.074)^{* *}$ & $(0.140)^{* *}$ & $(0.148)^{* *}$ & $(0.152)^{* *}$ & $(0.179)^{* *}$ & $(0.212)^{* *}$ & $(0.214)^{* *}$ & $(0.204)^{* *}$ \\
\hline & $\{-0.479\}$ & $\{-0.634\}$ & $\{-0.836\}$ & $\{-0.973\}$ & $\{-1.151\}^{* *}$ & $\{-1.231\}^{* *}$ & $\{-1.313\}^{* *}$ & $\{-1.355\}^{* *}$ \\
\hline & {$[0.176]$} & {$[0.280]$} & {$[0.409]$} & {$[0.486]$} & {$[0.571]$} & {$[0.604]$} & {$[0.635]$} & {$[0.650]$} \\
\hline \multirow[t]{4}{*}{$d e$} & 0.035 & 0.017 & -0.032 & -0.018 & 0.091 & 0.036 & 0.004 & -0.004 \\
\hline & $(0.111)$ & $(0.161)$ & $(0.182)$ & $(0.256)$ & $(0.276)$ & $(0.322)$ & $(0.390)$ & $(0.414)$ \\
\hline & $\{0.034\}$ & $\{0.012\}$ & $\{-0.021\}$ & $\{-0.010\}$ & $\{0.041\}$ & $\{0.014\}$ & $\{0.002\}$ & $\{-0.001\}$ \\
\hline & {$[-0.020]$} & {$[-0.022]$} & {$[-0.022]$} & {$[-0.023]$} & {$[-0.021]$} & {$[-0.024]$} & {$[-0.024]$} & {$[-0.025]$} \\
\hline
\end{tabular}

This table presents OLS beta parameter estimates for univariate regressions of excess returns on the traditional predictor variables. Excess returns are measured at annual frequencies for the period 1946-1994 and cumulated for up to 8 periods. In parentheses, below the parameter estimates, are Newey-West (1987) corrected t-statistics, the $t / \sqrt{T}$ test of Valkanov (2003) in curly brackets, and adjusted $R^{2}$ statistics in square brackets. $r^{e m}$ is the log excess return on the CRSP VW portfolio, $c$ is $\log$ consumption, def is the default premium on bonds, $p e$ is the log price-earnings ratio on the $\mathrm{S} \& \mathrm{P} 500$, and $p d$ is the log price-dividend ratio on the CRSP value-weighted portfolio, and de is the log dividend-earnings ratio on the S\&P 500 * $* 10 \%$ significance, $* *-5 \%$ significance. 
Table 33: Annual univariate long-horizon regressions, 1946-1994

\begin{tabular}{|c|c|c|c|c|c|c|c|c|}
\hline \multicolumn{9}{|c|}{ Horizon h (in years) } \\
\hline & 1 & 2 & 3 & 4 & 5 & 6 & 7 & 8 \\
\hline \multirow[t]{4}{*}{ py } & -0.085 & -0.176 & -0.251 & -0.350 & $\begin{array}{l}-0.487 \\
\end{array}$ & $\begin{array}{c}-0.620 \\
\end{array}$ & -0.727 & $\begin{array}{c}-0.837 \\
\end{array}$ \\
\hline & $(0.040)^{* *}$ & $(0.074)^{* *}$ & $(0.089)^{* *}$ & $(0.095)^{* *}$ & $(0.109)^{* *}$ & $(0.132)^{* *}$ & $(0.132)^{* *}$ & $(0.119)^{* *}$ \\
\hline & $\{-0.272\}$ & $\{-0.426\}$ & $\{-0.591\}$ & $\{-0.785\}$ & $\{-0.975\}^{*}$ & $\{-1.133\}^{* *}$ & $\{-1.322\}^{* *}$ & $\{-1.537\}^{* *}$ \\
\hline & {$[0.052]$} & {$[0.141]$} & {$[0.268]$} & {$[0.378]$} & {$[0.487]$} & {$[0.563]$} & {$[0.638]$} & {$[0.705]$} \\
\hline \multirow[t]{4}{*}{$p c$} & -0.088 & -0.181 & -0.257 & -0.355 & -0.492 & -0.624 & -0.730 & -0.839 \\
\hline & $(0.040)^{* *}$ & $(0.073)^{* *}$ & $(0.085)^{* *}$ & $(0.091)^{* *}$ & $(0.106)^{* *}$ & $(0.129)^{* *}$ & $(0.127)^{* *}$ & $(0.113)^{* *}$ \\
\hline & $\{-0.283\}$ & $\{-0.440\}$ & $\{-0.614\}$ & $\{-0.813\}$ & $\{-1.011\}^{*}$ & $\{-1.178\}^{* *}$ & $\{-1.378\}^{* *}$ & $\{-1.616\}^{* *}$ \\
\hline & {$[0.057]$} & {$[0.150]$} & {$[0.266]$} & {$[0.395]$} & {$[0.506]$} & {$[0.583]$} & {$[0.658]$} & {$[0.726]$} \\
\hline \multirow[t]{4}{*}{$y c_{1}$} & -0.855 & -1.754 & -2.709 & -3.419 & -3.872 & -4.391 & -4.863 & -5.181 \\
\hline & $(0.372)^{* *}$ & $(0.583)^{* *}$ & $(0.744)^{* *}$ & $(0.868)^{* *}$ & $(1.010)^{* *}$ & $(1.206)^{* *}$ & $(1.436)^{* *}$ & $(1.571)^{* *}$ \\
\hline & $\{-0.240\}$ & $\{-0.383\}$ & $\{-0.607\}^{*}$ & $\{-0.731\}^{* *}$ & $\{-0.660\}^{* *}$ & $\{-0.645\}^{*}$ & $\{-0.664\}^{* *}$ & $\{-0.647\}^{*}$ \\
\hline & {$[0.037]$} & {$[0.114]$} & {$[0.262]$} & {$[0.344]$} & {$[0.297]$} & {$[0.287]$} & {$[0.299]$} & {$[0.288]$} \\
\hline \multirow[t]{4}{*}{$y c_{2}$} & -0.876 & -1.633 & -2.516 & -3.417 & -4.114 & -4.607 & -5.024 & -5.521 \\
\hline & $(0.361)^{* *}$ & $(0.487)^{* *}$ & $(0.496)^{* *}$ & $(0.702)^{* *}$ & $(0.974)^{* *}$ & $(1.147)^{* *}$ & $(1.198)^{* *}$ & $(1.166)^{* *}$ \\
\hline & $\{-0.264\}$ & $\{-0.378\}$ & $\{-0.598\}^{* *}$ & $\{-0.805\}^{* *}$ & $\{-0.796\}^{* *}$ & $\{-0.760\}^{* *}$ & $\{-0.764\}^{* *}$ & $\{-0.782\}^{* *}$ \\
\hline & [0.048] & [0.111] & {$[0.255]$} & {$[0.390]$} & {$[0.385]$} & {$[0.362]$} & {$[0.365]$} & {$[0.376]$} \\
\hline \multirow[t]{4}{*}{$y c_{3}$} & -1.185 & -2.620 & -4.248 & -6.009 & -7.291 & -8.579 & -9.514 & -10.278 \\
\hline & $(0.625)^{*}$ & $(1.128)^{* *}$ & $(1.460)^{* *}$ & $(1.730)^{* *}$ & $(1.939)^{* *}$ & $(2.132)^{* *}$ & $(2.273)^{* *}$ & $(2.408)^{* *}$ \\
\hline & $\{-0.208\}$ & $\{-0.356\}$ & $\{-0.597\}^{*}$ & $\{-0.863\}^{* *}$ & $\{-0.853\}^{* *}$ & $\{-0.871\}^{* *}$ & $\{-0.901\}^{* *}$ & $\{-0.897\}^{* *}$ \\
\hline & {$[0.023]$} & {$[0.098]$} & {$[0.255]$} & {$[0.425]$} & {$[0.419]$} & {$[0.429]$} & {$[0.447]$} & {$[0.444]$} \\
\hline \multirow[t]{4}{*}{ nhe } & -0.744 & 1.915 & 3.334 & 4.887 & 6.470 & 7.700 & 8.835 & 10.118 \\
\hline & $(0.759)$ & $(1.271)$ & $(1.604)^{* *}$ & $(1.750)^{* *}$ & $(1.973)^{* *}$ & $(2.282)^{* *}$ & $(2.639)^{* *}$ & $(2.956)^{* *}$ \\
\hline & $\{0.115\}$ & $\{0.224\}$ & $\{0.381\}$ & $\{0.527\}^{*}$ & $\{0.588\}^{* *}$ & $\{0.609\}^{* *}$ & $\{0.653\}^{* *}$ & $\{0.701\}^{* *}$ \\
\hline & {$[-0.007]$} & {$[0.029]$} & {$[0.112]$} & {$[0.208]$} & {$[0.249]$} & {$[0.263]$} & {$[0.292]$} & {$[0.324]$} \\
\hline
\end{tabular}

This table presents OLS beta parameter estimates for univariate regressions of excess returns on the new ratios. Excess returns are measured at annual frequencies for the period 1946-1994 and cumulated for up to 8 periods. In parentheses, below the parameter estimates, are Newey-West (1987) corrected standard errors, the $t / \sqrt{T}$ test of Valkanov (2003) in curly brackets, and adjusted $R^{2}$ statistics in square brackets. $p y$ is the $\log$ price-output ratio, $p c$ is the $\log$ price-consumption ratio, $y c_{1}$ is the log labour income-consumption ratio, $y c_{2}$ is the $\log$ compensation of employees-consumption ratio, $y c_{3}$ is the log labour income-compensation of employees ratio, and nhe is the log non-housing consumption share. $*-10 \%$ significance, $* *-5 \%$ significance. 
Table 34: Annual univariate long-horizon regressions, 1946-1994

\begin{tabular}{|c|c|c|c|c|c|c|c|c|}
\hline \multicolumn{9}{|c|}{ Horizon $\mathrm{h}$ (in years) } \\
\hline & 1 & 2 & 3 & 4 & 5 & 6 & 7 & 8 \\
\hline \multirow[t]{4}{*}{$\overline{c a y \_d l s}$} & 3.707 & 6.419 & 7.025 & 7.038 & 8.405 & 10.685 & 11.500 & 12.236 \\
\hline & $(1.400)^{* *}$ & $(2.280)^{* *}$ & $(1.871)^{* *}$ & $(1.721)^{* *}$ & $(2.930)^{* *}$ & $(4.392)^{* *}$ & $(4.611)^{* *}$ & $(3.886)^{* *}$ \\
\hline & $\{0.503\}^{*}$ & $\{0.710\}^{* *}$ & $\{0.739\}^{* *}$ & $\{0.631\}^{* *}$ & $\{0.605\}^{* *}$ & $\{0.697\}^{* *}$ & $\{0.689\}^{* *}$ & $\{0.672\}^{* *}$ \\
\hline & {$[0.192]$} & {$[0.330]$} & {$[0.349]$} & {$[0.278]$} & {$[0.260]$} & {$[0.322]$} & {$[0.316]$} & {$[0.304]$} \\
\hline \multirow[t]{4}{*}{$c d y \_d l s$} & 0.731 & 2.302 & 3.621 & 4.769 & 5.697 & 7.200 & 8.400 & 9.889 \\
\hline & $(0.494)$ & $(1.136)^{* *}$ & $(1.304)^{* *}$ & $(1.331)^{* *}$ & $(1.576)^{* *}$ & $(2.281)^{* *}$ & $(2.482)^{* *}$ & $(2.065)^{* *}$ \\
\hline & $\{0.130\}$ & $\{0.316\}$ & $\{0.498\}^{*}$ & $\{0.621\}^{* *}$ & $\{0.603\}^{* *}$ & $\{0.687\}^{* *}$ & $\{0.770\}^{* *}$ & $\{0.870\}^{* *}$ \\
\hline & {$[-0.004]$} & {$[0.075]$} & {$[0.188]$} & {$[0.271]$} & {$[0.258]$} & {$[0.315]$} & {$[0.368]$} & {$[0.429]$} \\
\hline \multirow[t]{4}{*}{$l r \_y$} & -0.960 & -1.262 & -2.067 & -4.694 & -6.898 & -9.328 & -11.105 & -12.568 \\
\hline & $(2.384)$ & $(2.858)$ & $(2.781)$ & $(3.175)$ & $(4.166)$ & $(4.692)^{*}$ & $(4.628)^{* *}$ & $(6.154)^{* *}$ \\
\hline & $\{-0.070\}$ & $\{-0.068\}$ & $\{-0.105\}$ & $\{-0.218\}$ & $\{-0.267\}$ & $\{-0.317\}$ & $\{-0.352\}$ & $\{-0.369\}$ \\
\hline & {$[-0.016]$} & {$[-0.017]$} & {$[-0.010]$} & {$[0.026]$} & {$[0.048]$} & {$[0.074]$} & [0.093] & {$[0.104]$} \\
\hline \multirow[t]{4}{*}{ lr_comp. } & -1.279 & -1.722 & -0.737 & -1.178 & -4.310 & -5.836 & -7.020 & -6.646 \\
\hline & $(1.784)$ & $(2.790)$ & $(2.184)$ & $(2.401)$ & $(3.300)$ & $(3.754)$ & $(3.014)^{* *}$ & $(5.220)$ \\
\hline & $\{-0.103\}$ & $\{-0.103\}$ & $\{-0.041\}$ & $\{-0.058\}$ & $\{-0.178\}$ & $\{-0.210\}$ & $\{-0.234\}$ & $\{-0.203\}$ \\
\hline & {$[-0.010]$} & {$[-0.011]$} & {$[-0.020]$} & {$[-0.019]$} & {$[0.010]$} & {$[0.022]$} & [0.031] & {$[0.018]$} \\
\hline \multirow[t]{4}{*}{$y \_l d$} & 0.033 & 0.095 & 0.155 & 0.243 & 0.356 & 0.465 & 0.577 & 0.685 \\
\hline & $(0.038)$ & $(0.069)$ & (0.093) & $(0.107)^{* *}$ & $(0.123)^{* *}$ & $(0.159)^{* *}$ & $(0.196)^{* *}$ & $(0.212)^{* *}$ \\
\hline & $\{0.097\}$ & $\{0.205\}$ & $\{0.314\}$ & $\{0.447\}$ & $\{0.547\}$ & $\{0.612\}^{*}$ & $\{0.700\}^{* *}$ & $\{0.792\}^{* *}$ \\
\hline & {$[-0.011]$} & {$[0.021]$} & {$[0.073]$} & {$[0.154]$} & {$[0.221]$} & {$[0.264]$} & {$[0.324]$} & {$[0.382]$} \\
\hline \multirow[t]{4}{*}{$y \_l s$} & 0.113 & 0.211 & 0.249 & 0.311 & 0.443 & 0.570 & 0.659 & 0.760 \\
\hline & $(0.042)^{* *}$ & $(0.088)^{* *}$ & $(0.116)^{* *}$ & $(0.138)^{* *}$ & $(0.177)^{* *}$ & $(0.227)^{* *}$ & $(0.252)^{* *}$ & $(0.258)^{* *}$ \\
\hline & $\{0.240\}$ & $\{0.343\}$ & $\{0.385\}$ & $\{0.441\}$ & $\{0.538\}$ & $\{0.624\}$ & $\{0.684\}$ & $\{0.752\}$ \\
\hline & {$[0.036]$} & {$[0.090]$} & {$[0.115]$} & {$[0.150]$} & {$[0.214]$} & {$[0.273]$} & {$[0.313]$} & {$[0.357]$} \\
\hline \multirow[t]{4}{*}{ mymo_dls } & 0.010 & 0.088 & 0.203 & 0.383 & 0.600 & 0.811 & 1.021 & 1.232 \\
\hline & $(0.072)$ & $(0.121)$ & $(0.168)$ & $(0.209)^{*}$ & $(0.267)^{* *}$ & $(0.329)^{* *}$ & $(0.384)^{* *}$ & $(0.423)^{* *}$ \\
\hline & $\{0.011\}$ & $\{0.076\}$ & $\{0.165\}$ & $\{0.289\}$ & $\{0.383\}$ & $\{0.461\}$ & $\{0.555\}^{*}$ & $\{0.640\}^{* *}$ \\
\hline & {$[-0.021]$} & {$[-0.016]$} & {$[0.006]$} & {$[0.059]$} & {$[0.113]$} & {$[0.163]$} & {$[0.225]$} & {$[0.284]$} \\
\hline
\end{tabular}

$\overline{\text { This table presents OLS beta parameter estimates for univariate regressions of excess returns on variables }}$ based on cointegration relations. Excess returns are measured at annual frequencies for the period 1946-1994 and cumulated for up to 8 periods. In parentheses, below the parameter estimates, are Newey-West (1987) corrected t-statistics, the $t / \sqrt{T}$ test of Valkanov (2003) in curly brackets, and adjusted $R^{2}$ statistics in square brackets. cay is the approximate consumption-aggregate wealth ratio, $c d y$ is the cointegration relation between consumption, dividends and labour income. $d l s$ implies that the relation has been computed by dynamic least squares. $l r_{-} y$ is the long-run labour income growth relation of Julliard (2005) computed using log labour income and $l r_{-}$comp is the same relation using log compensation of employees instead of log labour income. $y \_l d$ is based on a cointegration relation between labour income and dividends and $y_{-} l s$ is the cointegration relation between labour income and the log level of the CRSP value-weighted stock index. mymo is a housing collateral measure developed from a cointegration relation between aggregate labour income and the value of outstanding mortgages in the US. $*-10 \%$ significance, $* *-5 \%$ significance. 
Table 35: Implied long-horizon $R^{2}$, 1952Q1-1994Q4

\begin{tabular}{lrrrrrrrr}
\hline \hline & \multicolumn{8}{c}{ Horizon h (in quarters) } \\
\hline & 1 & 2 & 4 & 8 & 16 & 24 & 36 & 48 \\
\hline \hline$\Delta c$ & 0.006 & 0.006 & 0.004 & 0.002 & 0.001 & 0.001 & 0.001 & 0.000 \\
$d e f$ & 0.015 & 0.025 & 0.045 & 0.072 & 0.092 & 0.089 & 0.075 & 0.061 \\
$r t b$ & 0.065 & 0.082 & 0.080 & 0.053 & 0.028 & 0.019 & 0.013 & 0.010 \\
$p e$ & 0.014 & 0.031 & 0.068 & 0.140 & 0.251 & 0.323 & 0.368 & 0.364 \\
$p d$ & 0.042 & 0.088 & 0.194 & 0.366 & 0.517 & 0.498 & 0.386 & 0.289 \\
$d e$ & 0.012 & 0.020 & 0.037 & 0.062 & 0.089 & 0.099 & 0.101 & 0.097 \\
$p y$ & 0.015 & 0.033 & 0.074 & 0.152 & 0.278 & 0.362 & 0.418 & 0.418 \\
$p c$ & 0.019 & 0.040 & 0.089 & 0.181 & 0.327 & 0.421 & 0.477 & 0.468 \\
$y c_{1}$ & 0.016 & 0.028 & 0.053 & 0.090 & 0.130 & 0.146 & 0.149 & 0.142 \\
$y c_{2}$ & 0.040 & 0.071 & 0.123 & 0.191 & 0.249 & 0.264 & 0.260 & 0.244 \\
$y c_{3}$ & 0.015 & 0.016 & 0.031 & 0.057 & 0.094 & 0.116 & 0.133 & 0.138 \\
nhe & 0.001 & 0.002 & 0.003 & 0.005 & 0.009 & 0.011 & 0.014 & 0.015 \\
cay_dls & 0.102 & 0.177 & 0.288 & 0.315 & 0.209 & 0.141 & 0.092 & 0.068 \\
cdy_dls & 0.014 & 0.025 & 0.045 & 0.066 & 0.073 & 0.066 & 0.052 & 0.041 \\
lr_y & 0.027 & 0.025 & 0.017 & 0.008 & 0.004 & 0.003 & 0.002 & 0.001 \\
lr_comp. & 0.025 & 0.028 & 0.023 & 0.013 & 0.006 & 0.004 & 0.003 & 0.002 \\
$y \_l d$ & 0.000 & 0.000 & 0.001 & 0.002 & 0.004 & 0.005 & 0.008 & 0.010 \\
$y \_l s$ & 0.012 & 0.027 & 0.063 & 0.128 & 0.223 & 0.272 & 0.283 & 0.256 \\
\hline \hline
\end{tabular}

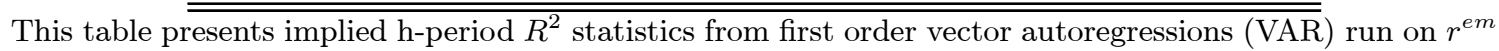
and the respective predictor variable. Data is quarterly for the period 1951Q4 to 1994Q3.

Table 36: Implied long-horizon $R^{2}, 1946-1994$

\begin{tabular}{lrrrrrrrr}
\hline \hline & \multicolumn{8}{c}{ Horizon h (in years) } \\
\hline & 1 & 2 & 3 & 4 & 5 & 6 & 7 & 8 \\
\hline \hline$\Delta c$ & 0.080 & 0.057 & 0.038 & 0.025 & 0.019 & 0.016 & 0.013 & 0.012 \\
$d e f$ & 0.000 & 0.000 & 0.000 & 0.000 & 0.000 & 0.000 & 0.000 & 0.000 \\
$p e$ & 0.079 & 0.141 & 0.186 & 0.225 & 0.256 & 0.282 & 0.301 & 0.316 \\
$p d$ & 0.215 & 0.369 & 0.441 & 0.490 & 0.519 & 0.533 & 0.536 & 0.532 \\
$d e$ & 0.001 & 0.003 & 0.003 & 0.003 & 0.003 & 0.003 & 0.003 & 0.002 \\
$p y$ & 0.053 & 0.094 & 0.120 & 0.149 & 0.175 & 0.200 & 0.223 & 0.245 \\
$p c$ & 0.062 & 0.113 & 0.146 & 0.182 & 0.215 & 0.247 & 0.276 & 0.304 \\
$y c_{1}$ & 0.052 & 0.099 & 0.113 & 0.126 & 0.133 & 0.138 & 0.140 & 0.140 \\
$y c_{2}$ & 0.055 & 0.093 & 0.095 & 0.096 & 0.094 & 0.089 & 0.084 & 0.079 \\
$y c_{3}$ & 0.034 & 0.069 & 0.082 & 0.097 & 0.108 & 0.117 & 0.124 & 0.129 \\
$n h e$ & 0.001 & 0.002 & 0.003 & 0.004 & 0.005 & 0.005 & 0.005 & 0.006 \\
cay_dls & 0.168 & 0.172 & 0.140 & 0.107 & 0.085 & 0.069 & 0.058 & 0.051 \\
$c d y \_d l s$ & 0.020 & 0.027 & 0.027 & 0.026 & 0.025 & 0.023 & 0.022 & 0.020 \\
lr_y & 0.007 & 0.006 & 0.005 & 0.004 & 0.003 & 0.003 & 0.002 & 0.002 \\
lr_comp. & 0.014 & 0.006 & 0.004 & 0.003 & 0.002 & 0.002 & 0.001 & 0.001 \\
$y \_l d$ & 0.004 & 0.005 & 0.005 & 0.005 & 0.006 & 0.006 & 0.007 & 0.007 \\
y_ls & 0.052 & 0.091 & 0.118 & 0.143 & 0.164 & 0.181 & 0.196 & 0.207 \\
mymo_dls & 0.001 & 0.001 & 0.001 & 0.001 & 0.001 & 0.001 & 0.001 & 0.001 \\
\hline \hline
\end{tabular}

This table presents implied h-period $R^{2}$ statistics from first order vector autoregressions (VAR) run on $r^{e m}$ and the respective predictor variable. Data is annual for the period 1945 to 1993. 
Table 37: Quarterly multivariat regressions, 1952Q1-2005Q4

\begin{tabular}{|c|c|c|c|c|c|c|}
\hline$h$ & $p d$ & pe & $d e$ & py & $p c$ & $\overline{R^{2}}$ \\
\hline $\bar{~} 1$ & $\begin{array}{l}-0.046 \\
(0.033)\end{array}$ & $\begin{array}{l}0.021 \\
(0.031)\end{array}$ & & & & $\overline{0.008}$ \\
\hline 1 & $\begin{array}{l}-0.0256 \\
(0.017)\end{array}$ & & $\begin{array}{l}0.006 \\
(0.030)\end{array}$ & & & 0.006 \\
\hline 1 & $\begin{array}{l}-0.092 \\
(0.043)^{* *}\end{array}$ & & & $\begin{array}{l}0.045 \\
(0.027)^{*}\end{array}$ & & 0.018 \\
\hline 1 & $\begin{array}{l}-0.084 \\
(0.044)^{*}\end{array}$ & & & & $\begin{array}{l}0.040 \\
(0.028)\end{array}$ & 0.015 \\
\hline 8 & $\begin{array}{l}-0.287 \\
(0.169)^{*}\end{array}$ & $\begin{array}{l}0.099 \\
(0.126)\end{array}$ & & & & 0.106 \\
\hline 8 & $\begin{array}{l}-0.175 \\
(0.080)^{* *}\end{array}$ & & $\begin{array}{l}0.161 \\
(0.146)\end{array}$ & & & 0.115 \\
\hline 8 & $\begin{array}{l}-0.473 \\
(0.227)^{* *}\end{array}$ & & & $\begin{array}{l}0.199 \\
(0.152)\end{array}$ & & 0.130 \\
\hline 8 & $\begin{array}{l}-0.442 \\
(0.227)^{*}\end{array}$ & & & & $\begin{array}{l}0.178 \\
(0.154) \\
\end{array}$ & 0.122 \\
\hline 24 & $\begin{array}{l}-0.675 \\
(0.216)^{* *}\end{array}$ & $\begin{array}{l}0.184 \\
(0.170)\end{array}$ & & & & 0.209 \\
\hline 24 & $\begin{array}{l}-0.448 \\
(0.108)^{* *}\end{array}$ & & $\begin{array}{l}0.428 \\
(0.237)^{*}\end{array}$ & & & 0.243 \\
\hline 24 & $\begin{array}{l}-1.174 \\
(0.266)^{* *}\end{array}$ & & & $\begin{array}{l}0.474 \\
(0.201)^{* *}\end{array}$ & & 0.281 \\
\hline 24 & $\begin{array}{l}-1.088 \\
(0.267)^{* *} \\
\end{array}$ & & & & $\begin{array}{l}0.420 \\
(0.202)^{* *}\end{array}$ & 0.259 \\
\hline 48 & $\begin{array}{l}-0.941 \\
(0.438)^{* *}\end{array}$ & $\begin{array}{l}-0.294 \\
(0.266)\end{array}$ & & & & 0.404 \\
\hline 48 & $\begin{array}{l}-1.434 \\
(0.208)^{* *}\end{array}$ & & $\begin{array}{l}0.406 \\
(0.303)\end{array}$ & & & 0.404 \\
\hline 48 & $\begin{array}{l}-2.150 \\
(0.321)^{* *}\end{array}$ & & & $\begin{array}{l}0.620 \\
(0.222)^{* *}\end{array}$ & & 0.475 \\
\hline 48 & $\begin{array}{l}-2.119 \\
(0.326)^{* *}\end{array}$ & & & & $\begin{array}{l}0.605 \\
(0.230)^{* *}\end{array}$ & 0.465 \\
\hline
\end{tabular}

This table presents OLS beta parameter estimates from multivariate regressions of excess returns on preditor variables. Excess returns are measured at quarterly frequencies for the period 1952Q1-2005Q4 and cumulated for up to 48 periods. In parentheses, below the parameter estimates, are Newey-West (1987) corrected standard errors. $p d$ is the log price-dividend ratio on the CRSP value-weighted portfolio, de is the log dividend-earnings ratio on the $\mathrm{S} \& \mathrm{P} 500, p y$ is the $\log$ price-output ratio, and $p c$ is the log price-consumption ratio. $*-10 \%$ significance, $* *-5 \%$ significance. 
Table 38: Quarterly multivariat regressions, 1952Q1-2005Q4

\begin{tabular}{llllll}
\hline \hline$h$ & $p d$ & $y c_{1}$ & $y c_{2}$ & $y c_{3}$ & $R^{2}$ \\
\hline \hline 1 & -0.024 & -0.304 & & & 0.020 \\
& $(0.016)$ & $(0.177)^{*}$ & & & \\
1 & -0.031 & & -0.639 & & 0.059 \\
& $(0.015)^{* *}$ & & $(0.174)^{* *}$ & & \\
1 & -0.031 & & & -0.494 & 0.021 \\
& $(0.016)^{*}$ & & & $(0.267)^{*}$ & \\
\hline 8 & -0.185 & -1.875 & & & 0.172 \\
& $(0.089)^{* *}$ & $(0.748)^{* *}$ & & & \\
8 & -0.217 & & -3.340 & & 0.307 \\
& $(0.076)^{* *}$ & & $(0.797)^{* *}$ & & \\
8 & -0.237 & & & -4.066 & 0.233 \\
& $(0.092)^{* *}$ & & & $(1.287)^{* *}$ & \\
\hline 24 & -0.507 & -3.826 & & & 0.337 \\
& $(0.093)^{* *}$ & $(0.684)^{* *}$ & & & 0.554 \\
24 & -0.588 & & -6.380 & & \\
& $(0.094)^{* *}$ & & $(1.065)^{* *}$ & & 0.487 \\
24 & -0.611 & & & -8.695 & 0.390 \\
& $(0.089)^{* *}$ & & & $(1.329)^{* *}$ & \\
\hline 48 & -1.310 & -0.482 & & & 0.390 \\
& $(0.239)^{* *}$ & $(1.102)$ & & & 0.439 \\
48 & -1.360 & & -3.121 & & 0.550 \\
& $(0.204)^{* *}$ & & $(1.297)^{* *}$ & & -8.189 \\
48 & -1.338 & & & $(1.610)^{* *}$ & \\
& $(0.194)^{* *}$ & & & \\
\hline \hline
\end{tabular}

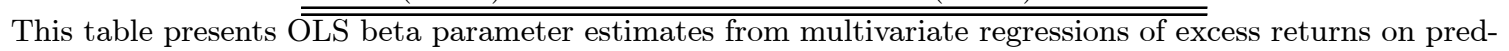
itor variables. Excess returns are measured at quarterly frequencies for the period 1952Q1-2005Q4 and cumulated for up to 48 periods. In parentheses, below the parameter estimates, are Newey-West (1987) corrected standard errors. $p d$ is the log price-dividend ratio on the CRSP value-weighted portfolio, $y c_{1}$ is the log labour income-consumption ratio, $y c_{2}$ is the log compensation of employees-consumption ratio, and $y c_{3}$ is the log labour income-compensation of employees ratio. $*-10 \%$ significance, $* *-5 \%$ significance. 
Table 39: Quarterly multivariat regressions, 1952Q1-2005Q4

\begin{tabular}{|c|c|c|c|c|c|c|c|}
\hline$h$ & $p d$ & cay_dls & $c d y \_d l s$ & $y_{2} l s$ & $l r_{-} y$ & $l r_{-} c o m p$ & $R^{2}$ \\
\hline 1 & $\begin{array}{l}-0.011 \\
(0.017)\end{array}$ & $\begin{array}{l}1.126 \\
(0.346)^{* *}\end{array}$ & & & & & 0.048 \\
\hline 1 & $\begin{array}{l}-0.027 \\
(0.017)\end{array}$ & & $\begin{array}{l}0.352 \\
(0.321)\end{array}$ & & & & 0.011 \\
\hline 1 & $\begin{array}{l}-0.036 \\
(0.038)\end{array}$ & & & $\begin{array}{l}-0.011 \\
(0.039)\end{array}$ & & & 0.006 \\
\hline 1 & & $\begin{array}{l}1.089 \\
(0.405)^{* *}\end{array}$ & & & $\begin{array}{l}-4.432 \\
(5.587)\end{array}$ & & 0.050 \\
\hline 1 & & $\begin{array}{l}1.123 \\
(0.383)^{* *}\end{array}$ & & & & $\begin{array}{l}-1.146 \\
(1.154)\end{array}$ & 0.050 \\
\hline 8 & $\begin{array}{l}-0.110 \\
(0.081)\end{array}$ & $\begin{array}{l}7.164 \\
(1.488)^{* *}\end{array}$ & & & & & 0.331 \\
\hline 8 & $\begin{array}{l}-0.210 \\
(0.089)^{* *}\end{array}$ & & $\begin{array}{l}3.890 \\
(1.415)^{* *}\end{array}$ & & & & 0.172 \\
\hline 8 & $\begin{array}{l}-0.166 \\
(0.179)\end{array}$ & & & $\begin{array}{l}0.030 \\
(0.155)\end{array}$ & & & 0.100 \\
\hline 8 & & $\begin{array}{l}7.862 \\
(1.647)^{* *}\end{array}$ & & & $\begin{array}{l}-1.977 \\
(16.209)\end{array}$ & & 0.298 \\
\hline 8 & & $\begin{array}{l}7.668 \\
(1.620)^{* *}\end{array}$ & & & & $\begin{array}{l}-2.952 \\
(4.115)\end{array}$ & 0.301 \\
\hline 24 & $\begin{array}{l}-0.384 \\
(0.117)^{* *}\end{array}$ & $\begin{array}{l}13.372 \\
(2.166)^{* *}\end{array}$ & & & & & 0.568 \\
\hline 24 & $\begin{array}{l}-0.431 \\
(0.086)^{* *}\end{array}$ & & $\begin{array}{l}9.844 \\
(2.400)^{* *}\end{array}$ & & & & 0.390 \\
\hline 24 & $\begin{array}{l}-0.402 \\
(0.315)\end{array}$ & & & $\begin{array}{l}0.074 \\
(0.285)\end{array}$ & & & 0.200 \\
\hline 24 & & $\begin{array}{l}14.048 \\
(2.165)^{* *}\end{array}$ & & & $\begin{array}{l}-15.073 \\
(22.416)\end{array}$ & & 0.438 \\
\hline 24 & & $\begin{array}{l}13.784 \\
(2.060)^{* *}\end{array}$ & & & & $\begin{array}{l}-7.936 \\
(5.617) \\
\end{array}$ & 0.447 \\
\hline 48 & $\begin{array}{l}-1.209 \\
(0.202)^{* *}\end{array}$ & $\begin{array}{l}10.750 \\
(2.756)^{* *}\end{array}$ & & & & & 0.503 \\
\hline 48 & $\begin{array}{l}-1.141 \\
(0.221)^{* *}\end{array}$ & & $\begin{array}{l}7.788 \\
(2.662)^{* *}\end{array}$ & & & & 0.456 \\
\hline 48 & $\begin{array}{l}-0.517 \\
(0.502)\end{array}$ & & & $\begin{array}{l}0.656 \\
(0.335)^{*}\end{array}$ & & & 0.436 \\
\hline 48 & & $\begin{array}{l}11.804 \\
(3.499)^{* *}\end{array}$ & & & $\begin{array}{c}-40.492 \\
(32.168)\end{array}$ & & 0.179 \\
\hline 48 & & $\begin{array}{l}12.219 \\
(3.457)^{* *}\end{array}$ & & & & $\begin{array}{l}-9.959 \\
(8.513) \\
\end{array}$ & 0.177 \\
\hline
\end{tabular}

This table presents OLS beta parameter estimates from multivariate regressions of excess returns on preditor variables. Excess returns are measured at quarterly frequencies for the period 1952Q1-2005Q4 and cumulated for up to 48 periods. In parentheses, below the parameter estimates, are Newey-West (1987) corrected standard errors. $p d$ is the log price-dividend ratio on the CRSP value weighted portfolio, cay is the approximate consumption-aggregate wealth ratio, $c d y$ is the cointegration relation between consumption, dividends, and labour income. $l r_{-} y$ is the long-run labour income growth relation of Julliard (2005) computed using log labour income and $l r_{-}$comp is the same relation using log compensation of employees instead of log labour income. $y_{-} l s$ is the cointegration relation between labour income and the log level of the CRSP value-weighted stock index. $*-10 \%$ sign 693 cance, $* *-5 \%$ significance. 
Table 40: Annual multivariat regressions, 1946-2005

\begin{tabular}{|c|c|c|c|c|c|c|}
\hline $\bar{h}$ & $p d$ & $p e$ & $\overline{d e}$ & $p y$ & $p c$ & 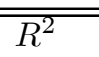 \\
\hline 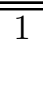 & $\begin{array}{l}-0.156 \\
(0.080)^{*}\end{array}$ & $\begin{array}{l}0.050 \\
(0.071)\end{array}$ & & & & 0.047 \\
\hline 1 & $\begin{array}{l}-0.115 \\
(0.046)^{* *}\end{array}$ & & $\begin{array}{l}-0.037 \\
(0.089)\end{array}$ & & & 0.045 \\
\hline 1 & $\begin{array}{l}-0.273 \\
(0.110)^{* *}\end{array}$ & & & $\begin{array}{l}0.104 \\
(0.061)^{*}\end{array}$ & & 0.077 \\
\hline 1 & $\begin{array}{l}-0.260 \\
(0.108)\end{array}$ & & & & $\begin{array}{l}0.097 \\
(0.060)\end{array}$ & 0.071 \\
\hline 4 & $\begin{array}{l}-0.527 \\
(0.170)^{* *}\end{array}$ & $\begin{array}{l}0.176 \\
(0.147)\end{array}$ & & & & 0.239 \\
\hline 4 & $\begin{array}{l}-0.361 \\
(0.112)\end{array}$ & & $\begin{array}{l}0.046 \\
(0.216)\end{array}$ & & & 0.225 \\
\hline 4 & $\begin{array}{l}-0.396 \\
(0.202)^{*}\end{array}$ & & & $\begin{array}{l}0.020 \\
(0.139)\end{array}$ & & 0.224 \\
\hline 4 & $\begin{array}{l}-0.346 \\
(0.196)^{*}\end{array}$ & & & & $\begin{array}{l}-0.013 \\
(0.135)\end{array}$ & 0.224 \\
\hline 8 & $\begin{array}{l}-1.005 \\
(0.280)^{* *}\end{array}$ & $\begin{array}{l}0.155 \\
(0.275)\end{array}$ & & & & 0.327 \\
\hline 8 & $\begin{array}{l}-0.855 \\
(0.275)^{* *}\end{array}$ & & $\begin{array}{l}0.321 \\
(0.401)\end{array}$ & & & 0.338 \\
\hline 8 & $\begin{array}{l}-0.856 \\
(0.483)^{*}\end{array}$ & & & $\begin{array}{l}0.002 \\
(0.291)\end{array}$ & & 0.321 \\
\hline 8 & $\begin{array}{l}-0.767 \\
(0.477)\end{array}$ & & & & $\begin{array}{l}-0.051 \\
(0.289)\end{array}$ & 0.322 \\
\hline
\end{tabular}

This table presents $\overline{\overline{\text { OLS beta parameter estimates from multivariate regressions of excess }}}$ returns on preditor variables. Excess returns are measured at annual frequencies for the period 1946-2005 and cumulated for up to 8 periods. In parentheses, below the parameter estimates, are Newey-West (1987) corrected standard errors. $p d$ is the log price-dividend ratio on the CRSP value-weighted portfolio, de is the log dividendearnings ratio on the $\mathrm{S} \& \mathrm{P} 500, p y$ is the log price-output ratio, and $p c$ is the log price-consumption ratio. $*-10 \%$ significance, $* *-5 \%$ significance. 
Table 41: Annual multivariat regressions, 1946-2005

\begin{tabular}{|c|c|c|c|c|c|c|}
\hline $\bar{h}$ & $p d$ & $y c_{1}$ & $y c_{2}$ & $y c_{3}$ & nhe & 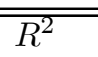 \\
\hline 1 & $\begin{array}{l}-0.095 \\
(0.050)^{*}\end{array}$ & $\begin{array}{l}-0.519 \\
(0.387)\end{array}$ & & & & 0.059 \\
\hline 1 & $\begin{array}{l}-0.088 \\
(0.047)^{*}\end{array}$ & & $\begin{array}{l}-0.883 \\
(0.417)^{* *}\end{array}$ & & & 0.098 \\
\hline 1 & $\begin{array}{l}-0.104 \\
(0.049)^{* *}\end{array}$ & & & $\begin{array}{l}-0.887 \\
(0.672)\end{array}$ & & 0.063 \\
\hline 1 & $\begin{array}{l}-0.111 \\
(0.051)^{* *}\end{array}$ & & & & $\begin{array}{l}0.022 \\
(0.684)\end{array}$ & 0.043 \\
\hline 4 & $\begin{array}{l}-0.029 \\
(0.092)^{* *}\end{array}$ & $\begin{array}{l}-2.816 \\
(0.668)^{* *}\end{array}$ & & & & 0.385 \\
\hline 4 & $\begin{array}{l}-0.270 \\
(0.091)^{* *}\end{array}$ & & $\begin{array}{l}-3.270 \\
(0.894)^{* *}\end{array}$ & & & 0.479 \\
\hline 4 & $\begin{array}{l}-0.331 \\
(0.095)^{* *}\end{array}$ & & & $\begin{array}{l}-4.940 \\
(1.425)^{* *}\end{array}$ & & \\
\hline 4 & $\begin{array}{l}-0.318 \\
(0.093)^{* *}\end{array}$ & & & & $\begin{array}{l}2.542 \\
(1.205)^{* *}\end{array}$ & 0.264 \\
\hline 8 & $\begin{array}{l}-0.712 \\
(0.201)^{* *}\end{array}$ & $\begin{array}{l}-3.639 \\
(0.783)^{* *}\end{array}$ & & & & 0.451 \\
\hline 8 & $\begin{array}{l}-0.703 \\
(0.155)^{* *}\end{array}$ & & $\begin{array}{l}-4.201 \\
(0.885)^{* *}\end{array}$ & & & 0.527 \\
\hline 8 & $\begin{array}{l}-0.670 \\
(0.157)^{* *}\end{array}$ & & & $\begin{array}{l}-8.819 \\
(1.453)^{* *}\end{array}$ & & 0.632 \\
\hline 8 & $\begin{array}{l}-0.702 \\
(0.223)^{* *}\end{array}$ & & & & $\begin{array}{l}4.529 \\
(1.913)^{* *}\end{array}$ & 0.379 \\
\hline
\end{tabular}

This table presents OLS beta parameter estimates from multivariate regressions of excess returns on preditor variables. Excess returns are measured at annual frequencies for the period 1946-2005 and cumulated for up to 8 periods. In parentheses, below the parameter estimates, are Newey-West (1987) corrected standard errors. $p d$ is the log price-dividend ratio on the CRSP value-weighted portfolio, $y c_{1}$ is the log labour income-consumption ratio, $y c_{2}$ is the log compensation of employees-consumption ratio, $y c_{3}$ is the $\log$ labour income-compensation of employees ratio. $*-10 \%$ significance, $* *-5 \%$ significance. 
Table 42: Annual multivariat regressions, 1946-2005

\begin{tabular}{|c|c|c|c|c|c|c|c|c|}
\hline$\overline{c h}$ & $p d$ & cay_dls & $c d y \_d l s$ & $y_{-} l s$ & $l r_{-} y$ & lr_comp & mymo_dls & $\overline{\overline{R^{2}}}$ \\
\hline 1 & $\begin{array}{l}-0.076 \\
(0.047)\end{array}$ & $\begin{array}{l}2.647 \\
(0.969)^{* *}\end{array}$ & & & & & & 0.151 \\
\hline 1 & $\begin{array}{l}-0.110 \\
(0.050)^{* *}\end{array}$ & & $\begin{array}{l}0.482 \\
(0.586)\end{array}$ & & & & & 0.051 \\
\hline 1 & $\begin{array}{l}-0.113 \\
(0.080)\end{array}$ & & & $\begin{array}{l}-0.003 \\
(0.070)\end{array}$ & & & & 0.043 \\
\hline 1 & $\begin{array}{l}-0.120 \\
(0.054)^{* *}\end{array}$ & & & & & & $\begin{array}{l}-0.090 \\
(0.071)\end{array}$ & 0.053 \\
\hline 1 & & $\begin{array}{l}3.155 \\
(0.931)^{* *}\end{array}$ & & & $\begin{array}{l}0.695 \\
(1.843)\end{array}$ & & & 0.118 \\
\hline 1 & & $\begin{array}{l}3.038 \\
(0.945)^{* *}\end{array}$ & & & & $\begin{array}{l}0.002 \\
(1.412)\end{array}$ & & 0.116 \\
\hline 4 & $\begin{array}{l}-0.271 \\
(0.101)^{* *}\end{array}$ & $\begin{array}{l}7.119 \\
(2.304)^{* *}\end{array}$ & & & & & & 0.486 \\
\hline 4 & $\begin{array}{l}-0.347 \\
(0.095)^{* *}\end{array}$ & & $\begin{array}{l}4.063 \\
(1.566)^{* *}\end{array}$ & & & & & 0.417 \\
\hline 4 & $\begin{array}{l}-0.258 \\
(0.183)\end{array}$ & & & $\begin{array}{l}0.125 \\
(0.153)\end{array}$ & & & & 0.232 \\
\hline 4 & $\begin{array}{l}-0.358 \\
(0.111)\end{array}$ & & & & & & $\begin{array}{l}0.073 \\
(0.145)\end{array}$ & 0.226 \\
\hline 4 & & $\begin{array}{l}8.005 \\
(2.323)^{* *}\end{array}$ & & & $\begin{array}{l}-2.297 \\
(3.152)\end{array}$ & & & 0.359 \\
\hline 4 & & $\begin{array}{l}8.345 \\
(2.371)^{* *}\end{array}$ & & & & $\begin{array}{l}-0.473 \\
(3.004) \\
\end{array}$ & & 0.352 \\
\hline 8 & $\begin{array}{l}-0.791 \\
(0.173)^{* *}\end{array}$ & $\begin{array}{l}9.333 \\
(3.302)^{* *}\end{array}$ & & & & & & 0.531 \\
\hline 8 & $\begin{array}{l}-0.671 \\
(0.151)^{* *}\end{array}$ & & $\begin{array}{l}7.326 \\
(1.869)^{* *}\end{array}$ & & & & & 0.598 \\
\hline 8 & $\begin{array}{l}-0.421 \\
(0.369)\end{array}$ & & & $\begin{array}{l}0.442 \\
(0.329)\end{array}$ & & & & 0.368 \\
\hline 8 & $\begin{array}{l}-0.704 \\
(0.225)^{* *}\end{array}$ & & & & & & $\begin{array}{l}0.643 \\
(0.313)^{* *}\end{array}$ & 0.397 \\
\hline 8 & & $\begin{array}{l}9.074 \\
(3.792)^{* *}\end{array}$ & & & $\begin{array}{l}-8.279 \\
(6.595)\end{array}$ & & & 0.274 \\
\hline 8 & & $\begin{array}{l}9.905 \\
(3.795)^{* *} \\
\end{array}$ & & & & $\begin{array}{l}-5.357 \\
(5.674) \\
\end{array}$ & & 0.253 \\
\hline
\end{tabular}

This table presents OLS beta parameter estimates from multivariate regressions of excess returns on preditor variables. Excess returns are measured at quarterly frequencies for the period 1952Q1-2005Q4 and cumulated for up to 48 periods. In parentheses, below the parameter estimates, are Newey-West (1987) corrected standard errors. $p d$ is the log price-dividend ratio on the CRSP value-weighted portfolio, cay is the approximate consumption-aggregate wealth ratio, $c d y$ is the cointegration relation between consumption, dividends, and labour income. dls implies the relation has been computed by dynamic least squares. $l r_{-} y$ is the long-run labour income growth relation of Julliard (2005) computed using log labour income and lr_comp is the same relation using log compensation of employees instead of log labour income. $y_{-} l s$ is the cointegration relation between labour income and the log level of the CRSP value-weighted stock index. mymo is a housing collateral measure developed from a cointegration relation between aggregate labour income and the value of outstanding mortgages in the US. $*-10 \%$ significance, $* *-5 \%$ significance. 
Table 43: Quarterly cross-sectional regressions on 25 Fama-French portfolios, 1952Q1-2005Q4

\begin{tabular}{|c|c|c|c|c|c|c|c|}
\hline & intercept & state $_{t}$ & $\Delta c_{t+1}$ & $\Delta c_{t+1} *$ state $_{t}$ & $\bar{a} \overline{a d j} R^{2}$ & $\chi^{2}$ & $\chi_{\text {shanken }}^{2}$ \\
\hline$\overline{d e f}$ & $\begin{array}{l}\text { 3.552 } \\
(0.779)^{* *} \\
\{1.753\}^{* *}\end{array}$ & $\begin{array}{l}0.038 \\
(0.040) \\
\{0.089\}\end{array}$ & $\begin{array}{l}-0.361 \\
(0.150)^{* *} \\
\{0.332\}\end{array}$ & $\begin{array}{l}-0.065 \\
(0.044) \\
\{0.097\}\end{array}$ & "0.538 & $77.607^{* *}$ & 15.320 \\
\hline$r t b$ & $\begin{array}{l}2.681 \\
(0.654)^{* *} \\
\{1.018\}^{* *}\end{array}$ & $\begin{array}{l}0.144 \\
(0.071)^{* *} \\
\{0.109\}\end{array}$ & $\begin{array}{l}0.316 \\
(0.142)^{* *} \\
\{0.218\}\end{array}$ & $\begin{array}{l}0.107 \\
(0.047)^{* *} \\
\{0.072\}\end{array}$ & 0.152 & $86.72^{* *}$ & 35.771 \\
\hline pe & $\begin{array}{l}2.089 \\
(0.579)^{* *} \\
\{1.001\}^{* *}\end{array}$ & $\begin{array}{l}0.440 \\
(0.140)^{* *} \\
\{0.239\}\end{array}$ & $\begin{array}{l}0.2469 \\
(0.157) \\
\{0.268\}\end{array}$ & $\begin{array}{l}0.069 \\
(0.104) \\
\{0.178\}\end{array}$ & 0.133 & $82.870^{* *}$ & 27.715 \\
\hline$p d$ & $\begin{array}{l}2.786 \\
(0.560)^{* *} \\
\{0.907\}^{* *}\end{array}$ & $\begin{array}{l}0.402 \\
(0.099)^{* *} \\
\{0.157\}^{* *}\end{array}$ & $\begin{array}{l}0.108 \\
(0.162) \\
\{0.260\}\end{array}$ & $\begin{array}{l}0.080 \\
(0.068) \\
\{0.108\}\end{array}$ & 0.583 & $74.145^{* *}$ & 28.243 \\
\hline$d e$ & $\begin{array}{l}3.056 \\
(0.604)^{* *} \\
\{1.369\}^{* *}\end{array}$ & $\begin{array}{l}0.128 \\
(0.045)^{* *} \\
\{0.096\}\end{array}$ & $\begin{array}{l}-0.378 \\
(0.227)^{*} \\
\{0.510\}\end{array}$ & $\begin{array}{l}0.178 \\
(0.034)^{* *} \\
\{0.074\}^{* *}\end{array}$ & 0.504 & $79.338^{* *}$ & 15.468 \\
\hline py & $\begin{array}{l}2.103 \\
(0.537)^{* *} \\
\{1.102\}^{*}\end{array}$ & $\begin{array}{l}0.580 \\
(0.125)^{* *} \\
\{0.247\}^{* *}\end{array}$ & $\begin{array}{l}0.071 \\
(0.180) \\
\{0.366\}\end{array}$ & $\begin{array}{l}-0.051 \\
(0.096) \\
\{0.192\}\end{array}$ & 0.638 & $74.618^{* *}$ & 17.692 \\
\hline$p c$ & $\begin{array}{l}-2.141 \\
(0.536)^{* *} \\
\{1.080\}^{* *}\end{array}$ & $\begin{array}{l}0.544 \\
(0.121)^{* *} \\
\{0.233\}^{* *}\end{array}$ & $\begin{array}{l}-0.075 \\
(0.180) \\
\{0.358\}\end{array}$ & $\begin{array}{l}-0.057 \\
(0.962) \\
\{0.188\}\end{array}$ & 0.642 & $74.708^{* *}$ & 18.434 \\
\hline$y c_{1}$ & $\begin{array}{l}3.958 \\
(0.672)^{* *} \\
\{1.275\}^{* *}\end{array}$ & $\begin{array}{l}3.919 \\
(1.283)^{* *} \\
\{2.409\}\end{array}$ & $\begin{array}{l}-0.201 \\
(0.147) \\
\{0.274\}\end{array}$ & $\begin{array}{l}0.663 \\
(0.983) \\
\{1.847\}\end{array}$ & 0.618 & $79.550^{* *}$ & 22.104 \\
\hline$y c_{2}$ & $\begin{array}{l}3.978 \\
(0.800)^{* *} \\
\{1.436\}^{* *}\end{array}$ & $\begin{array}{l}0.029 \\
(1.256)^{* *} \\
\{2.234\}\end{array}$ & $\begin{array}{l}-0.071 \\
(0.198) \\
\{0.352\}\end{array}$ & $\begin{array}{l}-0.209 \\
(0.889) \\
\{1.582\}\end{array}$ & 0.582 & $84.573^{* *}$ & 26.251 \\
\hline$y c_{3}$ & $\begin{array}{l}3.618 \\
(0.725)^{* *} \\
\{1.397\}^{* *}\end{array}$ & $\begin{array}{l}0.862 \\
(0.621) \\
\{1.176\}\end{array}$ & $\begin{array}{l}-0.040 \\
(0.128) \\
\{0.242\}\end{array}$ & $\begin{array}{l}-0.945 \\
(0.534)^{*} \\
\{1.018\}\end{array}$ & 0.320 & $87.359^{* *}$ & 23.500 \\
\hline nhe & $\begin{array}{l}2.397 \\
(0.544)^{* *} \\
\{0.935\}^{* *}\end{array}$ & $\begin{array}{l}-0.012 \\
(0.006)^{* *} \\
\{0.010\}\end{array}$ & $\begin{array}{l}-0.077 \\
(0.148) \\
\{0.251\}\end{array}$ & $\begin{array}{l}0.002 \\
(0.004) \\
\{0.008\}\end{array}$ & 0.298 & $84.898^{* *}$ & 28.818 \\
\hline
\end{tabular}

This table presents Fama-MacBeth estimates of $\lambda$ for the conditional C-CAPM. The model is estimated seperately for each state variable. Stock portfolios are the 25 Fama-French portfolios. Excess returns are measured at quarterly frequencies for the period 1952Q1-2005Q4. In parentheses, below the parameter estimates, are Newey-West (1987) corrected standard errors and in curly brackets Shanken corrected standard errors. The final two columns present $\chi^{2}$ and Shanken corrected $\chi^{2}$ tests of the hypothesis of zero pricing errors. def is the default premium on bonds, $r t b$ is the relative t-bill rate, pe is the log price-earnings ratio on the $\mathrm{S} \& \mathrm{P} 500, p d$ is the log price-dividend ratio on the CRSP value-weighted portfolio, de is the log dividendearnings ratio on the $\mathrm{S} \& \mathrm{P} 500, p y$ is the log price-output ratio, $p c$ is the log price-consumption ratio, $y c_{1}$ is the log labour income-consumption ratio, $y c_{2}$ is the $\log$ compensation of employees-consumption ratio, $y c_{3}$ is the log labour income-compensation of employees ratio, and nhe is the log non-housing consumption share. $*-10 \%$ significance, $* *-5 \%$ significance. 
Table 44: Quarterly cross-sectional regressions on 25 Fama-French portfolios, 1952Q1-2005Q4

\begin{tabular}{llllllll}
\hline \hline & intercept & state $_{t}$ & $\Delta c_{t+1}$ & $\Delta c_{t+1} *$ state $_{t}$ & $a d j R^{2}$ & $\chi^{2}$ & $\chi_{\text {shanken }}^{2}$ \\
\hline \hline cay_dls & 4.423 & -1.530 & -0.012 & -0.151 & 0.592 & $81.037^{* *}$ & 31.269 \\
& $(0.745)^{* *}$ & $(0.470)^{* *}$ & $(0.196)$ & $(0.318)$ & & & \\
& $\{1.199\}^{* *}$ & $\{0.744\}^{* *}$ & $\{0.314\}$ & $\{0.505\}$ & & & \\
cay_joh & 3.939 & -2.076 & 0.083 & -0.297 & 0.476 & $83.697^{* *}$ & 29.604 \\
& $(0.766)^{* *}$ & $(0.846)^{* *}$ & $(0.128)$ & $(0.529)$ & & & \\
& $\{1.288\}^{* *}$ & $\{1.409\}$ & $\{0.211\}$ & $\{0.880\}$ & & & \\
cdy_dls & -0.518 & 2.417 & 0.342 & 1.530 & 0.461 & $87.700^{* *}$ & 20.958 \\
& $(0.917)$ & $(0.685)^{* *}$ & $(0.153)^{* *}$ & $(0.543)^{* *}$ & & & \\
& $\{1.876\}$ & $\{1.388\}^{*}$ & $\{0.308\}$ & $\{1.103\}$ & & & \\
cdy_joh & -0.062 & 2.815 & 0.268 & 1.746 & 0.532 & $87.446^{* *}$ & 21.689 \\
& $(0.872)$ & $(0.806)^{* *}$ & $(0.148)^{*}$ & $(0.655)^{* *}$ & & & \\
& $\{1.751\}$ & $\{1.604\}^{*}$ & $\{0.292\}$ & $\{1.307\}$ & & & \\
lr_y & 4.725 & 0.325 & 0.019 & 0.354 & 0.604 & $78.093^{* *}$ & 4.958 \\
& $(0.868)^{* *}$ & $(0.088)^{* *}$ & $(0.146)$ & $(0.076)^{* *}$ & & & \\
lr_comp. & $\{3.445\}$ & $\{0.347\}$ & $\{0.568\}$ & $\{0.301\}$ & & & \\
& 3.606 & 0.956 & 0.400 & 0.636 & 0.195 & $82.929^{* *}$ & 14.740 \\
& $(0.706)^{* *}$ & $(0.236)^{* *}$ & $(0.155)^{* *}$ & $(0.119)^{* *}$ & & & \\
y_ld & $\{1.675\}^{* *}$ & $\{0.555\}^{*}$ & $\{0.361\}$ & $\{0.278\}^{* *}$ & & & \\
& 0.669 & -0.550 & 0.076 & 0.057 & 0.446 & $79.870^{* *}$ & 11.994 \\
& $(0.628)$ & $(0.101)^{* *}$ & $(0.170)$ & $(0.076)$ & & & \\
$y \_l s$ & $\{1.620\}$ & $\{0.252\}^{* *}$ & $\{0.433\}$ & $\{0.190\}$ & & & \\
& 2.419 & -0.399 & 0.205 & -0.035 & 0.313 & $79.752^{* *}$ & 24.468 \\
& $(0.575)^{* *}$ & $(0.126)^{* *}$ & $(0.152)$ & $(0.092)$ & & & \\
& $\{1.038\}^{* *}$ & $\{0.225\}^{*}$ & $\{0.270\}$ & $\{0.164\}$ & & & \\
\hline
\end{tabular}

This table presents Fama-MacBeth estimates of $\lambda$ for the conditional C-CAPM. The model is estimated seperately for each state variable. Stock portfolios are the 25 Fama-French portfolios. Excess returns are measured at quarterly frequencies for the period 1952Q1-2005Q4. In parentheses, below the parameter estimates, are Newey-West (1987) corrected standard errors and in curly brackets Shanken corrected standard errors. The final two columns present $\chi^{2}$ and Shanken corrected $\chi^{2}$ tests of the hypothesis of zero pricing errors. cay is the approximate consumption-aggregate wealth ratio, $c d y$ is the cointegration relation between consumption, dividends, and labour income. $d l s$ implies that the relation has been computed by dynamic least squares and $j o h$ by the Johansen (1991) procedure. $l r_{-} y$ is the long-run labour income growth relation of Julliard (2005) computed using log labour income and lr_comp is the same relation using log compensation of employees instead of log labour income. $y_{-} l d$ is based on a cointegration relation between labour income and dividends and $y_{-} l s$ is the cointegration relation between labour income and the log level of the CRSP value weighted stock index. $*-10 \%$ significance, $* *-5 \%$ significance. 
Table 45: Pricing errors from quarterly cross-sectional regressions, 1952Q1-2005Q4

\begin{tabular}{|c|c|c|c|c|c|c|c|c|c|c|c|}
\hline & def & $r t b$ & pe & $p d$ & $d e$ & py & $p c$ & $y c_{1}$ & $y c_{2}$ & $y c_{3}$ & nhe \\
\hline$s 1 b m 1$ & 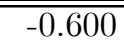 & -1.471 & -1.703 & -1.048 & -0.890 & $\overline{-0.761}$ & 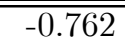 & "-0.857 & -1.028 & "-1.307 & $\overline{-1.140}$ \\
\hline$s 1 b m 2$ & -0.236 & -0.156 & -0.224 & -0.233 & 0.325 & -0.159 & -0.147 & -0.038 & 0.011 & -0.400 & -0.055 \\
\hline$s 1 b m 3$ & 0.113 & 0.602 & -0.164 & -0.400 & 0.228 & -0.234 & -0.229 & -0.007 & 0.076 & 0.186 & 0.463 \\
\hline$s 1 b m 4$ & 0.693 & 1.039 & 0.110 & -0.177 & 0.535 & -0.169 & -0.149 & 0.741 & 0.791 & 0.947 & 1.067 \\
\hline$s 1 b m 5$ & 0.843 & 1.098 & 0.765 & 0.383 & 0.190 & 0.470 & 0.468 & 0.584 & 0.675 & 0.676 & 1.056 \\
\hline$s 2 b m 1$ & -0.574 & -0.673 & -0.732 & -0.200 & -0.628 & -0.258 & -0.243 & -0.555 & -0.233 & -0.538 & -0.725 \\
\hline s $2 b m 2$ & -0.268 & 0.120 & 0.283 & 0.286 & -0.733 & 0.391 & 0.366 & -0.381 & -0.592 & -0.483 & -0.118 \\
\hline$s 2 b m 3$ & 0.369 & 0.413 & 0.247 & 0.229 & 0.515 & -0.003 & 0.003 & 0.359 & 0.513 & 0.850 & 0.558 \\
\hline$s 2 b m 4$ & 0.020 & 0.804 & 0.761 & 0.372 & 0.013 & 0.123 & 0.125 & 0.169 & 0.305 & 0.565 & 0.229 \\
\hline$s 2 b m 5$ & 0.754 & 0.386 & 0.929 & 0.724 & 0.421 & 0.742 & 0.721 & 0.475 & 0.290 & 0.779 & 0.606 \\
\hline$s 3 b m 1$ & -0.493 & -0.484 & -0.055 & 0.502 & -0.579 & 0.282 & 0.288 & 0.017 & 0.057 & -0.069 & -0.502 \\
\hline$s 3 b m 2$ & -0.303 & 0.447 & 0.367 & 0.390 & 0.254 & 0.383 & 0.393 & 0.133 & 0.292 & 0.085 & 0.242 \\
\hline s $3 b m 3$ & -0.235 & 0.073 & 0.117 & -0.041 & -0.204 & -0.213 & -0.222 & -0.214 & -0.150 & 0.027 & 0.062 \\
\hline s $3 b m 4$ & .114 & 0.350 & 0.654 & 0.530 & 0.199 & 0.471 & 0.464 & 0.302 & 0.190 & 0.394 & 0.314 \\
\hline s $3 b m 5$ & 0.198 & 0.292 & 0.623 & 0.215 & 0.560 & 0.130 & 0.130 & -0.253 & -0.062 & 0.230 & -0.079 \\
\hline$s 4 b m 1$ & -0.077 & -0.262 & -0.283 & 0.266 & 0.564 & 0.345 & 0.369 & 0.396 & 0.358 & 0.123 & -0.110 \\
\hline$s 4 b m 2$ & -0.082 & -0.166 & -0.559 & -0.469 & -0.027 & -0.377 & -0.354 & 0.087 & 0.184 & -0.190 & 0.041 \\
\hline$s 4 b m 3$ & -0.033 & 0.319 & 0.519 & 0.351 & 0.177 & 0.572 & 0.565 & 0.046 & 0.026 & -0.217 & 0.411 \\
\hline$s 4 b m 4$ & 0.110 & 0.137 & 0.227 & 0.121 & 0.727 & 0.258 & 0.262 & 0.026 & 0.085 & 0.392 & 0.025 \\
\hline$s 4 b m 5$ & -0.110 & -0.007 & 0.589 & 0.333 & -0.085 & 0.141 & 0.116 & -0.295 & -0.386 & -0.151 & -0.392 \\
\hline$s 5 b m 1$ & 0.097 & -0.650 & -0.945 & -0.415 & -0.026 & -0.373 & -0.372 & 0.411 & 0.093 & 0.136 & -0.360 \\
\hline s $5 b m 2$ & 0.269 & -0.117 & -0.582 & -0.569 & -0.039 & -0.616 & -0.618 & -0.482 & -0.312 & -0.365 & -0.358 \\
\hline s5bm3 & 0.852 & -0.390 & 0.683 & -0.459 & -0.039 & -0.193 & -0.196 & 0.397 & 0.140 & -0.028 & 0.434 \\
\hline$s 5 b m 4$ & -0.814 & -0.637 & -0.046 & -0.277 & -0.829 & -0.288 & -0.307 & -0.779 & -0.891 & -0.820 & -0.712 \\
\hline$s 5 b m 5$ & -0.608 & -1.067 & -0.215 & -0.415 & -0.632 & -0.664 & -0.670 & -0.281 & -0.433 & -0.822 & -0.957 \\
\hline \multirow[t]{2}{*}{$\overline{\overline{R M S E}}$} & 0.449 & 0.609 & 0.615 & 0.427 & 0.466 & 0.398 & 0.395 & 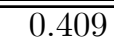 & 0.427 & 0.545 & 0.554 \\
\hline & $(0.043)$ & $(0.066)$ & $(0.066)$ & $(0.040)$ & $(0.044)$ & $(0.037)$ & $(0.037)$ & $(0.033)$ & $(0.039)$ & $(0.049)$ & $(0.058)$ \\
\hline \multirow[t]{2}{*}{$C E_{\text {full }}$} & 0.772 & 0.701 & 0.738 & 0.671 & 0.809 & 0.731 & 0.724 & 0.782 & 0.762 & 0.840 & 0.748 \\
\hline & $(0.066)$ & $(0.048)$ & $(0.050)$ & $(0.053)$ & $(0.075)$ & $(0.063)$ & $(0.061)$ & $(0.065)$ & $(0.061)$ & $(0.076)$ & $(0.059)$ \\
\hline \multirow[t]{2}{*}{$C E_{\text {diag. }}$} & 0.235 & 0.283 & 0.286 & 0.205 & 0.229 & 0.199 & 0.198 & 0.204 & 0.208 & 0.258 & 0.264 \\
\hline & $(0.023)$ & $(0.032)$ & $(0.033)$ & $(0.022)$ & $(0.023)$ & $(0.022)$ & $(0.022)$ & $(0.017)$ & $(0.020)$ & $(0.024)$ & $(0.028)$ \\
\hline \multirow[t]{2}{*}{$H J-d i s t$} & 0.723 & 0.620 & 0.700 & 0.648 & 0.755 & 0.711 & 0.703 & 0.723 & 0.699 & 0.762 & 0.667 \\
\hline & $(0.066)$ & $(0.045)$ & (0.057) & $(0.055)$ & $(0.074)$ & $(0.065)$ & $(0.063)$ & $(0.064)$ & $(0.060)$ & $(0.076)$ & $(0.058)$ \\
\hline
\end{tabular}

This table presents time-series averages of pricing errors resulting from estimating the conditional C-CAPM on the 25 Fama-French portfolios. The bottom rows show weighted average pricing errors across the 25 portfolios. $R M S E$ is the square root of the average of squared pricing errors. $C E_{f u l l}$ weights the pricing errors of the 25 portfolios by the variance-covariance matrix of portfolio returns. $C E_{\text {diag. }}$ weights the pricing errors of the 25 portfolios by the diagonal variance matrix of portfolio returns. HJ - dist weights the pricing errors of the 25 portfolios by the moment matrix of portfolio returns. Asymptotic standard errors for the pricing error measures are in parentheses. def is the default premium on bonds, rtb is the relative t-bill rate, $p e$ is the $\log$ price-earnings ratio on the $\mathrm{S} \& \mathrm{P} 500$, and $p d$ is the $\log$ price-dividend ratio on the CRSP value-weighted portfolio, de is the log dividend-earnings ratio on the $\mathrm{S} \& \mathrm{P} 500, p y$ is the log price-output ratio, $p c$ is the log price-consumption ratio, $y c_{1}$ is the log labour income-consumption ratio, $y c_{2}$ is the $\log$ compensation of employees-consumption ratio, $y c_{3}$ is the log labour income-compensation of employees ratio, and nhe is the log non-housing consumption share. 
Table 46: Pricing errors from quarterly cross-sectional regressions, 1952Q1-2005Q4

\begin{tabular}{|c|c|c|c|c|c|c|c|c|}
\hline & cay_dls & cay_joh & $c d y \_d l s$ & $c d y_{-} j o h$ & $l r_{-} y$ & lr_comp. & $\overline{y \_l d}$ & $y \_l s$ \\
\hline$s 1 b m 1$ & -1.354 & -1.583 & -0.847 & -0.870 & -0.805 & -1.489 & -0.474 & -1.516 \\
\hline$s 1 b m 2$ & 0.138 & 0.137 & -0.567 & -0.460 & -0.164 & 0.209 & -0.320 & -0.117 \\
\hline$s 1 b m 3$ & -0.306 & -0.424 & 0.099 & 0.067 & 0.255 & 0.304 & 0.313 & -0.274 \\
\hline$s 1 b m 4$ & 0.348 & 0.148 & 0.557 & 0.517 & 0.436 & 0.635 & 0.454 & -0.109 \\
\hline$s 1 b m 5$ & 0.445 & 0.485 & 0.534 & 0.422 & 0.565 & 0.864 & 0.986 & 0.636 \\
\hline$s 2 b m 1$ & -0.239 & -0.278 & -0.369 & -0.386 & -0.212 & -0.460 & -0.671 & -0.489 \\
\hline$s 2 b m 2$ & -0.370 & -0.259 & 0.329 & 0.277 & -0.276 & -0.043 & 0.336 & 0.314 \\
\hline$s 2 b m 3$ & 0.371 & 0.336 & 0.605 & 0.596 & -0.075 & 0.498 & -0.092 & 0.220 \\
\hline$s 2 b m 4$ & 0.447 & 0.568 & 0.641 & 0.542 & 0.360 & 0.596 & 0.171 & 0.510 \\
\hline$s 2 b m 5$ & 0.315 & 0.398 & 0.494 & 0.401 & 0.597 & -0.022 & 0.830 & 0.820 \\
\hline$s 3 b m 1$ & 0.530 & 0.559 & -0.167 & -0.115 & -0.577 & -1.045 & -0.529 & 0.278 \\
\hline$s 3 b m 2$ & 0.179 & 0.196 & 0.575 & 0.505 & 0.034 & 0.471 & 0.463 & 0.330 \\
\hline$s 3 b m 3$ & -0.233 & -0.168 & 0.075 & 0.019 & -0.364 & 0.112 & -0.166 & 0.063 \\
\hline s $3 b m 4$ & 0.340 & 0.440 & 0.266 & 0.191 & -0.231 & 0.345 & 0.477 & 0.575 \\
\hline$s 3 b m 5$ & 0.221 & 0.501 & 0.479 & 0.409 & 0.152 & 0.375 & -0.019 & 0.547 \\
\hline$s 4 b m 1$ & 0.598 & 0.436 & 0.456 & 0.631 & 0.502 & 0.044 & -0.274 & -0.076 \\
\hline$s 4 b m 2$ & -0.091 & -0.289 & -0.640 & -0.591 & -0.213 & -0.237 & -0.200 & -0.520 \\
\hline$s 4 b m 3$ & -0.082 & 0.017 & -0.023 & -0.131 & 0.298 & 0.545 & 0.766 & 0.551 \\
\hline$s 4 b m 4$ & 0.110 & 0.218 & 0.430 & 0.426 & -0.033 & 0.169 & 0.105 & 0.189 \\
\hline$s 4 b m 5$ & 0.090 & 0.350 & -0.403 & -0.365 & 0.561 & 0.626 & -0.349 & 0.575 \\
\hline$s 5 b m 1$ & 0.102 & -0.214 & -0.328 & -0.016 & 0.019 & -1.246 & -0.665 & -0.788 \\
\hline s5bm2 & -0.433 & -0.439 & -0.482 & -0.517 & 0.560 & 0.035 & -0.435 & -0.600 \\
\hline s $5 b m 3$ & -0.322 & -0.619 & -0.441 & -0.407 & -0.235 & -0.465 & 0.468 & -0.633 \\
\hline s5bm4 & -0.498 & -0.255 & -0.626 & -0.658 & -0.882 & -0.468 & -0.474 & -0.000 \\
\hline$s 5 b m 5$ & -0.304 & -0.261 & -0.648 & -0.487 & -0.273 & -0.354 & -0.704 & -0.484 \\
\hline \multirow[t]{2}{*}{$R M S E$} & 0.422 & 0.478 & 0.485 & 0.452 & 0.416 & 0.593 & 0.492 & 0.548 \\
\hline & $(0.036)$ & $(0.043)$ & $(0.049)$ & $(0.042)$ & $(0.036)$ & $(0.067)$ & $(0.057)$ & $(0.057)$ \\
\hline \multirow[t]{2}{*}{$C E_{f u l l}$} & 0.691 & 0.720 & 0.855 & 0.849 & 0.791 & 0.856 & 0.817 & 0.743 \\
\hline & $(0.053)$ & $(0.055)$ & $(0.071)$ & $(0.072)$ & $(0.067)$ & $(0.067)$ & $(0.067)$ & $(0.061)$ \\
\hline \multirow[t]{2}{*}{$C E_{\text {diag. }}$} & 0.187 & 0.212 & 0.242 & 0.225 & 0.211 & 0.275 & 0.246 & 0.259 \\
\hline & $(0.017)$ & $(0.020)$ & $(0.027)$ & $(0.023)$ & $(0.019)$ & $(0.033)$ & $(0.029)$ & $(0.029)$ \\
\hline \multirow[t]{2}{*}{$H J-d i s t$} & 0.638 & 0.676 & 0.786 & 0.778 & 0.752 & 0.804 & 0.786 & 0.719 \\
\hline & $(0.052)$ & $(0.057)$ & $(0.071)$ & $(0.071)$ & $(0.068)$ & $(0.066)$ & $(0.068)$ & $(0.064)$ \\
\hline
\end{tabular}

This table presents time-series averages of pricing errors resulting from estimating the conditional C-CAPM on the 25 Fama-French portfolios. The bottom rows show weighted average pricing errors across the 25 portfolios. RMSE is the square root of the average of squared pricing errors. $C E_{f u l l}$ weights the pricing errors of the 25 portfolios by the variance-covariance matrix of portfolio returns. $C E_{d i a g}$. weights the pricing errors of the 25 portfolios by the diagonal variance matrix of portfolio returns. $H J-d i s t$ weights the pricing errors of the 25 portfolios by the moment matrix of portfolio returns. Asymptotic standard errors for the pricing error measures are in parentheses. cay is the approximate consumption-aggregate wealth ratio, $c d y$ is the cointegration relation between consumption, dividends, and labour income. $d l s$ implies that the relation has been computed by dynamic least squares. $j o h$ by the Johansen (1991) procedure. $l r_{-} y$ is the long-run labour income growth relation of Julliard (2005) computed using log labour income and $l r_{-} c o m p$ is the same relation using log compensation of employees instead of log labour income. $y \_l d$ is based on a cointegration relation between labour income and dividends and $y_{-} l s$ is the cointegration relation between labour income and the log level of the CRSP value-weighted stock index. 
Table 47: Quarterly cross-sectional regressions, 1947Q2-2005Q4

\begin{tabular}{|c|c|c|c|c|c|c|c|}
\hline & intercept & state $_{t}$ & $\overline{\Delta \Delta c_{t+1}}$ & $\overline{\Delta \Delta c_{t+1} * \text { state }_{t}}$ & 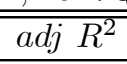 & $\overline{\chi^{2}}$ & $\chi_{\text {shanken }}^{2}$ \\
\hline def & $\begin{array}{l}3.831 \\
(0.722)^{* *} \\
\{1.661\}^{* *}\end{array}$ & $\begin{array}{l}0.032 \\
(0.035) \\
\{0.079\}\end{array}$ & $\begin{array}{l}-0.347 \\
(0.163)^{* *} \\
\{0.370\}\end{array}$ & $\begin{array}{l}-0.072 \\
(0.041)^{*} \\
\{0.094\}\end{array}$ & 0.486 & $81.711^{* *}$ & 15.456 \\
\hline$r t b$ & $\begin{array}{l}2.856 \\
(0.597)^{* *} \\
\{0.968\}^{* *}\end{array}$ & $\begin{array}{l}0.168 \\
(0.067)^{* *} \\
\{0.107\}\end{array}$ & $\begin{array}{l}0.355 \\
(0.172)^{* *} \\
\{0.276\}\end{array}$ & $\begin{array}{l}0.094 \\
(0.045)^{* *} \\
\{0.072\}\end{array}$ & 0.177 & $87.523^{* *}$ & $33.297^{* *}$ \\
\hline pe & $\begin{array}{l}2.769 \\
(0.527)^{* *} \\
\{0.847\}^{* *}\end{array}$ & $\begin{array}{l}0.497 \\
(0.124)^{* *} \\
\{0.196\}^{* *}\end{array}$ & $\begin{array}{l}0.226 \\
(0.201) \\
\{0.321\}\end{array}$ & $\begin{array}{l}0.193 \\
(0.117)^{*} \\
\{0.186\}\end{array}$ & 0.114 & $84.246^{* *}$ & 32.65 \\
\hline$p d$ & $\begin{array}{l}2.745 \\
(0.499)^{* *} \\
\{1.023\}^{* *}\end{array}$ & $\begin{array}{l}0.532 \\
(0.148)^{* *} \\
\{0.297\}^{*}\end{array}$ & $\begin{array}{l}0.176 \\
(0.205) \\
\{0.417\}\end{array}$ & $\begin{array}{l}0.551 \\
(0.182)^{* *} \\
\{0.370\}\end{array}$ & 0.426 & $72.400^{* *}$ & 17.254 \\
\hline$d e$ & $\begin{array}{l}2.980 \\
(0.530)^{* *} \\
\{1.197\}^{* *}\end{array}$ & $\begin{array}{l}0.097 \\
(0.046)^{* *} \\
\{0.101\}\end{array}$ & $\begin{array}{l}-0.500 \\
(0.254)^{* *} \\
\{0.569\}\end{array}$ & $\begin{array}{l}0.156 \\
(0.031)^{* *} \\
\{0.068\}^{* *}\end{array}$ & 0.443 & $79.276^{* *}$ & 15.565 \\
\hline py & $\begin{array}{l}2.857 \\
(0.486)^{* *} \\
\{1.002\}^{* *}\end{array}$ & $\begin{array}{l}0.758 \\
(0.140)^{* *} \\
\{0.278\}^{* *}\end{array}$ & $\begin{array}{l}0.198 \\
(0.202) \\
\{0.411\}\end{array}$ & $\begin{array}{l}-0.153 \\
(0.181) \\
\{0.370\}\end{array}$ & 0.414 & $80.583^{* *}$ & 18.970 \\
\hline$p c$ & $\begin{array}{l}2.883 \\
(0.486)^{* *} \\
\{1.011\}^{* *}\end{array}$ & $\begin{array}{l}-0.732 \\
(0.137)^{* *} \\
\{0.274\}^{\text {** }}\end{array}$ & $\begin{array}{l}0.214 \\
(0.202) \\
\{0.415\}\end{array}$ & $\begin{array}{l}0.194 \\
(0.189) \\
\{0.390\}\end{array}$ & 0.414 & $80.681^{* *}$ & 18.646 \\
\hline$y c_{1}$ & $\begin{array}{l}2.800 \\
(0.500)^{* *} \\
\{1.402\}^{* *}\end{array}$ & $\begin{array}{l}0.306 \\
(0.094)^{* *} \\
\{0.259\}\end{array}$ & $\begin{array}{l}-0.400 \\
(0.215)^{*} \\
\{0.599\}\end{array}$ & $\begin{array}{l}0.654 \\
(0.115)^{* *} \\
\{0.318\}^{* *}\end{array}$ & 0.197 & $77.807^{* *}$ & 9.887 \\
\hline$y c_{2}$ & $\begin{array}{l}2.886 \\
(0.500)^{* *} \\
\{1.388\}^{* *}\end{array}$ & $\begin{array}{l}0.326 \\
(0.097)^{* *} \\
\{0.264\}\end{array}$ & $\begin{array}{l}-0.360 \\
(0.219) \\
\{0.601\}\end{array}$ & $\begin{array}{l}0.659 \\
(0.116)^{* *} \\
\{0.317\}^{* *}\end{array}$ & 0.159 & $78.965^{* *}$ & 10.270 \\
\hline$y c_{3}$ & $\begin{array}{l}3.775 \\
(0.643)^{* *} \\
\{1.451\}^{* *}\end{array}$ & $\begin{array}{l}1.567 \\
(0.713)^{* *} \\
\{1.577\}\end{array}$ & $\begin{array}{l}0.146 \\
(0.150) \\
\{0.332\}\end{array}$ & $\begin{array}{l}-1.828 \\
(0.840)^{* *} \\
\{1.882\}\end{array}$ & 0.142 & $89.250^{* *}$ & 17.542 \\
\hline nhe & $\begin{array}{l}3.360 \\
(0.521)^{* *} \\
\{1.116\}^{* *}\end{array}$ & $\begin{array}{l}-2.355 \\
(0.579)^{* *} \\
\{1.227\}^{*}\end{array}$ & $\begin{array}{l}-0.007 \\
(0.150) \\
\{0.315\}\end{array}$ & $\begin{array}{l}0.292 \\
(0.668) \\
\{1.424\}\end{array}$ & 0.231 & $88.400^{* *}$ & 19.219 \\
\hline
\end{tabular}

This table presents Fama-MacBeth estimates of $\lambda$ for the conditional C-CAPM. The model is estimated seperately for each state variable. Stock portfolios are the 25 Fama-French portfolios. Excess returns are measured at quarterly frequencies for the period 1947Q2-2005Q4. In parentheses, below the parameter estimates, are Newey-West (1987) corrected standard errors and in curly brackets Shanken corrected standard errors. The final two columns present $\chi^{2}$ and Shanken corrected $\chi^{2}$ tests of the hypothesis of zero pricing errors. def is the default premium on bonds, $r t b$ is the relative t-bill rate, pe is the log price-earnings ratio on the $\mathrm{S} \& \mathrm{P} 500$, and $p d$ is the log price-dividend ratio on the CRSP value-weighted portfolio, de is the log dividend-earnings ratio on the $\mathrm{S} \& \mathrm{P} 500, p y$ is the $\log$ price-output ratio, $p c$ is the $\log$ price-consumption ratio, $y c_{1}$ is the log labour income-consumption ratio, $y c_{2}$ is the log compensation of employees-consumption ratio, $y c_{3}$ is the log labour income-compensation of employees ratio, and nhe is the log non-housing consumption share. $*-10 \%$ significance, $* *-5 \%$ significance. 
Table 48: Quarterly cross-sectional regressions, 1947Q2-2005Q4

\begin{tabular}{llllllll}
\hline \hline & intercept & state $_{t}$ & $\Delta c_{t+1}$ & $\Delta c_{t+1} *$ state $_{t}$ & adj $R^{2}$ & $\chi^{2}$ & $\chi_{\text {shanken }}^{2}$ \\
\hline \hline lr_y & 1.88 & 0.0061 & -0.361 & 0.097 & 0.325 & $82.917^{* *}$ & 17.507 \\
& $(0.502)^{* *}$ & $(0.030)^{* *}$ & $(0.148)^{* *}$ & $(0.028)^{* *}$ & & & \\
& $\{1.093\}^{*}$ & $\{0.064\}$ & $\{0.316\}$ & $\{0.061\}$ & & & \\
lr_comp. & 3.060 & 0.835 & 0.330 & 0.365 & 0.299 & $87.190^{* *}$ & 24.595 \\
& $(0.577)^{* *}$ & $(0.204)^{* *}$ & $(0.180)^{*}$ & $(0.106)^{* *}$ & & & \\
& $\{1.086\}^{* *}$ & $\{0.380\}^{* *}$ & $\{0.334\}$ & $\{0.196\}^{*}$ & & & \\
$y \_l d$ & 1.410 & -0.573 & 0.206 & 0.211 & 0.426 & $85.688^{* *}$ & 11.885 \\
& $(0.533)^{* *}$ & $(0.110)^{* *}$ & $(0.181)$ & $(0.120)^{*}$ & & & \\
& $\{1.432\}$ & $\{0.286\}^{* *}$ & $\{0.480\}$ & $\{0.317\}$ & & & \\
& 3.094 & -0.495 & 0.224 & -0.254 & 0.160 & $83.708^{* *}$ & 29.146 \\
& $(0.538)^{* *}$ & $(0.125)^{* *}$ & $(0.199)$ & $(0.127)^{* *}$ & & & \\
& $\{0.912\}^{* *}$ & $\{0.209\}^{* *}$ & $\{0.335\}$ & $\{0.214\}$ & & & \\
\hline \hline
\end{tabular}

This table presents Fama-MacBeth estimates of $\lambda$ for the conditional C-CAPM. The model is estimated seperately for each state variable. Stock portfolios are the 25 Fama-French portfolios. Excess returns are measured at quarterly frequencies for the period 1947Q2-2005Q4. In parentheses, below the parameter estimates, are Newey-West (1987) corrected standard errors and in curly brackets Shanken corrected standard errors. The final two columns present $\chi^{2}$ and Shanken corrected $\chi^{2}$ tests of the hypothesis of zero pricing errors. $l r_{-} y$ is the long-run labour income growth relation of Julliard (2005) computed using log labour income and $l r_{-}$comp is the same relation using log compensation of employees instead of log labour income. $y_{-} l d$ is based on a cointegration relation between labour income and dividends and $y_{-} l s$ is the cointegration relation between labour income and the log level of the CRSP value-weighted stock index. $*-10 \%$ significance, $* *-5 \%$ significance. 
Table 49: Pricing errors from quarterly cross-sectional regressions, 1947Q2-2005Q4

\begin{tabular}{lrrrr}
\hline \hline & $R M S E$ & $C E_{\text {full }}$ & $C E_{\text {diag. }}$ & $H J-$ dist \\
\hline \hline$d e f$ & 0.459 & 0.772 & 0.238 & 0.727 \\
& $(0.043)$ & $(0.063)$ & $(0.023)$ & $(0.064)$ \\
$r t b$ & 0.581 & 0.680 & 0.268 & 0.601 \\
& $(0.062)$ & $(0.046)$ & $(0.030)$ & $(0.043)$ \\
$p e$ & 0.602 & 0.751 & 0.281 & 0.715 \\
& $(0.063)$ & $(0.055)$ & $(0.031)$ & $(0.055)$ \\
$p d$ & 0.485 & 0.734 & 0.237 & 0.720 \\
& $(0.053)$ & $(0.061)$ & $(0.026)$ & $(0.063)$ \\
$d e$ & 0.478 & 0.773 & 0.229 & 0.730 \\
& $(0.046)$ & $(0.071)$ & $(0.023)$ & $(0.071)$ \\
$p y$ & 0.490 & 0.883 & 0.233 & 0.851 \\
& $(0.046)$ & $(0.080)$ & $(0.023)$ & $(0.081)$ \\
$p c$ & 0.490 & 0.890 & 0.232 & 0.855 \\
& $(0.046)$ & $(0.081)$ & $(0.023)$ & $(0.081)$ \\
$y c_{1}$ & 0.573 & 0.720 & 0.262 & 0.700 \\
& $(0.067)$ & $(0.051)$ & $(0.030)$ & $(0.052)$ \\
$y c_{2}$ & 0.587 & 0.721 & 0.267 & 0.698 \\
& $(0.068)$ & $(0.050)$ & $(0.031)$ & $(0.051)$ \\
$y c_{3}$ & 0.592 & 0.891 & 0.266 & 0.820 \\
& $(0.054)$ & $(0.082)$ & $(0.025)$ & $(0.082)$ \\
$n h e$ & 0.561 & 0.907 & 0.261 & 0.848 \\
& $(0.053)$ & $(0.076)$ & $(0.026)$ & $(0.076)$ \\
$l r_{-} y$ & 0.526 & 0.703 & 0.231 & 0.646 \\
& $(0.052)$ & $(0.052)$ & $(0.023)$ & $(0.051)$ \\
$l r_{-}$comp. & 0.536 & 0.797 & 0.250 & 0.733 \\
& $(0.057)$ & $(0.058)$ & $(0.029)$ & $(0.057)$ \\
$y \_l d$ & 0.485 & 0.916 & 0.253 & 0.877 \\
& $(0.050)$ & $(0.075)$ & $(0.026)$ & $(0.075)$ \\
$y \_l s$ & 0.586 & 0.758 & 0.273 & 0.727 \\
& $(0.061)$ & $(0.058)$ & $(0.030)$ & $(0.060)$ \\
\hline \hline
\end{tabular}

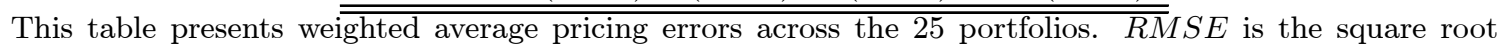
of the average of squared pricing errors. $C E_{f u l l}$ weights the pricing errors of the 25 portfolios by the variance-covariance matrix of portfolio returns. $C E_{\text {diag }}$. weights the pricing errors of the 25 portfolios by the diagonal variance matrix of portfolio returns. $H J$ - dist weights the pricing errors of the 25 portfolios by the moment matrix of portfolio returns. Asymptotic standard errors for the pricing error measures are in parentheses. def is the default premium on bonds, $r t b$ is the relative t-bill rate, $p e$ is the $\log$ price-earnings ratio on the $\mathrm{S} \& \mathrm{P} 500$, and $p d$ is the log price-dividend ratio on the CRSP value-weighted portfolio, de is the log dividend-earnings ratio on the $\mathrm{S} \& \mathrm{P} 500, p y$ is the log price-output ratio, $p c$ is the $\log$ price-consumption ratio, $y c_{1}$ is the $\log$ labour income-consumption ratio, $y c_{2}$ is the log compensation of employees-consumption ratio, $y c_{3}$ is the log labour income-compensation of employees ratio, and nhe is the log non-housing consumption share. cay is the approximate consumption-aggregate wealth ratio, $c d y$ is the cointegration relation between consumption, dividends, and labour income. $d l s$ implies that the relation has been computed by dynamic least squares. $l r_{-} y$ is the long-run labour income growth relation of Julliard (2005) computed using log labour income and lr_comp is the same relation using log compensation of employees instead of log labour income. $y_{-} l d$ is based on a cointegration relation between labour income and dividends and $y \_l s$ is the cointegration relation between labour income and the log level of the CRSP value-weighted stock index. 
Table 50: Quarterly cross-sectional regressions, 1952Q1-1994Q4

\begin{tabular}{|c|c|c|c|c|c|c|c|}
\hline & intercept & state $_{t}$ & $\overline{\Delta \Delta c_{t+1}}$ & $\overline{\Delta \Delta c_{t+1} * \text { state }_{t}}$ & 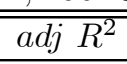 & $\chi^{2}$ & $\chi_{\text {shanken }}^{2}$ \\
\hline def & $\begin{array}{l}2.911 \\
(0.816)^{* *} \\
\{1.577\}^{*}\end{array}$ & $\begin{array}{l}-0.009 \\
(0.047) \\
\{0.090\}\end{array}$ & $\begin{array}{l}-0.187 \\
(0.149) \\
\{0.282\}\end{array}$ & $\begin{array}{l}-0.090 \\
(0.051)^{*} \\
\{0.098\}\end{array}$ & 0.559 & $70.047^{* *}$ & 18.762 \\
\hline$r t b$ & $\begin{array}{l}2.520 \\
(0.767)^{* *} \\
\{1.398\}^{*}\end{array}$ & $\begin{array}{l}0.216 \\
(0.070)^{* *} \\
\{0.125\}^{*}\end{array}$ & $\begin{array}{l}0.287 \\
(0.159)^{*} \\
\{0.277\}\end{array}$ & $\begin{array}{l}0.027 \\
(0.051) \\
\{0.092\}\end{array}$ & 0.612 & $61.840^{* *}$ & 18.605 \\
\hline pe & $\begin{array}{l}2.370 \\
(0.714)^{* *} \\
\{1.565\}\end{array}$ & $\begin{array}{l}0.058 \\
(0.119) \\
\{0.025\}\end{array}$ & $\begin{array}{l}-0.002 \\
(0.140) \\
\{0.297\}\end{array}$ & $\begin{array}{l}0.347 \\
(0.136)^{* *} \\
\{0.296\}\end{array}$ & 0.407 & $74.533^{* *}$ & 15.537 \\
\hline$p d$ & $\begin{array}{l}2.514 \\
(0.735)^{* *} \\
\{1.243\}^{* *}\end{array}$ & $\begin{array}{l}0.222 \\
(0.079)^{* *} \\
\{0.131\}^{*}\end{array}$ & $\begin{array}{l}0.392 \\
(0.162)^{* *} \\
\{0.270\}\end{array}$ & $\begin{array}{l}0.166 \\
(0.056)^{* *} \\
\{0.093\}^{*}\end{array}$ & 0.253 & $69.506^{* *}$ & 24.271 \\
\hline de & $\begin{array}{l}1.750 \\
(0.615)^{* *} \\
\{1.140\}\end{array}$ & $\begin{array}{l}0.101 \\
(0.054)^{*} \\
\{0.099\}\end{array}$ & $\begin{array}{l}-0.081 \\
(0.167) \\
\{0.303\}\end{array}$ & $\begin{array}{l}0.140 \\
(0.040)^{* *} \\
\{0.073\}^{*}\end{array}$ & 0.696 & $62.689^{* *}$ & 18.250 \\
\hline py & $\begin{array}{l}3.811 \\
(0.814)^{* *} \\
\{1.929\}^{* *}\end{array}$ & $\begin{array}{l}0.589 \\
(0.199)^{* *} \\
\{0.467\}\end{array}$ & $\begin{array}{l}0.289 \\
(0.168)^{*} \\
\{0.391\}\end{array}$ & $\begin{array}{l}0.471 \\
(0.149)^{* *} \\
\{0.351\}\end{array}$ & 0.285 & $67.036^{* *}$ & 11.930 \\
\hline$p c$ & $\begin{array}{l}3.708 \\
(0.822)^{* *} \\
\{1.822\}^{* *}\end{array}$ & $\begin{array}{l}0.560 \\
(0.190)^{* *} \\
\{0.418\}\end{array}$ & $\begin{array}{l}0.307 \\
(0.166)^{*} \\
\{0.362\}\end{array}$ & $\begin{array}{l}0.418 \\
(0.140) \\
\{0.309\}\end{array}$ & 0.249 & $67.359^{* *}$ & 13.688 \\
\hline$y c_{1}$ & $\begin{array}{l}3.108 \\
(0.647)^{* *} \\
\{0.995\}^{* *}\end{array}$ & $\begin{array}{l}2.757 \\
(1.386)^{* *} \\
\{2.111\}\end{array}$ & $\begin{array}{l}-0.058 \\
(0.143) \\
\{0.215\}\end{array}$ & $\begin{array}{l}0.066 \\
(1.140) \\
\{1.740\}\end{array}$ & 0.562 & $74.555^{* *}$ & 31.513 \\
\hline$y c_{2}$ & $\begin{array}{l}2.580 \\
(0.645)^{* *} \\
\{0.958\}^{* *}\end{array}$ & $\begin{array}{l}1.184 \\
(1.049) \\
\{1.537\}\end{array}$ & $\begin{array}{l}0.013 \\
(0.207) \\
\{0.305\}\end{array}$ & $\begin{array}{l}-1.037 \\
(0.806) \\
\{1.184\}\end{array}$ & 0.570 & $74.514^{* *}$ & $33.696^{*}$ \\
\hline$y c_{3}$ & $\begin{array}{l}2.718 \\
(0.613)^{* *} \\
\{0.983\}^{* *}\end{array}$ & $\begin{array}{l}0.330 \\
(0.662) \\
\{1.042\}\end{array}$ & $\begin{array}{l}0.072 \\
(0.136) \\
\{0.213\}\end{array}$ & $\begin{array}{l}-1.032 \\
(0.580)^{*} \\
\{0.920\}\end{array}$ & 0.436 & $75.510^{* *}$ & 29.316 \\
\hline nhe & $\begin{array}{l}2.248 \\
(0.586)^{* *} \\
\{0.951\}^{* *}\end{array}$ & $\begin{array}{l}-0.993 \\
(0.442)^{* *} \\
\{0.707\}\end{array}$ & $\begin{array}{l}-0.053 \\
(0.147) \\
\{0.234\}\end{array}$ & $\begin{array}{l}0.195 \\
(0.392) \\
\{0.630\}\end{array}$ & 0.452 & $74.430^{* *}$ & 28.220 \\
\hline
\end{tabular}

This table presents Fama-MacBeth estimates of $\lambda$ for the conditional C-CAPM. The model is estimated seperately for each state variable. Stock portfolios are the 25 Fama-French portfolios. Excess returns are measured at quarterly frequencies for the period 1952Q1-1994Q4. In parentheses, below the parameter estimates, are Newey-West (1987) corrected standard errors and in curly brackets Shanken corrected standard errors. The final two columns present $\chi^{2}$ and Shanken corrected $\chi^{2}$ tests of the hypothesis of zero pricing errors. def is the default premium on bonds, $r t b$ is the relative t-bill rate, pe is the $\log$ price-earnings ratio on the $\mathrm{S} \& \mathrm{P} 500$, and $p d$ is the log price-dividend ratio on the CRSP value-weighted portfolio, de is the log dividend-earnings ratio on the $\mathrm{S} \& \mathrm{P} 500, p y$ is the $\log$ price-output ratio, $p c$ is the $\log$ price-consumption ratio, $y c_{1}$ is the log labour income-consumption ratio, $y c_{2}$ is the log compensation of employees-consumption ratio, $y c_{3}$ is the log labour income-compensation of employees ratio, and nhe is the log non-housing consumption share. $*-10 \%$ significance, $* *-5 \%$ significance. 
Table 51: Quarterly cross-sectional regressions, 1952Q1-1994Q4

\begin{tabular}{|c|c|c|c|c|c|c|c|}
\hline & intercept & state $_{t}$ & $\Delta c_{t+1}$ & $\Delta c_{t+1} *$ state $_{t}$ & $\overline{a d j} R^{2}$ & $\chi^{2}$ & $\chi_{\text {shanken }}^{2}$ \\
\hline cay_dls & $\begin{array}{l}2.883 \\
(1.048)^{* *} \\
\{1.628\}^{*}\end{array}$ & $\begin{array}{l}-0.052 \\
(0.405) \\
\{0.619\}\end{array}$ & $\begin{array}{l}-0.110 \\
(0.151) \\
\{0.231\}\end{array}$ & $\begin{array}{l}0.743 \\
(0.304)^{* *} \\
\{0.464\}\end{array}$ & 0.495 & $73.375^{* *}$ & $\begin{array}{l}30.418 \\
\end{array}$ \\
\hline$c d y \_d l s$ & $\begin{array}{l}0.601 \\
(0.966) \\
\{2.526\}\end{array}$ & $\begin{array}{l}0.300 \\
(0.550) \\
\{1.413\}\end{array}$ & $\begin{array}{l}0.459 \\
(0.175)^{* *} \\
\{0.450\}\end{array}$ & $\begin{array}{l}1.684 \\
(0.493)^{* *} \\
\{1.272\}\end{array}$ & 0.469 & $69.075^{* *}$ & 10.094 \\
\hline$l r \_y$ & $\begin{array}{l}5.433 \\
(1.039)^{* *} \\
\{3.359\}\end{array}$ & $\begin{array}{l}0.328 \\
(0.094)^{* *} \\
\{0.302\}\end{array}$ & $\begin{array}{l}-0.077 \\
(0.154) \\
\{0.486\}\end{array}$ & $\begin{array}{l}0.305 \\
(0.071)^{* *} \\
\{0.227\}\end{array}$ & 0.364 & $71.527^{* *}$ & 6.839 \\
\hline$l r \_c o m p$. & $\begin{array}{l}3.504 \\
(0.745)^{* *} \\
\{1.784\}^{* *}\end{array}$ & $\begin{array}{l}1.056 \\
(0.268)^{* *} \\
\{0.634\}^{*}\end{array}$ & $\begin{array}{l}0.447 \\
(0.175)^{* *} \\
\{0.411\}\end{array}$ & $\begin{array}{l}0.795 \\
(0.156)^{* *} \\
\{0.368\}^{* *}\end{array}$ & 0.307 & $67.494^{* *}$ & 11.763 \\
\hline$y \_l d$ & $\begin{array}{l}0.957 \\
(0.723) \\
\{0.918\}\end{array}$ & $\begin{array}{l}-0.149 \\
(0.079)^{*} \\
\{0.099\}\end{array}$ & $\begin{array}{l}0.157 \\
(0.173) \\
\{0.218\}\end{array}$ & $\begin{array}{l}0.029 \\
(0.074) \\
\{0.092\}\end{array}$ & -0.029 & $72.890^{* *}$ & $45.171^{* *}$ \\
\hline$y \_l s$ & $\begin{array}{l}1.759 \\
(0.689)^{* *} \\
\{1.337\}\end{array}$ & $\begin{array}{l}-0.121 \\
(0.113) \\
\{0.216\}\end{array}$ & $\begin{array}{l}0.130 \\
(0.153) \\
\{0.290\}\end{array}$ & $\begin{array}{l}-0.313 \\
(0.125)^{* *} \\
\{0.240\}\end{array}$ & 0.236 & $74.720^{* *}$ & 19.869 \\
\hline
\end{tabular}

This table presents Fama-MacBeth estimates of $\lambda$ for the conditional C-CAPM. The model is estimated seperately for each state variable. Stock portfolios are the 25 Fama-French portfolios. Excess returns are measured at quarterly frequencies for the period 1952Q1-1994Q4. In parentheses, below the parameter estimates, are Newey-West (1987) corrected standard errors and in curly brackets Shanken corrected standard errors. The final two columns present $\chi^{2}$ and Shanken corrected $\chi^{2}$ tests of the hypothesis of zero pricing errors. cay is the approximate consumption-aggregate wealth ratio, $c d y$ is the cointegration relation between consumption, dividends, and labour income. $d l s$ implies that the relation has been computed by dynamic least squares. lr_y is the long-run labour income growth relation of Julliard (2005) computed using log labour income and lr_comp is the same relation using log compensation of employees instead of log labour income. $y \_l d$ is based on a cointegration relation between labour income and dividends and $y \_l s$ is the cointegration relation between labour income and the log level of the CRSP value-weighted stock index. $*-10 \%$ significance, $* *-5 \%$ significance. 
Table 52: Pricing errors from quarterly cross-sectional regressions, 1952Q1-1994Q4

\begin{tabular}{|c|c|c|c|c|}
\hline & $\overline{R M S E}$ & $\overline{C E_{\text {full }}}$ & $C E_{\text {diag. }}$ & $\overline{H J}-$ dist \\
\hline \multirow[t]{2}{*}{$d e f$} & 0.408 & 0.767 & 0.214 & 0.704 \\
\hline & $(0.031)$ & $(0.057)$ & $(0.017)$ & $(0.055)$ \\
\hline \multirow[t]{2}{*}{$r t b$} & 0.383 & 0.665 & 0.197 & 0.614 \\
\hline & $(0.039)$ & $(0.053)$ & $(0.019)$ & $(0.052)$ \\
\hline \multirow[t]{2}{*}{ pe } & 0.473 & 0.880 & 0.236 & 0.805 \\
\hline & $(0.040)$ & $(0.065)$ & $(0.020)$ & $(0.064)$ \\
\hline \multirow[t]{2}{*}{$p d$} & 0.532 & 0.748 & 0.253 & 0.688 \\
\hline & $(0.047)$ & $(0.054)$ & $(0.023)$ & $(0.054)$ \\
\hline \multirow[t]{2}{*}{$d e$} & 0.339 & 0.688 & 0.181 & 0.632 \\
\hline & $(0.027)$ & $(0.047)$ & $(0.015)$ & $(0.045)$ \\
\hline \multirow[t]{2}{*}{$p y$} & 0.520 & 0.796 & 0.257 & 0.767 \\
\hline & $(0.048)$ & $(0.072)$ & $(0.024)$ & $(0.077)$ \\
\hline \multirow[t]{2}{*}{$p c$} & 0.533 & 0.784 & 0.260 & 0.752 \\
\hline & $(0.049)$ & $(0.069)$ & $(0.025)$ & $(0.074)$ \\
\hline \multirow[t]{2}{*}{$y c_{1}$} & 0.407 & 0.791 & 0.204 & 0.720 \\
\hline & $(0.031)$ & $(0.052)$ & $(0.015)$ & $(0.048)$ \\
\hline \multirow[t]{2}{*}{$y c_{2}$} & 0.403 & 0.766 & 0.203 & 0.692 \\
\hline & $(0.033)$ & $(0.055)$ & $(0.016)$ & $(0.051)$ \\
\hline \multirow[t]{2}{*}{$y c_{3}$} & 0.462 & 0.802 & 0.226 & 0.727 \\
\hline & $(0.034)$ & $(0.056)$ & $(0.017)$ & $(0.054)$ \\
\hline \multirow[t]{2}{*}{ nhe } & 0.455 & 0.756 & 0.226 & 0.675 \\
\hline & $(0.035)$ & $(0.050)$ & $(0.017)$ & $(0.046)$ \\
\hline \multirow[t]{2}{*}{ cay_dls } & 0.437 & 0.797 & 0.199 & 0.731 \\
\hline & $(0.035)$ & $(0.054)$ & $(0.014)$ & $(0.052)$ \\
\hline \multirow[t]{2}{*}{$c d y \_d l s$} & 0.448 & 0.805 & 0.223 & 0.754 \\
\hline & $(0.036)$ & $(0.056)$ & $(0.018)$ & $(0.055)$ \\
\hline \multirow[t]{2}{*}{$l r_{-} y$} & 0.491 & 0.833 & 0.228 & 0.785 \\
\hline & $(0.052)$ & $(0.065)$ & $(0.022)$ & $(0.065)$ \\
\hline \multirow[t]{2}{*}{ lr_comp. } & 0.512 & 0.872 & 0.244 & 0.834 \\
\hline & $(0.051)$ & $(0.069)$ & $(0.023)$ & $(0.069)$ \\
\hline \multirow[t]{2}{*}{$y \_l d$} & 0.624 & 0.698 & 0.273 & 0.597 \\
\hline & $(0.064)$ & $(0.044)$ & $(0.026)$ & $(0.038)$ \\
\hline \multirow[t]{2}{*}{$y \_l s$} & 0.538 & 0.891 & 0.255 & 0.803 \\
\hline & $(0.049)$ & $(0.065)$ & $(0.023)$ & $(0.063)$ \\
\hline
\end{tabular}

This table presents weighted average pricing errors across the 25 portfolios. $R M S E$ is the square root of the average of squared pricing errors. $C E_{\text {full }}$ weights the pricing errors of the 25 portfolios by the variance-covariance matrix of portfolio returns. $C E_{\text {diag. }}$. weights the pricing errors of the 25 portfolios by the diagonal variance matrix of portfolio returns. HJ - dist weights the pricing errors of the 25 portfolios by the moment matrix of portfolio returns. Asymptotic standard errors for the pricing error measures are in parentheses. def is the default premium on bonds, $r t b$ is the relative t-bill rate, pe is the log price-earnings ratio on the $\mathrm{S} \& \mathrm{P} 500$, and $p d$ is the log price-dividend ratio on the CRSP value-weighted portfolio, de is the log dividend-earnings ratio on the $\mathrm{S} \& \mathrm{P} 500, p y$ is the log price-output ratio, $p c$ is the $\log$ price-consumption ratio, $y c_{1}$ is the log labour income-consumption ratio, $y c_{2}$ is the $\log$ compensation of employees-consumption ratio, $y c_{3}$ is the log labour income-compensation of employees ratio, and nhe is the log non-housing consumption share. cay is the approximate consumption-aggregate wealth ratio, $c d y$ is the cointegration relation between consumption, dividends, and labour income. $l r_{-} y$ is the long-run

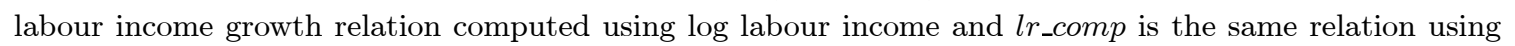
$\log$ compensation of employees instead. $y_{-} l d$ is based on a cointegration relation between labour income and dividends and $y$ ls is the cointegration relation tetween labour income and the log level of the CRSP value-weighted stock index. 


\section{Working Papers from Finance Research Group}

F-2006-05 Anne-Sofie Reng Rasmussen: How well do financial and macroeconomic variables predict stock returns: Time-series and cross-sectional evidence.

F-2006-04 Anne-Sofie Reng Rasmussen: Improving the asset pricing ability of the Consumption-Capital Asset Pricing Model.

F-2006-03 Jan Bartholdy, Dennis Olson \& Paula Peare: Conducting event studies on a small stock exchange.

F-2006-02 Jan Bartholdy \& Cesário Mateus: Debt and Taxes: Evidence from bankfinanced unlisted firms.

F-2006-01 Esben P. Høg \& Per H. Frederiksen: The Fractional Ornstein-Uhlenbeck Process: Term Structure Theory and Application.

F-2005-05 Charlotte Christiansen \& Angelo Ranaldo: Realized bond-stock correlation: macroeconomic announcement effects.

F-2005-04 Søren Willemann: GSE funding advantages and mortgagor benefits:

Answers from asset pricing.

F-2005-03 Charlotte Christiansen: Level-ARCH short rate models with regime switching: Bivariate modeling of US and European short rates.

F-2005-02 Charlotte Christiansen, Juanna Schröter Joensen and Jesper Rangvid: Do more economists hold stocks?

F-2005-01 Michael Christensen: Danish mutual fund performance - selectivity, market timing and persistence.

F-2004-01 Charlotte Christiansen: Decomposing European bond and equity volatility. 
ISBN 87-7882-147-9

Department of Business Studies

Aarhus School of Business

Fuglesangs Allé 4

DK-8210 Aarhus V - Denmark

Tel. +4589486688

Fax +4586150188

www.asb.dk 